Claremont Colleges

Scholarship@ Claremont

2014

\title{
An Investigation of Teachers' Noticing, Cognitive Demand, and Mathematical Knowledge for Teaching: Video Reflections in an Elementary Mathematics Context
}

Lorelei R. Coddington

Claremont Graduate University

\section{Recommended Citation}

Coddington, Lorelei R., "An Investigation of Teachers' Noticing, Cognitive Demand, and Mathematical Knowledge for Teaching: Video Reflections in an Elementary Mathematics Context" (2014). CGU Theses \& Dissertations. Paper 88.

http://scholarship.claremont.edu/cgu_etd/88

DOI: $10.5642 /$ cguetd $/ 88$

This Open Access Dissertation is brought to you for free and open access by the CGU Student Scholarship at Scholarship @ Claremont. It has been accepted for inclusion in CGU Theses \& Dissertations by an authorized administrator of Scholarship @ Claremont. For more information, please contact scholarship@cuc.claremont.edu. 
An Investigation of Teachers' Noticing, Cognitive Demand, and Mathematical Knowledge for Teaching: Video Reflections in an Elementary Mathematics Context

by

Lorelei R. Coddington

Claremont Graduate University

2014

(C) Copyright Lorelei R. Coddington, 2014

All rights reserved.

The data for this study were collected under a grant to Claremont Graduate University (CGU), number ITQ-08-0502, No Child Left Behind Act of 2001, Title II-A, Improving Teacher Quality State Grants Program, administered by the California Postsecondary Education Commission. Key contributors to the project were Stacy Brown, Project Director at CGU and Pitzer College, and Wayne Snyder, Kristen Baldridge, Lorelei Coddington, and Becky Orona at CGU. 


\begin{abstract}
APPROVAL OF THE REVIEW COMMITTEE
This dissertation has been duly read, reviewed, and critiqued by the Committee listed below, which hereby approves the manuscript of Lorelei R. Coddington as fulfilling the scope and quality requirements for meriting the degree of Doctor of Philosophy in Education.
\end{abstract}

\author{
Mary Poplin, Chair \\ Claremont Graduate University \\ Professor \\ David Drew, Committee Member \\ Claremont Graduate University \\ Professor \\ June Hilton, Committee Member \\ Claremont Graduate University \\ Professor
}

Stacy Brown, Committee Member

California State Polytechnic University, Pomona

Assistant Professor 


\begin{abstract}
An Investigation of Teachers' Noticing, Cognitive Demand, and Mathematical Knowledge for Teaching: Video Reflections in an Elementary Mathematics Context
\end{abstract}

by

\title{
Lorelei R. Coddington
}

Claremont Graduate University: 2014

In the past decade, mathematics performance by all students, especially minority students in low socioeconomic schools, has shown limited improvement nationwide (NCES, 2011). Traditionally in the United States, mathematics has consisted of arithmetic and computational fluency; however, mathematics researchers widely believe that this method of instruction does not enhance the development of mathematical reasoning and ignores the research on students' mathematical development (Blanton \& Kaput, 2005; Stigler \& Hiebert, 1999).

Recommendations by the mathematics community are to broaden and strengthen teacher content knowledge in mathematics and to provide the pedagogical tools needed by teachers to extend their students' thinking and reasoning (Darling-Hammond, Wei, Andree, Richardson, and Orphanos, 2009; Mewborn, 2003).

The purpose of this quantitative study was to investigate the relationship between the teachers' levels of noticing, the levels of cognitive demand in their enacted tasks, and their levels of mathematical knowledge for teaching in two urban high-need low performing elementary schools. The 54 elementary teachers participated in a long-term mathematics professional development program aimed at developing teachers' mathematical knowledge for teaching and recognizing and fostering students' early algebraic reasoning. The data for this dissertation included teachers' self-selected video segments, written video reflections, and mathematical knowledge for teaching levels from the second year of the professional development. 
Relationships were explored between mathematical knowledge for teaching, teachers' levels of noticing, and the levels of cognitive demand represented in mathematics lessons.

The findings indicated shifts in teachers' cognitive demand of enacted tasks and noticing over the course of the second year of professional development. Correlation results indicated significant relationships between teachers' cognitive demand, teacher noticing, participation, and teachers' mathematical knowledge for teaching. Moreover, the results showed that the teachers in the K-3 cohort benefited more from the professional development than their 4-6 cohort counterparts when it came to mathematical knowledge for teaching, noticing, and cognitive demand levels. 


\section{Dedication}

To my dear children,

Laurel, Nathan, and Joel, may you forever thirst for Knowledge and Truth. 


\section{Acknowledgements}

I would like to first acknowledge my dissertation committee. Each one has been extremely valuable and influential in my development as an individual and growth as an academic. Dr. Mary Poplin, thank you for your friendship and mentorship, both academically and spiritually. During the fourteen years of our relationship, when you were Dean and Director of CGU's Teacher Education and also as my graduate professor and advisor, you have constantly challenged my understandings and have had a profound influence on my professional work. Without your encouragement and support, I would not have made it to this point. It is an enormous privilege to call you both my advisor and friend. Dr. David Drew, your kind words and gentle spirit have taught me mathematics like no other teacher in my life. Your belief in me as your student built my confidence in research and statistical work, and I will be forever grateful. Dr. June Hilton, your guidance at the beginning of my research provided the "big picture" that became this dissertation. Thank you for your inspiration. My friend and colleague, Dr. Stacy Brown, it is through you that I have learned so much about teachers' mathematical knowledge and children's thinking. Thank you for your hours of mentorship and encouragement and the opportunity to work alongside you during the MAAP research. Without your support, the data for this dissertation would not have been possible.

A special thanks is due to my husband and children for their endless support, love, and sacrifice on my behalf. To my husband, John, thank you for believing in me and for providing the emotional, spiritual, and physical support needed to get to this point. There is no way I could have completed this process without you. I am truly blessed to have you as my partner in life. To my children, Laurel, Nathan, and Joel, thank you for your love and patience during my endless hours of reading and writing. 
My parents have had a profound influence on my life both as a child and as an adult. Thank you, Mom and Dad, for your model of hard work and excellence. It is through you that I have learned my spiritual grounding, potential, and discipline. Thank you for your love, support, and undying encouragement in this process.

I want to thank the MAAP research team members, Kristen Baldridge, Becky Orona, and Wayne Snyder, for your friendship over these many years and your strong support of my work. Your assistance in coding the data for this project was immeasurable and I will always be grateful for your time and energy.

A special thank you is needed to acknowledge all of the teachers who participated in the MAAP research. Thank you for your dedication and commitment to teaching and student learning. This dissertation would not have possible without your willingness to stretch, grow, and take risks during your participation in the MAAP professional development. 


\section{Table of Contents}

Chapter One: Statement of the Problem ................................................................................. 1

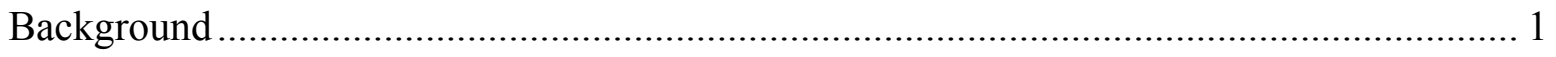

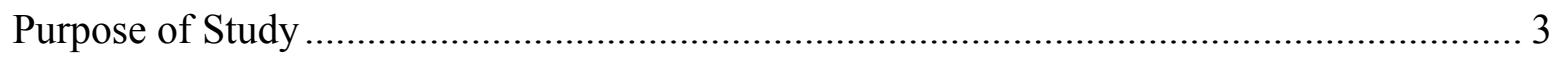

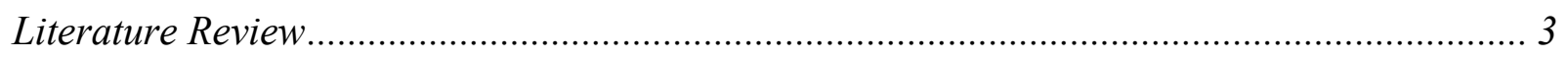

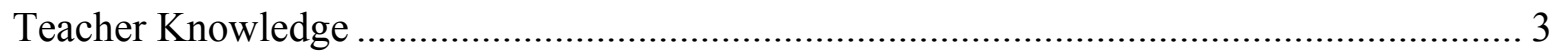

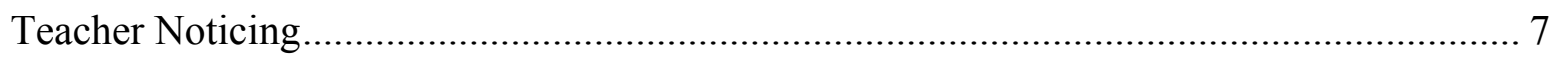

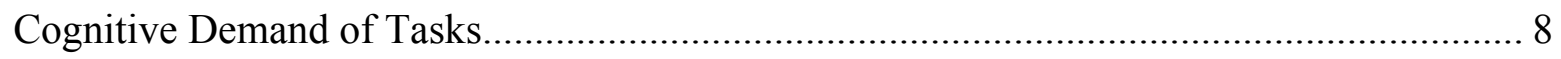

Significance and Research Questions ..................................................................... 9

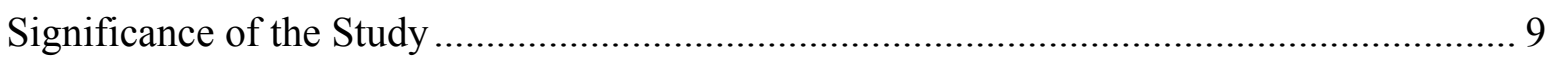

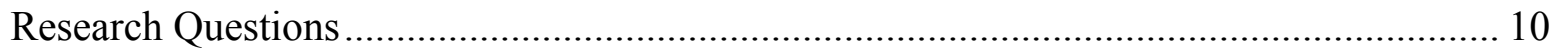

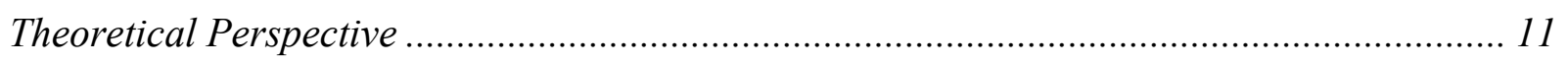

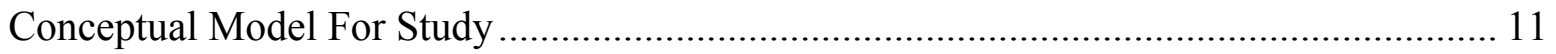

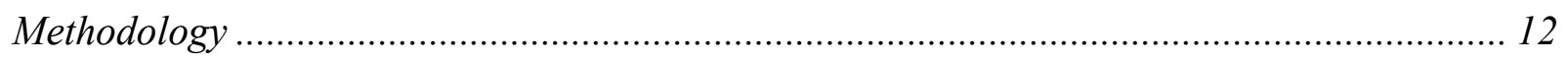

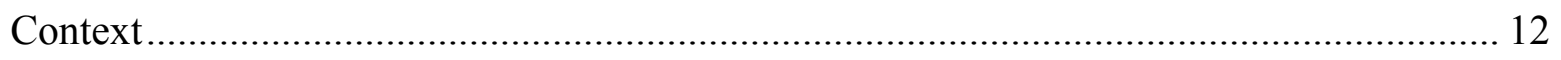

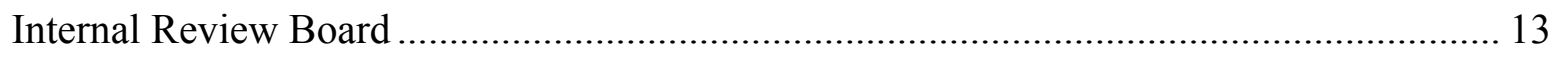

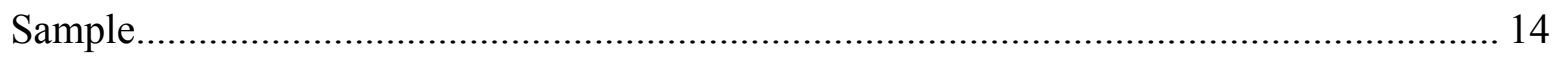

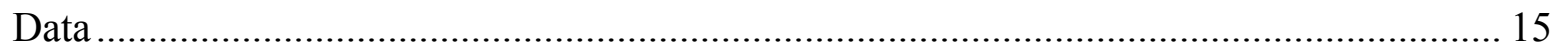

Video Segments and Video Reflection Form ........................................................ 16

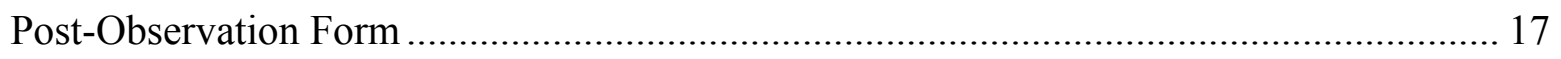

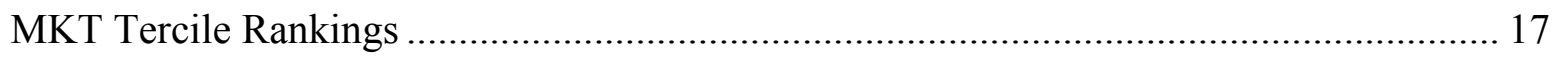

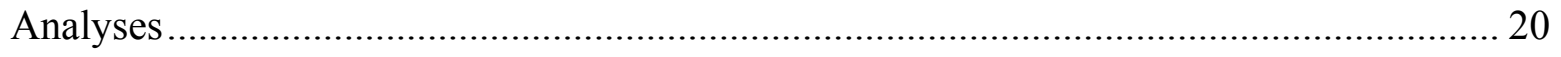


Chapter Two: Review of Relevant Literature................................................................................. 28

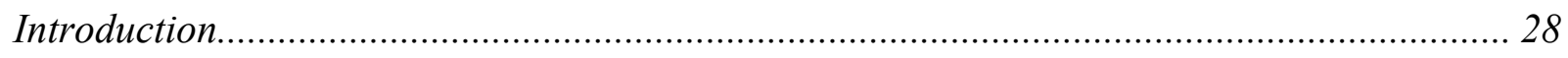

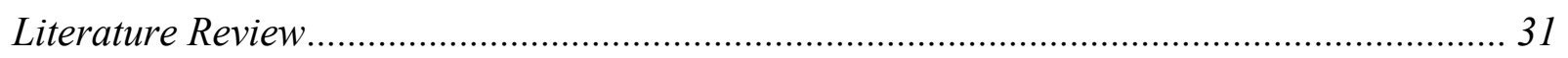

Mathematics Research and Professional Development ........................................................ 31

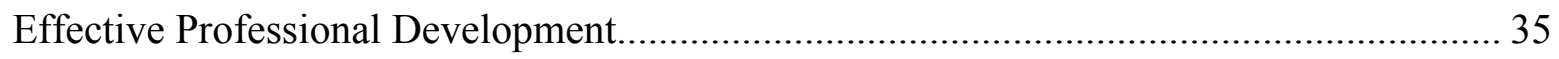

Mathematical Knowledge for Teaching............................................................................ 38

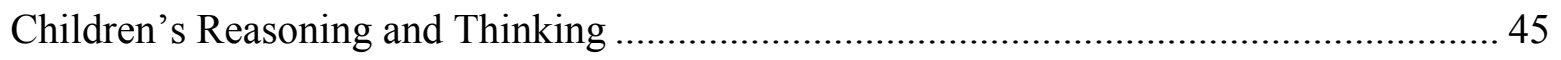

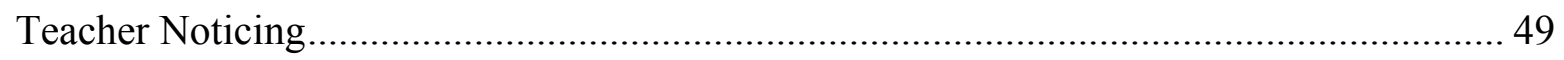

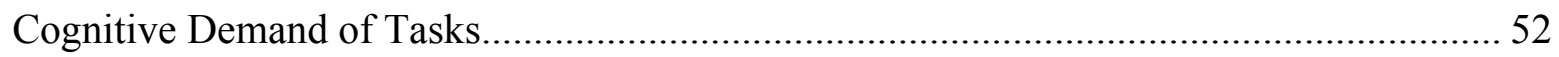

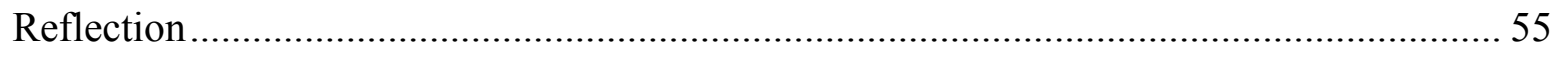

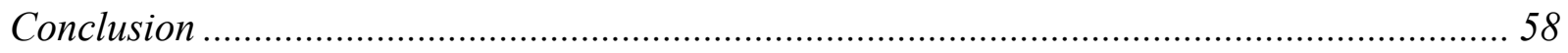

Chapter Three: Methodology ................................................................................................................59

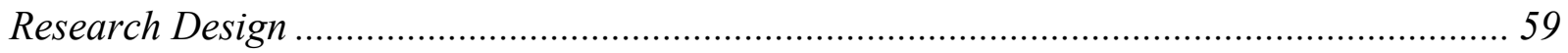

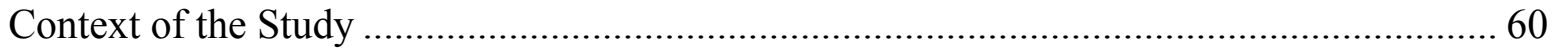

Sample

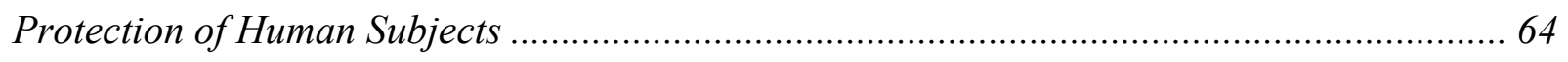

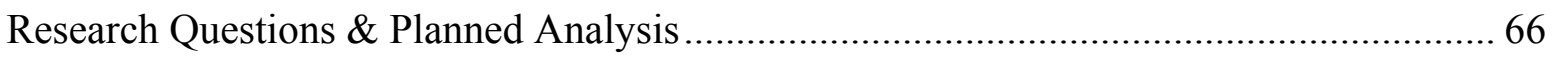

Data

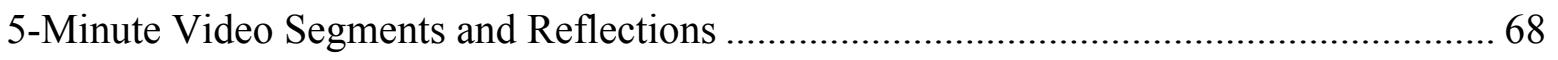

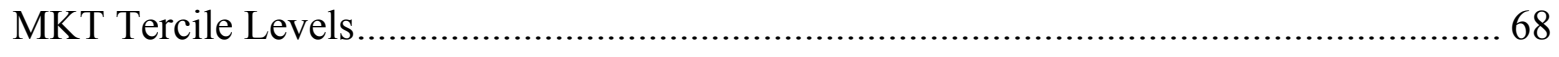

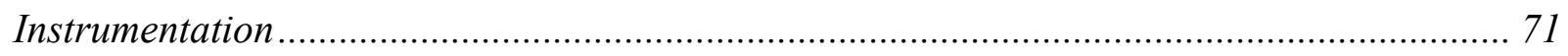

The Framework for Learning to Notice Student Mathematical Thinking ............................ 72

The Task Analysis Guide ................................................................................................. 73 


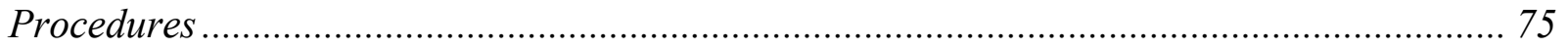

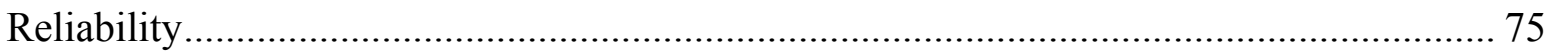

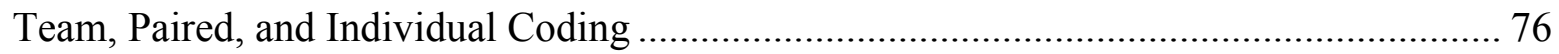

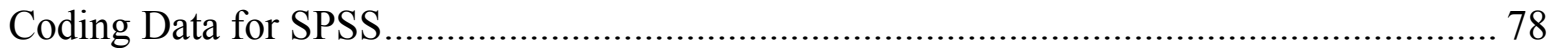

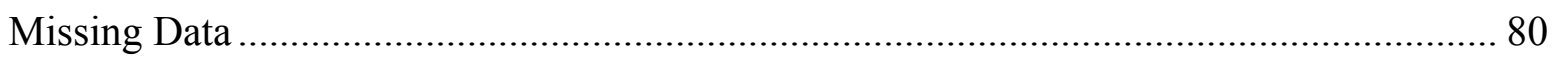

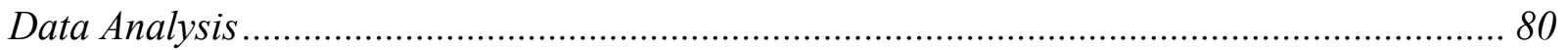

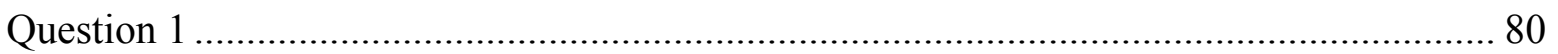

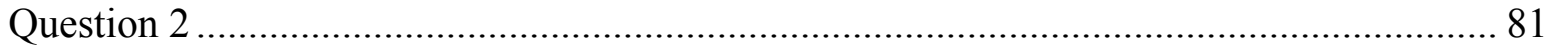

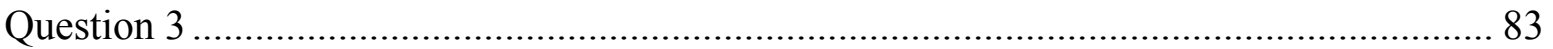

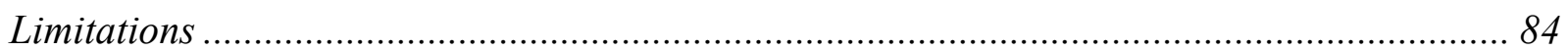

Chapter Four: Results .................................................................................................................... 85

Sample

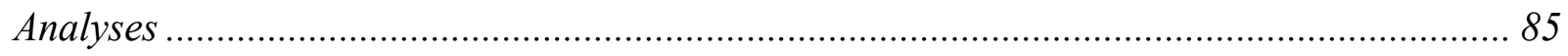

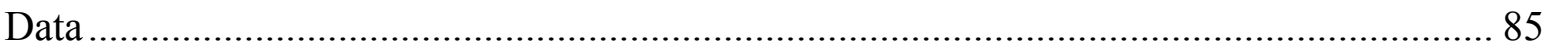

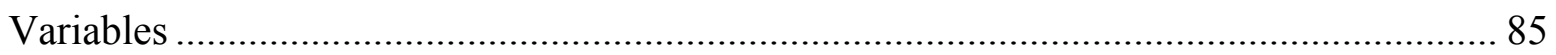

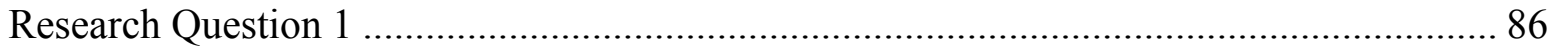

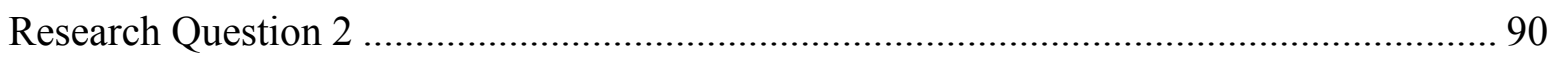

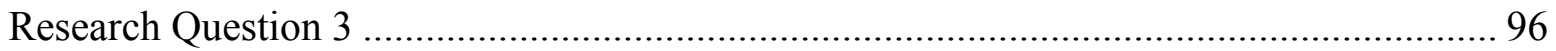

Chapter Five: Background, Discussion, Recommendations, and Conclusion ....................... 112

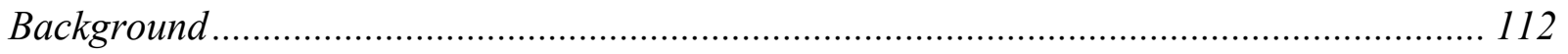

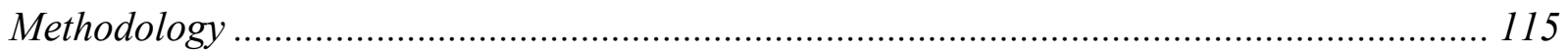

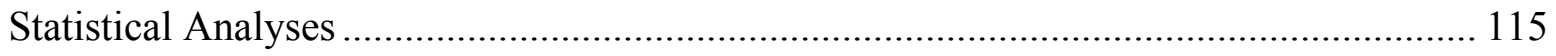

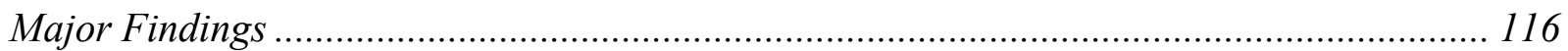




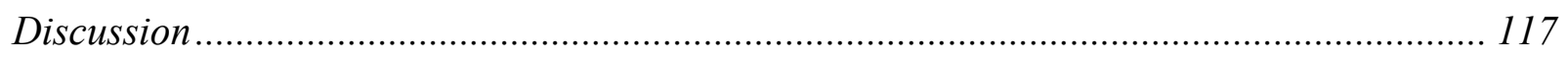

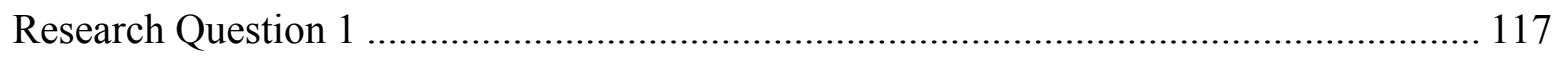

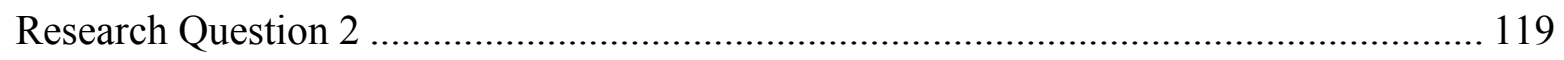

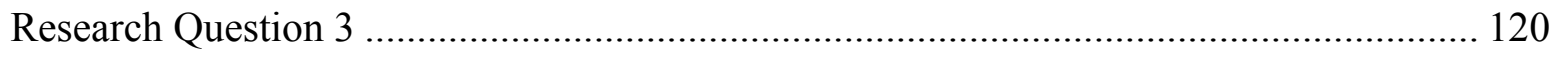

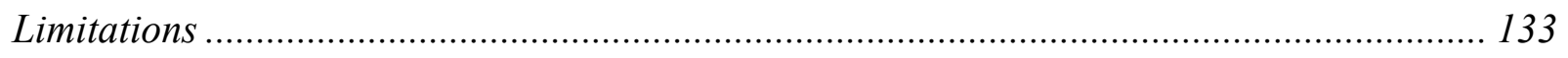

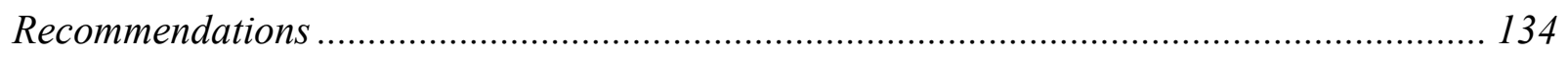

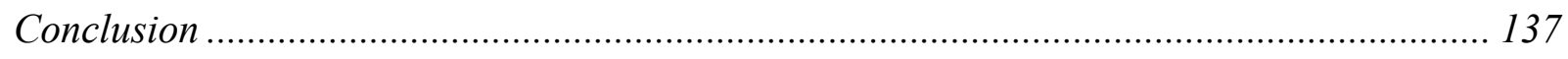

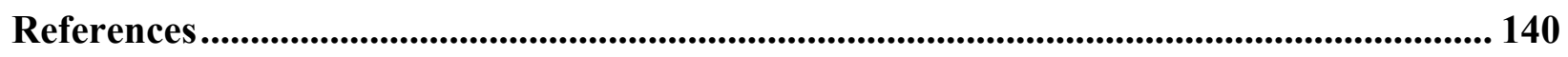

Appendix A: MAAP Video Reflection Form.................................................................... 156

Appendix B: The Task Analysis Guide ..................................................................................... 157

Appendix C: The Framework for Learning To Notice Student Mathematical Thinking • 158

Appendix D: MAAP Post-Observation Form ....................................................................... 159 


\section{List of Tables}

Table 1. Total LMT Change Score Analysis, Treatment, and Control .................................... 18

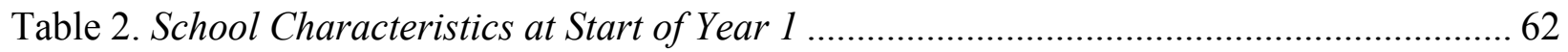

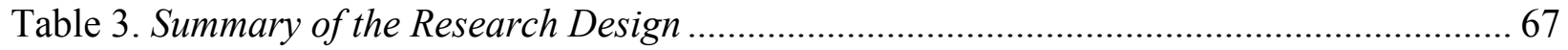

Table 4. Total LMT Change Score Analysis, Treatment, and Control ................................... 70

Table 5. SPSS Coding for Participation Variable ............................................................. 79

Table 6. SPSS Coding for MKT Tercile Level Variables ..................................................... 80

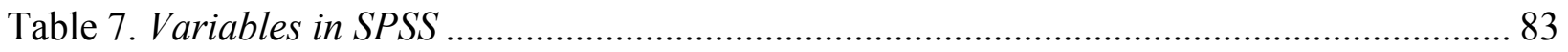

Table 8. Whole Group Descriptive Statistics ...................................................................... 86

Table 9. Whole Group Intermediate Noticing Level ........................................................... 87

Table 10. Shifts Between Intermediate and Ending Noticing Levels ...................................... 88

Table 11. Intermediate and Ending Cognitive Demand Level............................................... 91

Table 12. Shifts in Teachers' Intermediate and Ending Cognitive Demand Levels.................... 92

Table 13. Characteristics of Participants With an Ending Cognitive Demand Level 4 ............. 93

Table 14. Whole Group Correlations - Cognitive Demand, Participation, and Cohort Level..... 95

Table 15. K-3 Cohort Correlations - Cognitive Demand Level and Participation .................... 96

Table 16. Whole Group Correlations - Ending Cognitive Demand Level Variables With Cohort

Grade Level, Participation Level, and School ...................................................................... 97

Table 17. K-3 Cohort Correlations - Ending Cognitive Demand level Variables With Cohort

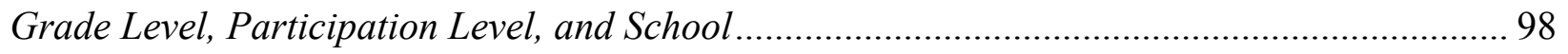

Table 18. 4-6 Cohort Correlations - Ending Cognitive Demand Level Variables With Cohort

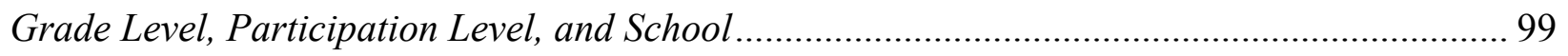

Table 19. Summary of Ending MKT Tercile Level Variables Correlated and Participation ..... 100 
Table 20. Whole Group Correlations - Intermediate and Ending Noticing, Intermediate and Ending Cognitive Demand, Beginning and Ending MKT Tercile Level, Participation Level, and Cohort Grade Level 101

Table 21. Summary of Intermediate Cognitive Demand and Intermediate Noticing Correlations Results 103

Table 22. K-3 Correlations - Beginning and Ending MKT Tercile Level and Intermediate and Ending Noticing Level.

Table 23. 4-6 Correlations - Beginning and Ending MKT Tercile Level and Intermediate and

Ending Noticing 105

Table 24. K-3 Cohort Correlations - Beginning and Ending MKT Tercile Level and Participation 106

Table 25. 4-6 Cohort Correlations - Beginning and Ending MKT Tercile Level and Participation 106

Table 26. Moderate Level Participation Correlations - MKT Tercile Levels and Cohort Grade

Level. 107

Table 27. High Level Participation Correlation - MKT Tercile Levels and Cohort Grade Level

Table 28. Summary of Variables Correlated With Beginning MKT Tercile Level. 108

Table 29. Regression Results Predicting Ending MKT Tercile Level

Table 30. Regression Results Predicting Ending Noticing Level ......................................... 110

Table 31. Regression Results Predicting Ending Cognitive Demand Level ............................. 111

Table 32. Summary of Variables Correlated With Participation Level.................................. 121

Table 33. Summary of Cognitive Demand and Noticing Correlations ................................... 128

Table 34. Summary of K-3 Cohort Significant Correlations ............................................... 130 
Table 35. Suggested Additions - Elementary Classroom Task Analysis Guide ........................ 133 


\section{Table of Figures}

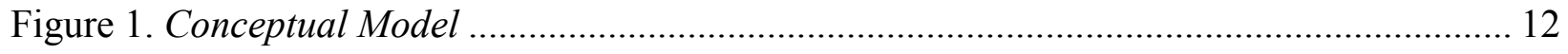

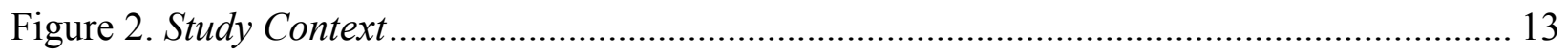

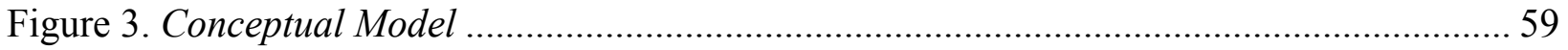

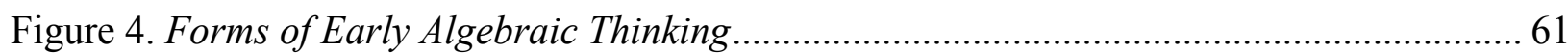

Figure 5. The MKT, Noticing, and Cognitive Demand Cycle ….......................................... 129

Figure 6. Model of K-3 Teachers in MKT-Focused Professional Development....................... 132

Figure 7. Original Conceptual Model ............................................................................ 138

Figure 8. Revised Conceptual Model ..................................................................................... 138 


\section{Chapter One: Statement of the Problem}

\section{Background}

In the past decade, mathematics performance by all students, especially minority students in low socioeconomic schools, has shown limited improvement nationwide (NCES, 2011). Traditionally in the United States, mathematics has consisted of arithmetic and computational fluency; however, mathematics researchers widely believe that this method of instruction does not enhance the development of mathematical reasoning and ignores current research on students' mathematical development (Battista, 1999; Blanton \& Kaput, 2005; Stigler \& Hiebert, 1999). According to Martin and Kasmer (2009), it is essential that children in the elementary classroom explore important mathematical ideas by reasoning and sense-making in order to provide a strong foundation for future success; however, American schools focus narrowly on skills, procedures, and fluency in mathematics rather than higher levels of reasoning and problem solving (Charalambous, 2010; Hiebert \& Carpenter, 2003; Ma, 1999; Stigler \& Hiebert, 1999). Recommendations by the mathematics community are to broaden and strengthen teacher content knowledge in mathematics and to provide the pedagogical tools needed by teachers to extend their students' thinking and reasoning (DarlingHammond, Wei, Andree, Richardson, and Orphanos, 2009; Mewborn, 2003).

To reduce the achievement gap and improve students' performance, professional development has been aimed at improving teachers' mathematical knowledge for teaching (Blanton \& Kaput, 2005; Hill \& Ball, 2004; Jacobs, Franke, Carpenter, Levi, \& Battey, 2007). Mathematical knowledge for teaching is considered knowledge about 
mathematics that is needed in the work of teaching. This type of knowledge is described as 'explaining terms and concepts to students, interpreting students' statements and solutions, judging and correcting textbook treatments of particular topics, using representations accurately in the classroom, and providing students with examples of mathematical concepts, algorithms, or proofs" (Hill, Rowan, \& Ball, 2005, p. 373). According to research, teachers' mathematical knowledge for teaching is a contributing factor in students' mathematics performance (Blanton \& Kaput, 2005; Hill \& Ball, 2004; Hill et al., 2005) and has a positive effect on student achievement (Hill et al., 2005). Thus, the effort of mathematics professional development (MPD) has been to increase teachers' mathematical knowledge for teaching thereby creating shifts in practice towards students' thinking.

One goal of increasing teachers' mathematical knowledge for teaching is to improve the depth and complexity of their mathematics instruction and tasks. This type of shift moves from procedural types of practice to more conceptual types of instruction and requires tasks of higher cognitive demand. Cognitively demanding tasks are described as mathematical activities that include "procedures with connections to understanding, meaning, or concepts" (Stein, Smith, Henningsen, \& Silver, 2009, p. 1). Students use various representations and require meaning to be attached to their work by referring to the representations, when engaging in cognitively demanding tasks. According to Stein et al.'s conceptual model, teachers' content knowledge influences the enactment of cognitively demanding tasks.

To promote a greater understanding of student thinking, mathematics professional development has investigated how teachers notice and respond to student thinking using 
videos of lessons and work samples (Jacobs, Lamb, and Philipp, 2010; Sherin, Jacobs, \& Philipp, 2011; Sherin \& van Es, 2009; van Es \& Sherin, 2002). This emerging field of study is known as teacher noticing. Teacher noticing in mathematics is conceptualized as teacher expertise in three interrelated skills: “attending to children's strategies, interpreting children's understandings, and deciding how to respond on the basis of children's understandings" (Jacobs et al., 2010, p. 172). Teacher noticing has shown promise in shifting teachers' instruction toward a focus on students' thinking, an area recommended by the National Council for Teachers of Mathematics (NCTM, 2000). Particularly, studies that used video to capture instruction with post-reflection showed gains in teacher change (van Es \& Sherin, 2002).

\section{Purpose of Study}

Specifically, how teachers notice, interpret, and respond to student thinking in mathematics is critical. Additionally, understanding the role of mathematical knowledge for teaching on practice and noticing student thinking is also an area ripe with possibilities to better understand the complexities of teaching and learning and improving instruction. Therefore, the purpose of this quantitative study is to investigate the relationship between the teachers' levels of noticing, the levels of cognitive demand in their enacted tasks, and their levels of mathematical knowledge for teaching.

\section{Literature Review}

\section{Teacher Knowledge}

Teaching is a highly complex task that requires significant amounts of varied types of knowledge in order for teachers to respond and interpret learning. Shulman 
(1987), in his seminal writing, identified pedagogical content knowledge as a distinctive body of knowledge needed by all teachers. He claimed, "Teachers must learn to use their knowledge base to provide the grounds for choices and actions" (p. 13). According to Shulman, the most critical point in teaching is where pedagogy and knowledge intersect. At this juncture, he believed a teacher could transform his or her content knowledge into "forms that [were] pedagogically powerful, yet adaptive to the variations in ability and background presented by the students" (p. 15). Thus, effective teaching was envisioned as more than just a set of skills; rather, it was a transformative experience in which content and pedagogy came together.

Ball, Thames, and Phelps (2008) continued to expand on Shulman's beliefs by exploring different types of pedagogical knowledge needed for teaching related to mathematics. In their analysis of teachers and the professional work of teaching, they conceptualized four domains of pedagogical knowledge: 1) common content knowledge, 2) specialized content knowledge, 3) knowledge of content and students, and 4) knowledge of content and teaching. First, common content knowledge was defined as knowledge and skill needed by teachers but also used in a variety of settings other than teaching. This type of mathematical knowledge is shared by other educated adults and thus is considered "common." Second, specialized content knowledge is described as mathematical knowledge and skill specific to teaching. Knowledge of this kind allows teachers to hold an understanding beyond what students' need and enables teachers to unpack a concept in multiple ways to make the content visible and learnable. Only teachers in their professional context need this type of knowledge. Third, teachers need to have combined knowledge of their students and what they know about mathematics so as 
to engage and motivate students and recognize misconceptions. This type of familiarity also allows teachers to hear and interpret their students' thinking. Fourth, teachers need to know both mathematical content and teaching. This type of knowledge impacts teachers' design for instruction. For example, instructional decisions about sequencing of content, examples, and representations are all impacted by teachers' knowledge of content and teaching. These four specific domains identified by Ball et al. have helped to define the various aspects of knowledge needed for teaching and also new areas to investigate.

Research has begun to establish a strong relationship between teachers' mathematical knowledge for teaching and its impact on student achievement. Hill et al.'s (2005) study supported a significant correlation between teachers' mathematical knowledge for teaching, as measured by the Learning Mathematics for Teaching (LMT) survey, and student achievement in first and third grade students. Teachers' mathematical knowledge for teaching was also found to be a strong predictor of student achievement, with higher levels of mathematical knowledge for teaching predicting greater gains in achievement. This study also found that teachers with mathematical knowledge for teaching in the bottom three deciles were most often found in low socioeconomic schools. Broad implications can be drawn from the results of Hill et al. to inform professional development, policy, and educational equity.

Building on the importance of pedagogical knowledge in mathematics teaching, research has begun to connect mathematical knowledge for teaching to teacher instruction (Charalambous, 2010) and teacher decisions in analyzing teaching (Kersting, Givvin, Sotelo, and Stigler, 2010). Charalambous, studied how the level of teachers' decision-making in task unfolding was impacted by the teachers' level of mathematical 
knowledge for teaching. The sample consisted of 10 teachers from which two were randomly selected. Before collecting the data, the two teachers' mathematical knowledge for teaching was assessed using the Learning Mathematics for Teaching survey. Then data was gathered through nine videotaped lessons from each of the teachers' mathematics lessons; these were analyzed both quantitatively and qualitatively. The findings suggested that the teachers' mathematical knowledge for teaching contributed to the enactment of the tasks. The teacher who possessed a higher level of mathematical knowledge for teaching was able to connect greater meaning to the mathematical content rather than focusing only on the mathematical procedure. Also, the teacher with the higher mathematical knowledge for teaching enacted tasks at a higher cognitive level when interacting with her students. Similarly, mathematical knowledge for teaching was correlated to the teachers' ability to accurately evaluate learning in Kersting et al.'s study. In this study, the teachers $(N=257)$ were assessed for their knowledge of fractions, evaluations of authentic online classroom video clips, and written observations. The findings were coded and analyzed and showed correlations between teachers' levels of MKT and their accuracy in responding to the mathematical events on the video clips.

In an effort to develop teachers' pedagogical content knowledge, Jacobs et al. (2007) and Blanton and Kaput (2005) conducted sustained professional development with a mathematical knowledge for teaching focus. Their work was distinct in that it directly linked teachers' pedagogical content knowledge to children's improved algebraic reasoning. In the study by Jacobs et al., the 180 teachers increased their ability to identify a wider variety of student strategies. Students of participating teachers also showed marked improvement in their ability to reason algebraically. Likewise, Blanton and 
Kaput conducted professional development to improve teachers' ability to foster algebraic reasoning by strengthening their pedagogical content knowledge. In the case study presented, the teacher not only showed an ability to extend students' thinking and ability to reason but also supported her students in making significant achievement gains in algebraic reasoning.

\section{Teacher Noticing}

Far less is understood about how pedagogical content knowledge manifests itself in teacher noticing through attending, interpreting, and responding to students' mathematical thinking. Jacobs et al. (2010) examined various levels of teachers' experience and their ability to notice based on teaching experience and degree of professional development. The findings suggested that those with the least amount of teaching experience were less able to interpret and respond to students' mathematical thinking. Those with teaching experience alone were still limited in their ability to interpret and respond to students' thinking. However, teachers who engaged in sustained mathematics professional development were more able to interpret and appropriately respond to students in the classroom context. This study suggested that there was a continuum of development in teachers' ability to notice students' thinking.

Teacher noticing and its developmental nature were the focus of studies by Sherin and van Es (2009) and van Es and Sherin (2006). These studies incorporated video clubs as the vehicle for teachers to observe classroom situations. Teachers regularly came together in video clubs to discuss their practice by watching videotapes of their lessons. The findings from these studies suggested that over time, in a collegial collaborative setting, teachers showed an increased ability to analyze the teaching context in more 
depth. At first, their focus was on pedagogical issues rather than content. After multiple discussions about the videotapes, teachers shifted in their discussions to address the underlying mathematical ideas and content rather than a focus on pedagogical issues.

\section{Cognitive Demand of Tasks}

Engaging students in quality mathematical tasks that require a high degree of cognitive demand has been found essential to developing student thinking and reasoning (Stein et al., 2009). In their early research, Stein, Grover, and Henningsen (1996) found that teachers who had engaged in professional development could select and initiate tasks with cognitive demand but were unable to sustain the level of cognitive demand throughout the lesson. Further research revealed that factors such as teachers' education, experience, and content knowledge affected the enacted quality of task as well as how the teacher used the curriculum that was provided (Stein \& Kaufman, 2010). In Stein and Kaufman's study, quality was defined by level of cognitive demand, student thinking, and student autonomy evident in a lesson. The findings from these studies showed that a task's level of cognitive demand was related to opportunities for student thinking.

Over the course of their NSF-funded research, Stein et al. (2009) used the Task Analysis Guide to differentiate levels of cognitive demand throughout a lesson. This four-level guide, previously developed by Stein \& Smith (1998) enabled researchers to evaluate enacted tasks based on the demand for student thinking and reasoning. Examples of case studies from the research demonstrated teachers' ability to sustain various levels of cognitive demand that influenced the building of students' capacity to think and reason.

Research by Smith, Bill, and Hughes (2008) and Stein and Kaufman (2010) have continued to support teachers' ability to effectively use curricular materials in ways that 
are cognitively demanding. Smith et al. showed that lesson design using the Thinking Through A Lesson Protocol allowed teachers more success at maintaining high levels of cognitive demand when planning instruction since the protocol prompted the teacher to start with a more open-ended type of problem and also allowed multiple pathways to the solution. Stein and Kaufman's study looked at teachers' planning of big mathematical ideas using two curricular materials, Everyday Mathematics and Investigations. The twoyear study suggested that Investigations curricular materials provided the teachers more support in using bigger mathematical ideas and allowing students multiple pathways to answers which promoted higher levels of cognitive demand, student thinking, and mathematical reasoning.

\section{Significance and Research Questions}

\section{Significance of the Study}

Little research exists to explain how teachers develop the ability to notice students' thinking (Jacobs, et al. 2010; Sherin \& Han, 2004; Sherin et al., 2011; Sherin \& van Es, 2009; van Es \& Sherin, 2006); nor do we know much about how teachers interpret or respond to student thinking through noticing (Scherrer \& Stein, 2012; Sherin et al., 2011; Stein et al., 2009; van Es \& Sherin, 2002). Though the field has begun to understand the mediating effects of teachers' knowledge on student achievement (Hill et al. 2004), there is a dearth of research connecting teacher knowledge to classroom practice (Charalambous, 2010). This dissertation adds to the body of research on teacher noticing in mathematics and will aid in understanding the relationship between mathematical knowledge for teaching, teacher noticing, and the cognitive demand of enacted tasks. 


\section{Research Questions}

This study seeks to understand teacher noticing and the cognitive demand of enacted tasks, as well as the relationship of these two constructs with teachers' mathematical knowledge for teaching. Thus, the following research questions will be addressed:

1) How do teachers' written reflections and observations of their mathematics lessons explain teachers' levels of noticing in the second year of mathematics professional development focused on developing teachers' mathematical knowledge for teaching?

2) How do teachers' self-selected video segments of mathematics lessons explain the level of cognitive demand of the teachers' enacted tasks during the second year of mathematics professional development focused on developing teachers' mathematical knowledge for teaching?

3) How do teachers' levels of mathematical knowledge for teaching relate to teachers' levels of noticing and levels of cognitive demand in enacted tasks during the second year of mathematics professional development focused on developing teachers' mathematical knowledge for teaching?

\section{Theoretical Perspective}

My theoretical perspective was influenced by the conceptualizations of both mathematical knowledge for teaching (Ball et al., 2008) and teacher noticing (Jacobs et al. 2010; van Es, 2011). Ball et al. identified mathematical knowledge for teaching as divided into two parts: subject matter knowledge and pedagogical content knowledge. It was my belief that teacher knowledge, both subject matter and pedagogical, influences 
teachers' classroom decisions, sense making, and teaching moves. In addition, I espoused Jacobs et al.'s (2010) conceptualization of teacher noticing as teachers' ability to attend to, respond to, and interpret students' thinking. Furthermore, the lens I used to view teacher noticing was guided by van Es' (2011) Framework for Learning To Notice Student Mathematical Thinking that recognized teachers at different levels on the continuum of noticing and responding to students' thinking. The level of teacher noticing was not dependent on teachers' years of experience, but rather on the teachers' mathematical knowledge and ability to identify specific aspects of student thinking and how to interpret and respond to students' thinking.

\section{Conceptual Model For Study}

Figure 1 below depicted my original conceptual model for this study within the context of mathematics professional development. I believed that the central parts, teacher noticing, and the cognitive demand of enacted tasks, were influenced by both teachers' mathematical knowledge for teaching and their reflection on practice.

Ultimately, the end results were shifts in the teachers' instruction that allowed students more opportunities for reasoning and thinking about mathematics. 
Figure 1

Conceptual Model

Conceptual Model for Teacher Instructional Shifts in MPD

Context of MPD

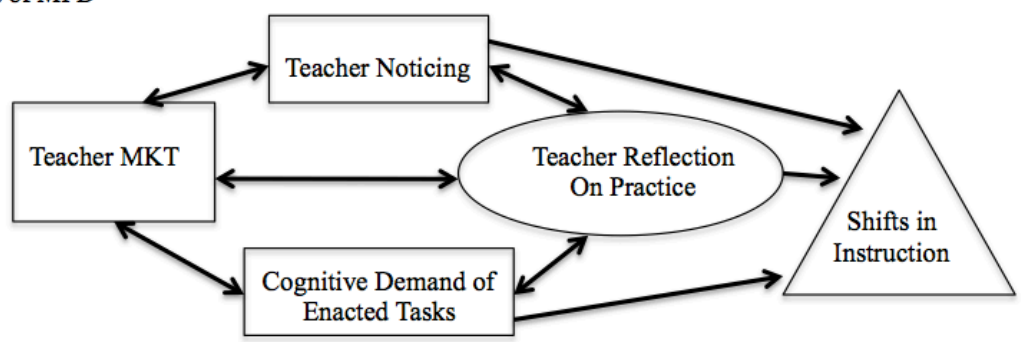

(Coddington, 2013)

\section{Methodology}

\section{Context}

The 54 teachers in this study were participants in a California funded Improving Teacher Quality grant called the Making Algebra Accessible Project (MAAP), a fouryear grant that began in 2008 and ended funding in 2012. This project was a partnership between Claremont Graduate University’s (CGU) Teacher Education, Pitzer College, and a participating urban predominantly minority southern California school district. From 2008-2011, the teachers participated in monthly seminars, summer institutes, and classroom observations. The teachers experienced the mathematics professional development in two cohorts with one year of overlap. The first cohort included the kindergarten through third grade teachers from 2008-2010. The second cohort included the fourth through sixth grade teachers from 2009-2011 (see Figure 2 below). The 
teachers were paid an hourly stipend for their participation in MAAP to cover the time that occurred beyond their district-contracted hours.

Figure 2

Study Context

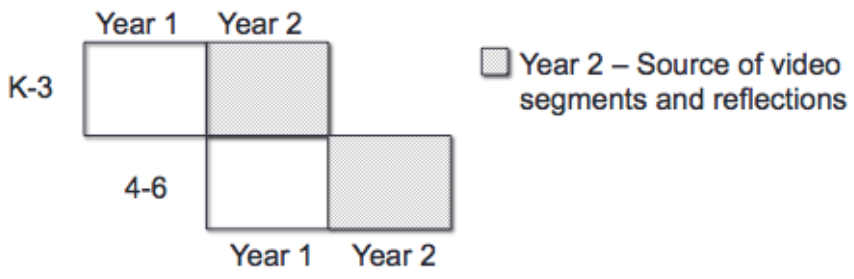

As a research associate, I was intimately involved in the video recording of the lessons, the planning and facilitating of the seminars and summer institutes, and the analysis of the data. Therefore, this dissertation continues to build on my prior research.

\section{Internal Review Board}

The MAAP research design, surveys, and the participation forms were approved by the Internal Review Board (IRB) of both CGU and Pitzer College in 2008, at the start of the grant funding. The proposed analyses described in this dissertation fits within the original and amended design of the MAAP IRB approval. The videos used in this dissertation were those gathered during the MAAP classroom observations; thus, the videos with student and teacher participants were under the auspices of the grant. Those students pictured on the videos submitted parent/guardian permission forms at the beginning of each year of MAAP and the teachers signed release forms at the start of the project. The participant video permission forms for both teachers and students were locked in a cabinet in the care of Teacher Education at CGU. All participant 
identification was protected and pseudonyms were used in the results. Since this study was situated within the MAAP grant, the data created and generated was still considered data analysis on behalf of the MAAP professional development and ultimately belonged to the State of California.

\section{Sample}

There were 54 participating teachers in the treatment group of the MAAP professional development. Each member of the population was used in the sample for this study. Previously, all teachers were categorized based on their level of participation in the project. These levels were determined by the MAAP research team based on the teachers' number of hours of participation in monthly seminars, summer institutes, and classroom observations. Over the two years, high-level participants had more than $75 \%$ participation in yearly seminars, summer institutes, and classroom observations; moderate-level participants more than 50\% seminars, summer institutes, and classroom observations; and low-level participants less than $50 \%$ seminar, summer institute, or classroom observation. It is important to note that those teachers who did not have high participation had incomplete sets of video data and/or reflection forms; nevertheless, analyses of all collected data was conducted regardless of quantity.

Even though there was a control group in the design of the MAAP research, there was no professional development offered to this group during the project. Therefore, there was no data to analyze. 


\section{Data}

The data for this dissertation was drawn from the MAAP professional development, particularly from the second year of each cohort in the mathematics professional development. The second year data was selected for analysis since it was a more accurate picture of teachers' skills in analyzing student thinking and the teachers experienced an initial year of professional development focused on attending and analyzing student thinking and reasoning. Also, second year data was used since there was a change in observation and reflection forms before the start of the second year of the first cohort. The use of second-year data in each cohort eliminated any differences caused by the change in forms.

Over the course of the two years of mathematics professional development, the teachers' mathematics lessons were videotaped six to seven times a year. For each videotaped lesson, the teachers completed a written pre-observation form, a postobservation form, and a video reflection form. Only the post-observation and the video reflection forms were examined in this study. Additionally, the five-minute teacherselected video segment as marked on the reflection form was analyzed. If no 5-minute video segment was identified, the section described in the teacher's reflection was found on the video and then coded.

The data drawn from MAAP for this dissertation included: 1) up to seven videotaped lessons per teacher, 2) up to seven post-observation forms for each videotape per teacher, 3) up to seven reflection forms for each video per teacher, and 4) teachers' mathematical knowledge for teaching tercile rankings. These data will continue to be described in more detail. 


\section{Video Segments and Video Reflection Form}

During MAAP, the teachers were asked to incorporate the concepts and ideas that were introduced during the seminars and summer institutes into their mathematics instruction; however, no packaged tasks or curricular material were given. The teachers' mathematics lessons were video recorded monthly by a member of the MAAP research team.

After the taping of a lesson, the teachers received a copy of their lesson on a compact disc and were asked to view and select a five-minute segment and record its corresponding time stamp. Then teachers were asked to situate the segment within the context of their lesson and describe why it was selected on the Video Reflection Form (see Appendix A).

In this dissertation the teacher-selected five-minute segments were analyzed for cognitive demand using the Task Analysis Guide (Stein \& Smith, 1998) (see Appendix B), and the written reflections were analyzed for teacher noticing of student thinking using the Framework for Learning to Notice Student Mathematical Thinking (van Es, 2011) (see Appendix C).

\section{Post-Observation Form}

The post-observation form (see Appendix D) asked the teachers to reflect on their mathematics lesson. They were also asked to state any connections of the lesson to the seminars and activities and to describe the types of discourse they observed in their lessons. The Framework for Learning to Notice Student Mathematical Thinking (van Es, 2011) was used in this study to analyze the teachers' post-observation forms. 


\section{MKT Tercile Rankings}

The teachers' mathematical knowledge for teaching (MKT) tercile levels came directly from the MAAP professional development data and were scores resulting from annual administrations of the Learning Mathematics for Teaching (LMT) survey. The scores represented the teachers' beginning terciles at the start of the first year and at the end of the second year of MPD. The LMT survey was nationally normed and found to be both valid and reliable (Hill, 2010; Hill \& Ball, 2004; Hill, Ball, Blunk, Goffney, \& Rowan, 2007). The survey consisted of questions developed to effectively measure teachers' mathematical knowledge for teaching. This collection of questions asked teachers to respond to classroom mathematics situations by analyzing students' responses, recognizing students' misconceptions, identifying appropriate mathematical content, and making decisions about ways to address mathematics instruction. As a way to evaluate teachers' growth in mathematical knowledge for teaching in MPD, the LMT survey was frequently used as a comparison pre- and post-test (Bell, Wilson, Higgins, \& McCoach, 2010; Charalambous, 2010; Santagata, 2009).

It is important to understand the derivation of the Learning Mathematics for Teaching survey scores and their interpretation. As described in the MAAP Final Report:

Since the LMT instrument used IRT theory to develop their instrument, all scores are $\theta$ scores that are based on a standard scale with a mean of 0 and a standard deviation of 1 . Due to this characteristic, the growth scores can be interpreted as effect sizes. Thus, a growth score of .3 equals an increase of $.3 S D$, which corresponds to an effect size of Cohen's $d$ of .3. (Brown, 2012, p. 31) 
Statistically significant growth occurred in MAAP teachers' mathematical knowledge for teaching as measured by the LMT (see Table 1). According to the MAAP Final Report, There was a significant overall increase of $(0.43, p<.01)$ for the treatment group and no overall change for the control group $(\mathrm{p}>.05)$. We also observed a significant increase for teachers who stayed one year $(0.52, p=.04)$ or two years $(0.49, \mathrm{p}<.001)$. There was no change for the group with less than one year of participation. Neither control group showed any significant overall change $(\mathrm{p}>.05)$. (Brown, 2012, p. 31)

Table 1

Total LMT Change Score Analysis, Treatment and Control

\begin{tabular}{llrrrr} 
& & Mean Difference & \multicolumn{1}{c}{$t$} & $d f$ & Sig. (2-tailed) \\
\hline \multirow{3}{*}{ Treatment } & $<1$ Year & -0.058 & -0.552 & 5 & 0.605 \\
& 1 Year & 0.524 & 2.429 & 8 & 0.041 \\
& 2 Years & 0.488 & 6.749 & 38 & 0.000 \\
& Overall & 0.433 & 6.412 & 53 & 0.000 \\
\multirow{2}{*}{ Control } & 1 Year & 0.080 & 0.436 & 11 & 0.672 \\
& 2 Years & 0.082 & 0.929 & 44 & 0.358 \\
& Overall & 0.082 & 1.034 & 56 & 0.306 \\
\hline
\end{tabular}

(Brown, 2012, p. 31)

From the MAAP professional development's LMT analysis, teachers' scores were ranked according to tercile. To better understand this process, the description from the MAAP Final Report (2012) is again helpful:

Both treatment and control site teachers' knowledge was measured annually with the Learning Mathematics for Teaching survey. Even though the LMT is scored using a continuous measure, we also analyzed the teachers' scores in terms of their tercile ranking. This analysis was carried out because we believe that the linearity assumption would be violated if we used a continuous LMT variable. Also, 
previous research (Hill et al., 2005) has shown that the relationship between teachers' mathematical knowledge for teaching (the content knowledge measured by the LMT) and student achievement is not consistent across the scoring continuum but rather significant effects existed between teachers scoring in the lowest $20-30 \%$ of teachers and those scoring in the top four deciles (Hill et al., 2005). This research indicates that attention should be paid to teachers' tercile rankings when considering growth.

In our research, the two cut points for the terciles were based on the norming sample and not the study sample. That is, $1^{\text {st }}$ tercile teachers are teachers whose LMT score falls below $33^{\text {rd }}$ percentile for the norming sample, $2^{\text {nd }}$ tercile are teachers between $33^{\text {rd }}$ and $66^{\text {th }}$ percentile, and $3^{\text {rd }}$ tercile are teachers above $66^{\text {th }}$ percentile. Since our cut points are based on the norming sample, distribution of teachers across the three terciles was not equal in this study. (Brown, 2011, p. 33-

Thus, it is important to note that the $1^{\text {st }}$ tercile represented those teachers scoring below -1 $S D$ from the mean, the $2^{\text {nd }}$ tercile between -1 and $+1 S D$, and the $3^{\text {rd }}$ tercile above $+1 S D$ above the mean. At the start of MAAP, $46 \%(n=25)$ of teachers scored in the $1^{\text {st }}$ tercile.

Since only one known study has been able to document a relationship between teachers' mathematical knowledge for teaching and instruction (Charalambous, 2010), examining the LMT results in correlation with both noticing and cognitive demand of enacted tasks added to this dissertation's significance and contribution to the field. 


\section{Analyses}

Quantitative analyses were used to analyze the five-minute video segments, teacher observations, and reflections to respond to the research questions in this study. A description of the method of analysis is listed for each question below.

Research question 1. How do the teachers' written reflections and observations of their mathematics lessons explain teachers' levels of noticing in the second year of mathematics professional development focused on developing teachers' mathematical knowledge for teaching?

The Framework for Learning to Notice Student Mathematical Thinking, developed by van Es (2011), was used to analyze how and what teachers noticed when they observed and reflected on their lessons. This framework was derived from van Es and Sherin's video club studies that occurred from 2000 - 2001. In the video clubs, teachers viewed their teaching and discussed what they noticed. Van Es described a detailed process of idea unit analysis of the discourse resulting in ten idea units. The meaning and scope of categories evolved from a detailed analysis of patterns and variations from ten video clubs resulting in two main categories or dimensions. For each category a trajectory was then developed. These analyses resulted in the Framework for Learning to Notice Student Mathematical Thinking.

The two dimensions proposed in van Es' (2011) framework first identified what is noticed and the second looks at how teachers reason about what they observe. These two dimensions were then organized across four levels of noticing: 1 -Baseline, 2 - Mixed, 3 - Focused, and 4 - Extended. The levels showed an increase in depth and interpretation of a situation or student thinking with Level 4 being the highest degree of noticing. For 
example, a Level 1 response in the what is noticed dimension might be focused more on the teachers' own pedagogy or the class as a whole. In contrast, a Level 4 might seek to make interpretations of students' thinking or make deeper connections between teaching strategies and students' mathematical thinking. In the dimension of how teachers notice, a Level 1 might include descriptive and evaluative comments of what occurred. In contrast, a Level 4 might give specific interpretive comments citing specific evidence or might make connections between the events of the classroom to bigger principles of teaching and learning.

For each video recorded lesson, the teachers completed a post-observation form and a video reflection form. There was potential for the teachers to have fourteen forms total for the second year; however for this study, the video reflection form and the postobservation form for each lesson were instead considered one reflection and received one score level using the Framework for Learning to Notice Student Mathematical Thinking. These forms were evaluated as a whole since they represented the teachers' reflection on their practice. Throughout the rest of the analyses, when I refer to reflections or reflection forms, I am referring to the score from these two combined forms.

In SPSS, a categorical score was recorded for each lesson based on the Framework for Learning to Notice Student Mathematical Thinking score: 1 -Baseline, 2 -Mixed, 3 -Focused, and 4 -Extended. Since the research question sought to explore how the data explained teacher noticing, I analyzed the noticing scores using descriptive statistics and frequency distributions for the teachers. The mean, mode, and standard deviations were calculated for the teachers' lessons from the start to the end of the second year. The mean provided information on the average level of noticing across the teachers' reflections. 
Calculating the mode helped to determine the most prevalent noticing level over the year of lessons. I looked for trends in the distribution of the noticing scores and shifts in the data to see if there were any noticeable changes as a group over the course of the second year. A paired samples $t$-test was conducted using the intermediate (beginning of the second year) and ending (of the second year) teacher noticing scores to look for differences in the means. A Pearson's correlation was conducted on the teachers' noticing levels and their overall mathematics professional development participation levels to see if there was a relationship between teacher participation and teacher noticing. These findings were then recorded.

Research question 2. How do teachers' self-selected video segments of mathematics lessons explain the level of cognitive demand of the teachers' enacted tasks during the second year of mathematics professional development focused on developing teachers' mathematical knowledge for teaching?

The Task Analysis Guide, developed by Stein and Smith (1998), was used to evaluate the levels of cognitive demand for teachers' enacted tasks. This four-level guide identified the levels of the five-minute teacher-selected video segments for each of the lessons. As previously stated, the Task Analysis Guide was developed as a result of an NSF-funded professional development entitled Quantitative Understanding: Amplifying Student Achievement and Reasoning Project (QUASAR). Stein et al. (2009) worked with teachers in this project to incorporate challenging tasks in the urban classroom to increase middle school students' opportunities to think, reason, problem-solve, and increase mathematical communication. Subsequent studies described by Stein et al. also used the Task Analysis Guide to evaluate curriculum and classroom enactment of tasks. 
Each level of the Task Analysis Guide increased in cognitive demand. The first level, Memorization Tasks, described tasks that included mostly reproduction of learned facts, rules, formulae, or definitions. This level had no connection to an underlying meaning and did not provide a procedure. Procedures Without Connections Tasks was the second level that included tasks that were algorithmic with limited cognitive demand. At this level, there was no connection to the procedures underlying the concepts or meaning and the focus was on the right answer. There were no explanations required by the students unless they specifically focused on describing the procedure that was used. The third level, Procedures with Connections Tasks, focused students' attention on procedures to develop deeper conceptual understanding and required some cognitive demand. In this level there were broad pathways for students to follow rather than narrow algorithms, and there could be multiple representations and connections between representations to bring about meaning. Students at this level needed to engage the conceptual ideas that were beneath the procedures in order to successfully complete the task. At the fourth Doing Mathematics Tasks level, the students were required to think in complex, non-algorithmic ways. There was no rehearsed approach or pathway that was suggested or worked-out as an example, and students must have analyzed the task for possible solutions, strategies, and limitations. At this level, the students had to explore the nature of the concept, relationship, or processes, and sustained a significant cognitive effort through self-monitoring and self-regulation. Also, students were to have accessed appropriate related knowledge and experiences and applied them while working through the task. 
To add to the reliability of the data, one third of the teacher videos were coded by members of the MAAP research team. At the start of the coding, the MAAP team began by reading through the work of Stein et al. (2009) and looking at examples of tasks and their cognitive demand levels. Discussion followed as the team examined the nuances and differences between levels as designed by Stein et al. on the Task Analysis Guide. Eight video segments were viewed as a team. Through discussion and agreement, a code level was given to the video segments and the highest coding level reached during the five-minute video segment was recorded. Then the team worked in pairs to continue to code the video segments for the rest of the 18 teachers. If disagreement or questions arose, the whole group viewed and discussed the video segment until consensus was reached.

The coded scores were recorded in Excel where I notated the teacher, the lesson number, and the score level for the video segment. The cognitive demand means for each teacher were calculated as well as the mode to look at variations between teachers and the most common level of cognitive demand gained by the teachers.

The Excel files were transferred to SPSS for further analyses. A categorical score was recorded for each lesson based on the Task Analysis Guide score: 1-Memorization Tasks, 2 - Procedures Without Connections Tasks, 3 - Procedures with Connections Tasks, and 4-Doing Mathematics Tasks. Since the research question asked how the video segments explained the level of cognitive demand of enacted tasks, I began by analyzing descriptive statistics. First, I analyzed the teachers' scores by calculating their mean, mode, and standard deviation of the cognitive demand across the seven video lessons. The mean provided information on the average level of cognitive demand achieved across the teachers' lesson segments. Calculating the mode helped to determine 
the most prevalent cognitive demand level over the year of lessons. I also looked at the data for trends in the teachers' levels of cognitive demand and the variation represented by the standard deviations. A paired samples $t$-test was conducted using the intermediate and ending cognitive demand scores to analyze differences in the second year. Since participation was possibly related to the cognitive demand in the enacted tasks, I also conducted Pearson's correlations between the teachers' level of cognitive demand and the teachers' participation level to see if these variables were related. Understanding the context of the mathematics professional development and the relationship to cognitive demand of lessons was valuable. All results were reported in detail.

Research question 3. How do teachers' levels of mathematical knowledge of teaching relate to teachers' levels of noticing and levels of cognitive demand in enacted tasks during the second year of mathematics professional development focused on developing teachers' mathematical knowledge for teaching?

The analysis suggested by this question drew on three groups of data: teachers' levels of mathematical knowledge for teaching; teachers' levels of noticing; and levels of cognitive demand of enacted task. Pearson's correlations were conducted to examine the relationships between the following variables: MKT tercile ranking; teacher noticing level; cognitive demand level; grade level; school; and level of participation in the MAAP project. The levels at the end of the second year of data were used in this analysis to examine the relationships between MKT tercile rankings, noticing levels, and cognitive demand levels.

\section{Sharing the Findings}


I shared the findings from this study with those who were integral to the MAAP professional development. This included the MAAP research team and the leadership of the Teacher Education Department at CGU. Additionally, I anticipate sharing my findings at national conferences such as the American Educational Research Association, National Council for Teachers of Mathematics, and the Association for Mathematics Teacher Educators. Publishing these results will benefit the educational community, and I plan to submit articles to the Journal for Research in Mathematics Education, Journal of Mathematics Teacher Education, and the Journal of Teacher Education.

I have provided a written report of the entire study consisting of five chapters. The first chapter provides a general overview of the project and its significance to the field. The second chapter gives a thorough review of the supporting literature. Third, I describe in detail the methods used to obtain the data with specific attention to the selection of the sample, the application of The Framework for Learning to Notice Student Mathematical Thinking (van Es, 2011), the Task Analysis Guide (Stein et al., 2009), and the use of teachers' mathematical knowledge for teaching as determined by the MKT tercile levels. Fourth, I delineate the results of the data analysis by sharing the evidence from both the teachers' noticing and from the cognitive demand of the enacted tasks. I also include the results from the comparison of the teachers' noticing levels the teachers' cognitive demand of enacted tasks level with their MKT tercile levels. Fifth, a comparison is made between the results and the existing literature on professional noticing, cognitive demand of tasks, and the development of teachers' mathematical knowledge for teaching. Additional findings are also described. I conclude by identifying recommendations for policy and further research. 


\section{Limitations \& Conclusion}

This study has its limitations. First, the sample size was small and represented only 54 teachers who participated in the two-year professional development. Second, some of the teachers did not complete a full set of videos and reflections in the second year of MAAP, thus in some instances the data was limited. Third, the teacher-selected video segments at times were limited in the richness of mathematical content, and this may have constrained the teachers' ability to notice higher levels of student thinking. Fourth, the teacher participants were under a great deal of stress during the two years of the professional development due to the Program Improvement status of their schools and the economic climate of California; therefore, the teachers' responses at times appeared rushed and limited in depth and attention to detail. Finally, the majority of the statistical strength of this study was limited to correlation and thus cannot prove causality between variables.

By conducting this study, I hoped to provide new data to the educational field regarding teacher noticing, the cognitive demand of enacted tasks, and their relationship to teachers' mathematical knowledge for teaching in the context of mathematics professional development. Little to no research currently exists to explore the relationship between these variables (Charalambous, 2010) and no study links these three variables in the context of professional development. Ideally, this study will help to shed light on the complexities of teaching and learning and help the field to better understand the relationship of teaching and learning in the context of effective professional development. Having a better grasp of this impact is needed if we expect to influence classroom practice and improve student achievement in mathematics. 


\section{Chapter Two: Review of Relevant Literature \\ Introduction}

In the past decade, mathematics performance for fourth and eighth grade students in the United States showed little improvement regardless of national efforts (NCES, 2011). In an attempt to improve student performance, professional development has been aimed at improving instruction by increasing teachers' mathematical content knowledge as it applies to classroom practice (Darling-Hammond et al., 2009). Mathematics reform has been the critical focus in education for the past decade (Cavanagh, 2009; Rampey, Dion, and Donahue, 2009) and the demand for students with competencies in the fields of science, technology, engineering, and mathematics (STEM) has become paramount (EdSource, 2008). According to the 2011 report by the National Center for Education Statistics, there was only slight growth in the mathematics scores of fourth and eighth graders between 2009 and 2011; only five states showed increases in their fourth grade results. In 32 states, there was no difference found between fourth graders' mathematics performance between the 2009 and 2011 scores.

Traditionally in the United States, mathematics has consisted of arithmetic and computational fluency, however mathematics researchers widely believed that this method of instruction does not enhance the development of mathematical reasoning and ignores current research on students' mathematical development (Battista, 1999; Blanton \& Kaput, 2005; Hiebert \& Carpenter, 2003; Stigler \& Hiebert, 1999). According to Martin and Kasmer (2009), it is essential that children in the elementary classroom explore important mathematical ideas by reasoning and sense-making in order to provide a strong foundation for future success. It seems that American schools focus narrowly on 
skills, procedures, and fluency in mathematics rather than higher levels of reasoning and problem solving (Charalambous, 2010; Hiebert \& Carpenter, 2003; Hiebert \& Stigler, 1999; Ma, 1999). According to experts in the field, the current narrow focus of mathematics instruction needs to be broadened by strengthening teacher content knowledge in mathematics and providing the pedagogical tools needed by teachers to extend their students' thinking and reasoning (Ball, Hill, \& Bass, 2005; Hill \& Ball, 2004; Hill et al., 2005).

In traditional teacher preparation, candidates for an elementary credential receive minimal learning experiences to enhance and deepen their own understanding of mathematical concepts. As a product of the same education system as their students, teachers often have past mathematics experiences that emphasized computation, memorization, and skills rather than deeper conceptual understandings (Ball, 1990; Ball, 1997; Ball et al., 2005). This is problematic since teachers are limited by their own knowledge (Hill \& Ball, 2004; Ball et al., 2005). Many teacher candidates in elementary education also have self-reported feelings of inadequacy and anxiety when it comes to mathematics and can point to an event that caused them to no longer feel motivated to learn mathematics. Teachers' experiences and feelings have a detrimental effect on their practice as well as their knowledge in mathematics (Ball, 1997; Drew, 2011; Swars, Daane, \& Giesen, 2006). Therefore, teachers' own base of knowledge needs to be expanded so they can provide students with rich mathematical learning experiences. This continued development of teachers' knowledge and skill is a critical aspect of deepening students' learning opportunities to reason and problem solve. 
Researchers in the area of mathematics professional development (MPD) have identified teachers' mathematical content knowledge with a focus on opportunities for reasoning and sense-making as essential elements needed to ensure a strong foundation for improved instruction in mathematics (Hill \& Ball, 2004; Martin and Kasmer, 2009; Mewborn, 2003). Various types of professional development (PD) reform have been implemented across the nation to improve teachers' mathematical content knowledge as it relates to teaching and planning (Bell et al., 2010; Hill \& Ball, 2004; Jones et al., 2009; Walker, 2007). Others strategies have focused on developing and strengthening teachers' abilities to notice and foster student reasoning and thinking (Blanton \& Kaput, 2005; Franke, Carpenter, Fennema, Ansell, Behrend, 1998; Franke, et al., 2007; Jacobs, Lamb, \& Philipp, 2010; Sherin, \& van Es, 2009; van Es \& Sherin, 2006). In the hopes of improving teachers' instructional practices, some researchers have used mathematics professional development to foster collaboration between teachers in their planning and evaluation of student work (Blanton \& Kaput, 2005; Franke et al. 2009; Jacobs et al., 2007; Santagata, 2009; Walker, 2007). The majority of these various professional development programs were geared toward shifting teachers' practice with the aim of improving student achievement; thus, the purpose of this paper is to review the research in elementary professional development, particularly those studies that address mathematical knowledge for teaching, student reasoning and thinking, teacher noticing, cognitive demand, and reflection. 


\section{Literature Review}

\section{Mathematics Research and Professional Development}

The current state of mathematics education is a result of its past history. In the 1920s and 1930s in the United States, there was great debate between superintendents, principals, educational researchers, and professors of education over the mathematics to be taught across the grade levels and the necessity of mathematics and other core subjects at the high school level for all students (Ravitch, 2000). According to Kilpatrick (1992), it was generally agreed that basic arithmetic at the elementary school level was important; however, at the high school level, there was disagreement about the required form of mathematics and who should take the courses. One of the big questions revolved around who should study algebra. In response to this growing disagreement within the mathematics community, the National Council of Teachers of Mathematics (NCTM) was formed in 1920. This organization not only called for increased research in mathematics but also declared that changes should not be made to learning that were not first supported by scientific research focused on the learners' needs, the learning process, and the needs of society.

One of the first major studies resulting from this call for research was the Eight Year Study, funded by the Carnegie Corporation and the General Education Board in 1932 (Kilpatrick, 1992). As described by Kilpatrick, 30 secondary schools were allowed to "experiment with innovative curricula" (p. 21) for five years. The research showed that the 1,475 students from the 30 schools did slightly better than their peers in college when it came to their grades, honors, and graduation rates; however, this study overlooked examining the effects of the curricular changes at the schools. Once this study's results 
were released, an emphasis on mathematics curriculum research and a measurement approach to education ensued that instituted national and international assessments of mathematics achievement.

Historical events and other outside influences began to impact the field of mathematics between the 1930s and the 1960s. Kilpatrick (1992) noted that during this time psychology began to influence mathematics research as the field attempted to define itself. In the 1960s there was also a lack of continuity between the mathematics of the universities in comparison to the lower schools. National concern about the declining enrollments in university mathematics, the atomic weapons of the 1940s, the Soviet launch of Sputnik in 1957, and the need for engineers and skilled technical workers brought increased federal funding for research in mathematics and science. Woodward (2004) called the 1950s and 1960s the "golden age" (p. 16) in mathematics education due to the enormous amount of research funding that was received to improve teaching and learning.

During the 1950s, a movement in mathematics education known as new math became paramount in the United States. In this movement an emphasis was placed on the new math curricula that emphasized instruction on abstract mathematical concepts at the elementary level. According to Woodward (2004), the goal of this mathematics education movement was to promote student understanding versus memorization and calculation.

Another aspect within the new math movement included discovery learning. This approach attempted to combat the behaviorist approaches from previous years and was to embody teachers as guides and prompters of learning while providing students the opportunity to draw diagrams, use manipulatives, and provide explanations in problem 
solving (Woodward, 2004). Though discovery learning appeared to be clearly envisioned by theorists and educational leaders, Woodward noted that teachers were not as successful at implementing the construct at the classroom level. What became apparent was that teachers needed high levels of pedagogical content knowledge to carry out all of the envisioned aspects to make discovery learning successful. Also, discovery learning required teachers to reconceptualize their own understanding of mathematics to that which was more abstract. The K-12 teachers not only needed these individual teacher attributes, but they also needed professional development to successfully implement this new way of teaching and learning; however, the professional development was nonexistent. As the nation moved into the 1970s, the back-to-basics movement drove schools away from discovery learning and instead emphasized reading, writing, and arithmetic within which the teacher was to be the dominant central figure (Woodward, 2004).

In the 1970s and 1980s the focus of researchers became the process of teaching and the resulting student outcomes or products. This became known as process-product research (Woodward 2004). Politically, it also became important during this time period to use standardized tests as a central dependent measure. According to Woodward, one influential research example from this time period was The Missouri Mathematics Effectiveness Project that studied the relationship between specific teaching behaviors and improved performance on standardized tests. The government funding of similar studies became a demonstration of the federal government's commitment to educational equity; however, using scripted materials placed a huge burden on static curricula that allowed few liberties for those who were teaching. 
Throughout the 1970s and 1980s, mathematics researchers also became increasingly interested in cognitive science and conducted smaller quasi-experimental and qualitative studies to analyze students' mathematical understanding. During this time, Skemp's (1987) influential book entitled, The Psychology of Learning Mathematics, provided insight into knowledge organization, the importance of schema, and metacognition. Interest in the late 1980s also included the relationship of visual imagery and memory (e.g., Marr, 1982), conceptual and procedural understanding (e.g., Hiebert, 1986) and the natural development of mathematical understanding in preschool children (e.g., Baroody, 1987; Fuson, 1988). These studies influenced the development of school curricula that attempted to "link an informal with a formal understanding of mathematics" (Woodward, 2004, p. 20). By the end of the 1980s, there were many researchers who were moving toward constructivist theory to provide a foundation for information processing (Woodward, 2004).

In the late 1980s and 1990s, there were some significant developments that continued to influence the face of mathematics education. Woodward (2004) pointed to the development of standards and comparative international research that showed weakness in the national teaching of mathematics. For example, NCTM developed standards that were introduced in 1989 in response to dissatisfaction with standardized testing. States began formulating their own standards and performance-based assessments to produce rigorous outcomes. Also, the findings from the Third International Mathematics and Science Study (TIMSS) produced harsh criticism about the lack of depth and increased breadth of American mathematics in comparison to other countries. Ravitch (2000) noted that NCTM revised their standards in 1997 in response to criticism 
for a lack of basic skills. Woodward described the 1990s as particularly unique since the research concentrated on analyses of conceptual topics that in turn pushed the field toward a constructivist approach. Moreover, a socio-cultural perspective became dominant in understanding teaching and learning.

By the 2000s, a marked shift occurred in relationship between the federal government and education. Woodward (2004) noted The Bush administration's No Child Left Behind Act of 2001 increased the degree of accountability in public education. Moreover, the concept of scientifically based research began to direct practices in schools. After a long history of decentralized education, the federal government began to force the hand of educators across the country in response to the accountability movement. As the current tenor of education suggests, the air of reform is again being enacted through the development and adoption of the Common Core Standards in Mathematics.

\section{Effective Professional Development}

In the mid to late 1990s, researchers and policy makers began paying closer attention to the effects of mathematics and science professional development on teaching practice and student achievement (Ball \& Cohen, 1999; Loucks-Horsley \& Matsumoto, 1999; Louks-Horsley, Stiles \& Hewson, 1996; Wilson \& Berne, 1999). At the time, there were only a handful of studies that supported a relationship between professional development, practice, and achievement (Campbell \& Robles, 1997; Cohen \& Hill, 2000; Stein \& Smith, 1998; Wiley \& Yoon, 1995). The context for teaching proved to be so complex that researchers felt that little was known about the true nature of teaching and learning and the role of professional development (Ball, 1997; Loucks-Horsley \& Matsumoto, 1999; Wilson \& Berne, 1999); thus, a call was made to the educational 
research community for research in this area. Since teaching had become more standardsbased, there was a new realization that teachers needed to not only be supported through professional development but also become active leaders and decision-makers in professional development to bring about change in their schools (Loucks-Horsley \& Matsumoto; Loucks-Horsley et al., 1996).

In this new effort to better understand effective PD, those in the mathematics community attempted to characterize its qualities, though there was no agreement in the field on a set of criteria (Ball, 1997; Loucks-Horsley, 1997; Loucks-Horsley \& Matsumoto, 1999; Loucks-Horsley et al., 1996; Wilson \& Berne, 1999). Some of the characteristics included collaboration, follow-up, knowledge of children, reflection, modeling of strategies/approaches, context of teaching, content/subject focused, cognitive dissonance, time, and continued support (Ball, 1997; Darling-Hammond \& Ball, 1998; Friel \& Bright, 1997; Loucks-Horsley, 1997; Loucks-Horsley \& Matsumoto, 1999; Loucks-Horsley et al., 1996; Thompson \& Zeuli, 1999; Wilson \& Berne, 1999). There was a wide range of opinion about what constituted effectiveness.

Since the early 2000s, more agreement has been reached in identifying the key factors of effective PD in mathematics and science (Darling-Hammond et al., 2009; Desimone, Porter, Garet, Yoon \& Birman, 2002; Garet, Porter, Desimone, Birman \& Yoon, 2001). Garet et al.'s research was the first large-scale empirical comparison of effective characteristics. This study was based on a national survey of science and math teachers who had participated in professional development through the Eisenhower program, funded by the federal government. It represented 1,027 teachers from across 358 districts that participated in math and science PD. As a result of this study, three 
main core features were found to have significant positive effects on teachers' selfreported increases in knowledge and skills and change in practice; these included: 1) focus on content knowledge, 2) opportunities for active learning, and 3) coherence with other learning activities. Three significant additional structural features were found within these core features: 1) the form of the activity (study group or workshop), 2) collective participation (grade, subject, or school), and 3) the duration of the activity. This study helped to solidify on a large scale the effectiveness characteristics; however, the data gathered was based on teacher self-report.

Garet et al.'s (2001) research was supported by Darling-Hammond et al.'s (2009) report by the National Staff Development Council. Darling-Hammond and colleagues based their characteristics of effective professional development on a meta-analysis of 1,300 research studies and evaluation reports. The characteristics consistent across successful studies included: intensive and ongoing; connected to practice; focused on student learning; addressed the teaching of subject-specific content; aligned with school priorities and goals; and built opportunities for collaboration and strong working relationships. The findings suggested a minimum of 49 hours a year was best for professional development with an ideal amount between 30 to 100 hours spread over six to 12 months.

Current reports and articles have drawn on these foundational studies to solidify and promote the characteristics of effective professional development (Bell et al., 2010; Borko, 2004; Wilson, 2009; Yoon, Duncan, Lee, Scarloss, \& Shapley, 2007); however, a recent call was made to reconsider effective professional development in terms of design and outcomes (Hill, Beisiegel, \& Jacob, 2013). Aside from this most recent call for an 
evaluation of effective professional development, previous agreement in the field identified that effective professional development:

- focuses on deepened content specifically for teaching, and includes relevant understandings of how students learn as well as difficulties and common misconceptions.

- is intensive and ongoing, including 40 or more hours of a course or program distributed over 12 months.

- is coherent by building on teachers' previous knowledge and abilities and is related to what teachers are asked to do regularly in their classrooms.

- engages teachers actively rather than showing through demonstrations or lecture.

- includes teams of teachers from the same school, the same grade, or the same subject, and provides opportunities for collaboration and mutual support in using what teachers have learned.

In the following section, application of effective mathematics professional development will be explored within the context of teachers' mathematical knowledge for teaching.

\section{Mathematical Knowledge for Teaching}

Shulman was the first to present a varied theory of teacher knowledge (1986, 1987). Countering the popular belief that pedagogy and content were separate, Shulman called for an examination of what teachers know and how they know it as well as an investigation of the source of teacher knowledge and how it was acquired, retrieved, and 
formed. In his seminal writing, Those Who Understand: Knowledge Growth in Teaching, Shulman (1986) presented a new theoretical framework for understanding teacher knowledge. He posited that teacher knowledge was divided into domains and categories; a major domain was content knowledge. Within content knowledge were the categories of subject matter content knowledge, pedagogical content knowledge, and curricular knowledge. Content knowledge was described by Shulman as teacher knowledge about particular content that included ways of defining and explaining truths for students. Shulman defined pedagogical content knowledge as the way a teacher uses representations to make content comprehensible. He extended this knowledge to include teachers' understanding and mediation of students' developmental needs as well as preconceptions and misconceptions. Lastly, Shulman defined curricular knowledge as teacher knowledge about the appropriate use of alternative curricular materials and tools (e.g. visuals, video, texts, software, inquiry) to enhance students' content learning. In addition, he wrote about lateral and vertical knowledge: teachers need to know gradelevel content in other subjects and how to make connections to this content, and they also need to know students' prior knowledge from preceding years and knowledge needed for later years. Considering teacher knowledge in this way was revolutionary and laid the foundation for researchers and teacher educators to examine its complexities more closely.

Since Shulman, others have continued the quest to understand more about teacher knowledge including how it should be defined and measured (Ball et al., 2008; Hill, Ball, \& Schilling, 2008; Hill \& Ball, 2004; Hill Schilling, \& Ball, 2004; Ma, 1999). In mathematics, Ball et al. have taken Shulman's theory and conceptualized mathematical 
knowledge for teaching as divided into two parts: content knowledge and pedagogical content knowledge. Within content knowledge, there was common content knowledge, specialized content knowledge, and horizon knowledge. Common content knowledge was conceived of as common knowledge that other adults have that use mathematics in their work or lives, but specialized content knowledge was knowledge that went beyond that of the general public and was specific content knowledge teachers possess as it relates to teaching. Horizon knowledge was teachers' understanding of what students needed to know in future grades; knowing future mathematical content, teachers were able to build on the knowledge students currently possessed or were learning. This type of knowledge helped teachers make decisions about introducing content in order for it to connect to future knowledge.

Pedagogical content knowledge, the second category of mathematical knowledge for teaching, was conceptualized as knowledge about content and students, knowledge about content and teaching, and knowledge of content and curriculum. These three types of knowledge were based on the way that content is taught and how students learn. Pedagogical knowledge supports teachers' understanding of the developmental needs of students and how students think about mathematics in knowledge of content and students. Knowledge about content and teaching helps teachers decide on methods and strategies to introduce content to students, and knowledge of content and curriculum enables a teacher to know how best to use the curriculum and materials in instruction.

In a quest to further understand mathematical knowledge for teaching, mathematics researchers and teacher educators have explored ways in which mathematical knowledge for teaching can be measured. Through a series of studies over 
many years and various professional development settings (Hill \& Ball, 2004; Hill et al., 2008; Hill et al., 2005; Hill et al., 2004; Ma, 1999), questions were developed to effectively measure teachers' mathematical knowledge for teaching. This collection of questions asked teachers to respond to classroom mathematics situations by analyzing students' responses, recognizing students' misconceptions, identifying appropriate mathematical content, and making decisions about ways to address mathematics instruction. The questions covered a broad range of domains and have been found to be valid and reliable (Hill, 2010; Hill \& Ball, 2004; Hill et al., 2007; Hill et al., 2004). This resulting tool, the Learning Mathematics for Teaching survey was used frequently as both pre- and post-tests in mathematics professional development to evaluate teachers' growth in mathematical knowledge for teaching (Bell et al., 2010; Charalambous, 2010; Santagata, 2009).

Researchers have tried to answer whether mathematical knowledge for teaching can be grown and, if so, under what conditions (Bell et al., 2010; Charalambous, 2010; Hill \& Ball, 2004; Hill et al., 2005). It was shown that teachers with an extensive amount of teaching experience had a higher rate of mathematical knowledge for teaching in general tests of teachers (Fennema \& Franke, 2005). Researchers attributed this higher rate of mathematical knowledge for teaching to teachers learning on their own from students and using curriculum materials (Hill, 2010; Fennema \& Franke, 2005); however, there was evidence to suggest that teachers' mathematical knowledge for teaching could be affected as a result of mathematics professional development (Bell et al.; Hill \& Ball, 2004). Several studies used the mathematical knowledge for teaching assessments developed by Ball and colleagues' to assess changes in elementary teachers' 
mathematical knowledge through mathematics professional development and to analyze the relationship of MKT to other variables in teaching and learning (Bell et al., 2010; Charalambous, 2010; Hill \& Ball, 2004; Hill \& Ball, 2005; Hill et al., 2008; Hill et al., 2004; Kersting et al., 2010; Santagata, 2009).

Charalambous (2010) and Santagata (2009) were studies that used mathematical knowledge for teaching in professional development as a pre- and post-test with a small number of elementary teachers; however, developing mathematical knowledge for teaching was not the sole purpose of the mathematics professional development. Charalambous analyzed how teacher knowledge informed teacher actions and decisions in the teaching of a lesson or "task unfolding," using Stein and Smith's (1986) Task Analysis Guide as the tool to measure the cognitive demand of the task. In his research, Charalambous found a relationship between the level of task unfolding and the teachers' mathematical knowledge for teaching. In a case study of two teachers, differences were highlighted between a teacher with higher mathematical knowledge for teaching and higher task unfolding in contrast to a teacher with lower mathematical knowledge for teaching and lower levels of task unfolding. The teacher with higher mathematical knowledge for teaching provided more meaningful explanations and presented and enacted tasks at higher cognitive levels. Limitations, however, pointed to differences in curriculum materials and the size of the sample.

Santagata (2009), in her two-year mathematics professional development working with sixth-grade teachers assessed teachers' mathematical knowledge for teaching, but she did not report final data; instead, Santagata stated that the teachers lacked the conceptual understanding of fractions and other content knowledge and this was 
"supported by the multiple-choice survey used to measure teacher content and pedagogical content knowledge" (p. 44). Since the teachers experienced difficulty with questions that relied on their own conceptual understandings, students' understandings, and deep analyses of students' work, it seemed apparent that the teachers held a low level of mathematical knowledge for teaching; however, Santagata omitted reporting on the results of the Learning Mathematics for Teaching survey as a result of the professional development.

In contrast to small examples of mathematics professional development, Hill and Ball (2004) and Bell et al. (2010) analyzed teachers' mathematical knowledge for teaching in large-scale professional development programs. Hill and Ball used the Learning Mathematics for Teaching survey as a pre- and post-test to evaluate California's Mathematics Professional Development Institutes (MPDIs). The MPDIs were conducted throughout the state and consisted of 80 hours of professional development by trained facilitators. Although the sample was to be much larger, it resulted in 398 participants. The findings of this study showed that teachers' mathematical content knowledge increased through one mathematics professional development program. Likewise, the results indicated a positive correlation between length of mathematics professional development and gains in mathematical knowledge for teaching.

Hill et al. (2005) found interesting relationships between mathematical knowledge for teaching and other variables in their analysis of a multi-school $(N=115)$ Comprehensive School Reform that focused on instructional improvements. This study was longitudinal in nature and included 26 comparison sites. A variety of data was collected from the teachers including interviews, questionnaires, teacher logs, and 
mathematical content questions. Hill and Ball found that teachers' mathematical knowledge for teaching positively predicted student gains in mathematics achievement in first and third grade. Findings also indicated that even the mathematics knowledge of early-grade teachers affected students' achievement. The results suggested that teachers in the lowest third of the distribution of knowledge were those who benefitted the most from the professional learning.

Two studies, Kersting et al. (2010) and Hill et al. (2008) compared mathematical knowledge for teaching and its relationship to other assessments; although these were not mathematics professional development programs, they were investigations that contributed to researchers' understanding of mathematical knowledge for teaching and were grounded in teachers' perspectives and classrooms. Kersting et al. (2010) used mathematical knowledge for teaching in the development of an alternate video-based assessment of elementary teachers' abilities to analyze lesson situations. In this study, the researchers provided the teachers with video clips of mathematics lessons to view and evaluate after which they responded individually to prompts on the computer. A comparison was drawn between the teachers' results of mathematical knowledge for teaching using Ball and colleagues' questions and the classroom video analysis (CVA) measure. Findings from this study showed that mathematical knowledge for teaching was significantly related to the CVA measure; however, the results were unable to predict student learning.

Hill et al. (2008) analyzed the relationship between mathematical knowledge for teaching and a teachers' mathematical quality of instruction (MQI) tool. Though ten teachers were involved in this study, only five were reported as case studies. The teachers' 
mathematical knowledge for teaching was assessed and their instruction was analyzed using the elements of MQI. The findings from this study suggested a strong relationship between "what a teacher knows, how she knows it, and what she can do in the context of instruction" (p. 496). The results indicated a correlation between teachers with low mathematical knowledge for teaching scores and the presence of mathematical error during instruction. Conversely, for those with high mathematical knowledge for teaching, there was the presence of mathematical richness of instruction and lack of mathematical error. The mediating factors appeared to be teachers' mathematical knowledge for teaching, teachers' beliefs about how mathematics should be learned, curriculum materials and how they should be used, and the availability of curriculum.

These studies illustrate the value of content focused professional development with an emphasis on mathematical knowledge for teaching and their impact on teachers' knowledge and development of expertise. The types of studies described in this section expounded on Shulman's $(1986,1987)$ theory of teacher knowledge and the need to unpack classroom interactions and underlying beliefs with care. As stated earlier, the process of teaching is highly complex and multi-faceted with many aspects yet to be understood; thus, teachers' knowledge of mathematics, the effects of this knowledge on instruction, and the role of mathematics professional development are critical elements for understanding the classroom context.

\section{Children's Reasoning and Thinking}

Mathematics professional development has focused not only on mathematical knowledge for teaching but also children's thinking and reasoning as a way to better understand the relationship between teaching and learning mathematics. Several 
elementary mathematics professional development programs were designed around teachers' learning from children's thinking and reasoning (Blanton \& Kaput, 2005; Campbell \& Robles, 1997; Fennema, Carpenter, \& Franke, 1997; Franke et al., 2009; Jacobs et al., 2007). This focus on children's thinking and reasoning allowed the teachers in these projects to learn from their students, engage in practical inquiry, and make instructional decisions based on their knowledge of children's mathematics (Franke et al., 1998).

One of the most successful and widely known studies centered on children's thinking was Cognitively Guided Instruction (CGI) (Carpenter, Fennema, Franke, Levi, \& Empson, 1999; Carpenter, Fenemma, \& Franke, 1996; Fenemma et al., 1996; Franke et al., 2009). The fundamental notion of this longitudinal study was that teachers make decisions based on knowledge of how students learn particular content. The CGI framework was founded on cognitive science and posited that new knowledge needs to be connected to existing knowledge (Koehler \& Grouws, 1992). In the CGI study, teachers were not provided curriculum or specific tasks; instead, they were exposed to the CGI framework and challenged to learn from children's thinking through video, observation, and analysis of student work. Over the course of ten years, CGI showed that primary grade teachers' knowledge of their students' thinking was related to students' mathematics achievement. Participants in the study focused on conceptual learning through problem solving more than computational skills and the results indicated that students scored significantly higher in problem solving than control classes. Also, these students did not lose any gains in computational skills because of the focus on problem solving (Carpenter et al., 1999). Moreover, teachers' instructional beliefs and practices 
changed so that teachers allowed students to engage in more problem solving rather than directing students' actions through explicit instruction (Fennema et al., 1996).

Similar to CGI, Increasing the Mathematical Power of All Children and Teachers (Project IMPACT), also focused on students' thinking; however, Project IMPACT was specifically targeted at urban, low performing, highly diverse classrooms (Campbell, 1996; Campbell \& Robles, 1997). Like CGI, this project did not purposefully focus on curriculum materials or specific implementation tasks. Rather, the K-3 teachers from the three treatment schools collaborated with their colleagues on instruction, worked with a math specialist provided by the project at each participating school site, and attended weekly grade-level meetings and summer institutes during which teachers worked on adult mathematics problems. The results of this program did not show an increase in the first year; however, in the second year, there was a significant increase in the mean for student achievement on items dealing with mathematical abstraction. This increase lasted through third grade until the end of the project. Though project IMPACT focused on providing students more opportunities to learn through discourse and group work, the authors admitted that $10-15 \%$ of the teachers could not easily probe students' ideas to consider their thinking. Nevertheless, observations showed that $40 \%$ of teachers had changed practices that included questioning and probing students and providing opportunities to engage in reasoning.

Two other studies investigated children's thinking, particularly focusing on developing children's algebraic reasoning (Jacobs et al., 2007; Blanton \& Kaput, 2005). Jacobs and colleagues provided a yearlong mathematics professional development for 19 urban elementary schools and 180 teachers in one of the lowest performing school 
districts in California. Their study focused on extending teachers' ideas about algebraic reasoning by helping teachers to see that this type of reasoning was deeply imbedded in the curriculum and relevant at the elementary level. Additionally, this study sought to develop teachers' ability to attend to their students' thinking by analyzing student work and observing students' strategies. Jacobs et al. also focused on relational thinking that helped turn teachers' focus away from computation to examining relationships between and among numbers as found in expressions and equations. The findings from this study indicated that teachers grew significantly in their ability to identify student strategies. Moreover, student achievement was positively affected and students of participating teachers were more likely to use relational strategies when problem solving.

Blanton and Kaput's (2005) Generalizing to Extend Arithmetic to Algebraic Reasoning (GEAAR) had a central focus aligned with Jacob et al.'s (2007); both studies' goal was to shift teachers' focus from computation to an understanding of reasoning. Through this study, Blanton and Kaput wanted to develop teachers "eyes" and "ears" to see and hear their students' thinking and to help teachers adapt their practice. During professional development sessions, 20 kindergarten through fifth grade teachers engaged in solving mathematics tasks and then adapted the tasks to teach in the classroom. The participant teachers were constantly challenged in the PD sessions to reflect on their practice and to develop their students' ability to question, pattern, conjecture, generalize, and justify relationships in math. The findings from this five-year study were described using a case study of a participant teacher. This teacher expanded the algebraic thinking in her teaching and in students' thinking in flexible ways. Results indicated that student achievement in the project's third grade students on the statewide test showed a 
significant improvement in relationship to third grade performance at the state and district level.

The fundamental idea generated by these studies was that studying children's thinking and reasoning was valuable and prompted teacher growth and change (Blanton \& Kaput, 2005; Campbell, 1996; Fennema et al., 1997; Franke et al., 2009; Jacobs et al., 2007). Teachers engaged in practical inquiry when analyzing what students bring to and know from learning. As these four studies indicated, inevitable shifts in teacher practice occurred when the teachers were confronted by children's thinking and reasoning.

\section{Teacher Noticing}

Giving attention to children's thinking goes back to the early twentieth century to the development of progressive pedagogy and encompasses Dewey's perspective on attention. In Dewey's essay, "The Relation of Theory to Practice in Education" (as cited in Erickson, 2007), Dewey believed that teachers, through observation, could make a distinction between two types of attention: outer attention referred to the physical behavior of the child (also known as "deportment"; e.g. sitting at attention with hands folded); the inner attention regarded the evidence that showed genuine interest of the child toward learning or disinterest in learning (e.g. a child looking out the window while the teacher or another student is talking). Dewey believed that novice teachers had a difficult time seeing the differences between these two types of observed attention, though teachers' attention to these cues were of fundamental importance to pedagogy. This attention to noticing, or observing, as discussed by Dewey, has continued to be expanded on through various lenses of research. 
Previous studies have commented on the subjectivity of noticing based on individual or group perception. Erickson (2007) described how a person's cultural lens affected the way in which a video of teaching was understood. After showing a brief video of a Native American reservation classroom, teachers held strong opinions about what they noticed based on their view of typical norms in American classrooms. The observers did not understand that the slow and monotone speech, lack of individual praise, and whole group questioning evidenced by the teacher was a cultural artifact rather than evidence of poor teaching. In fact, quite the opposite was true since the teacher they were observing was a highly effective teacher in that cultural setting. Similarly, Goodwin (1994) commented on the specific lens various professions bring to a situation. He argued that groups from the same profession possessed a framework that enabled them to make sense of a situation in particular ways. The way that the group viewed a situation was titled professional vision. For example, police would see a crime scene differently than a social worker. Stevens and Hall (1998) also described the visual practices of disciplines or professions as disciplined perception. Mason (2002) commented on intentional noticing which was a way of understanding a situation through the lens of a professional rather than an everyday lens. As can be seen through these perspectives, the idea of noticing has existed on a conceptual level; however, only until the past few years has it become a broadly known researched construct within the field of education.

Recent research on children's mathematical thinking and reasoning has given rise to the new field of teacher noticing. Sherin et al. (2011) described teacher noticing as encompassing two actions: 1) "attending to particular events in an instructional setting," and 2) "making sense of events in an instructional setting" (p. 5). These two actions were 
considered interrelated and a cyclical process in teaching. As Sherin et al. stated, "teachers select and ignore on the basis of their sense making; the way they respond shapes subsequent instructional events, resulting in a new and varied set of experiences from which teachers attend and make sense" (p. 5). During instruction, teachers have a barrage of information they sift through moment-to-moment. What they attend to in those moments and the sense making and decision-making that result are central to teacher noticing. Teacher noticing has become an object of study not only in teacher in-service but also pre-service professional development (Brunvand \& Fishman, 2006; Star, Lynch, \& Perova, 2011; Star \& Strickland, 2008). Studies in noticing have also crossed into other subject areas including science (Russ \& Luna, 2013; Tomanek, Talanquer, \& Novodvorsky, 2013) and literacy (Ross \& Gibson, 2010).

Several mathematics professional development studies in the context of video clubs shaped the mathematic community's understanding of teacher noticing in mathematics (Sherin \& Han, 2004; Sherin \& van Es, 2005; Sherin \& van Es, 2009; van Es \& Sherin, 2002; van Es \& Sherin, 2006). In these studies, elementary teachers watched videos of their own or their colleagues' teaching. The teachers were then asked what they noticed. Free discussion ensued about the content of the videos, and over the course of monthly video clubs the researchers noticed that teachers moved from discussions about the teachers' pedagogy toward discussions about the students' thinking. By the time the video clubs ended, the teachers were digging more deeply into the mathematical content, the focus was centered on students' thinking, and often teachers grappled with the interpretation of students' thinking. Although there was no evidence of a transfer directly to classroom practice, the research suggested that video could be used 
as a tool to deepen teachers' ability to listen to their students' thinking and attend to their mathematical ideas.

In a study by Jacobs et al. (2010), teachers' professional noticing of students' thinking was analyzed. The sample, both practicing and prospective K-3 teachers, was drawn from a larger study entitled Studying Teachers' Evolving Perspectives (STEP). STEP that was a professional development focused on children's mathematical thinking. Two written measures were designed to assess teachers' skills of attending, interpreting, and responding. The results indicated different levels of expertise among the participants: Initial Participants, Advancing Participants, and Emerging Teacher Leaders. Jacobs et al. noticed that the teachers' ability to notice the students' thinking increased with the amount of years of teaching; however, the length of teaching did not ensure that teachers could interpret children's understandings. The researchers also reported that teachers' expertise in noticing and interpreting students' thinking increased with two or more years of professional development and leadership activities.

\section{Cognitive Demand of Tasks}

In the 1980s, there was a significant amount of interest in students' cognition and the development and implementation of mathematical tasks. Doyle $(1983 ; 1988)$, Marx and Walsh (1988), and Hiebert and Wearne (1993) began to investigate the learning context and the influence of subject matter and task design on the cognition of students. International studies also looked at the differences of tasks across cultures to see if the teachers' implementation and the task design impacted students' learning (Stevenson \& Stigler, 1992; Ma, 1999).

Stein and colleagues (Silver \& Stein, 1996; Stein \& Lane, 1996; Stein et al., 1996; 
Stein \& Smith, 1998), funded by the National Science Foundation (NSF), began to investigate the cognitive demand and implementation of tasks in urban middle school mathematics classrooms. Their work became known as the Quantitative Understanding: Amplifying Student Achievement and Reasoning (QUASAR) project and was inspired by Doyle $(1983 ; 1988)$. In their research, they found that many teachers who were teaching sixth and seventh grade mathematics were trained elementary teachers who did not have mathematics beyond the high school level. They began to work with the teachers to examine their mathematical tasks and task implementation.

The research conducted by Stein and her colleagues (Silver \& Stein, 1996; Stein \& Lane, 1996; Stein et al., 1996; Stein \& Smith, 1998) examined many aspects of cognitive demand of tasks including students' capacity for reasoning and sense-making, teacher capacity for implementing and sustaining high cognitive demand, factors that support students in maintaining high levels of cognitive demand, and cognitive demand of specific curriculum implementation. Findings from their work showed that teachers could select and set up cognitively demanding tasks, however, the implementation of cognitive demand in the task was often not maintained due to insufficient time, poor management, a shift in emphasis from concepts and meaning to correctness of the answer, inappropriateness of tasks for the students, or lack of accountability for high-level products (Stein \& Smith, 1998). Likewise, Stein et al. (1996) found that teachers who had engaged in professional development could select and initiate tasks with cognitive demand but often were unable to sustain the level of cognitive demand throughout the lesson.

From Stein and Smith's (1998) early research, a four-level guide was developed. 
The two beginning levels characterized tasks with lower levels of cognitive demand such as memorization and procedures that did not have connections. The top two levels characterized higher-level tasks with procedures that were connected to concepts and an even higher level in which students were "doing mathematics" (Stein \& Smith, 1998, p. 348). This tool was originally used as a reflective tool for teachers as they viewed their personal videotaped lessons; however, the tool also became useful in professional development as teachers evaluated the cognitive demand of tasks and improved in their knowledge of how to select tasks with high levels of cognitive demand.

Based on their research, Stein et al. (2009) compiled a handbook for professional development providers to support teachers' selection of cognitively demanding tasks, as well as insight from their research in the form of case studies of implementation. In this text, they compiled a series of tasks that represented the different levels of cognitive demand. These materials were highly focused on the student thinking required by the demand of the tasks. Several teachers are chronicled and their stories told of how they implemented the tasks in their classrooms, some with greater fidelity and cognitive demand than others.

The research on cognitive demand has continued to look at task and curriculum implementation since there is still so much to understand. Research by Smith et al. (2008) and Stein and Kaufman (2010) has continued to support teachers' ability to effectively use curricular materials in ways that are cognitively demanding. Smith et al. showed that lesson design using the Thinking Through A Lesson Protocol allowed teachers more success at maintaining high levels of cognitive demand when planning instruction since the protocol prompted the teacher to start with a more open-ended type of problem and 
also allowed multiple pathways to the solution. Stein and Kaufman's study examined task quality and teachers' planning of big mathematical ideas using two curricular materials, Everyday Mathematics and Investigations. The two-year study suggested that Investigations curricular materials provided the teachers more support in using bigger mathematical ideas and allowing students multiple pathways to answers which promoted higher levels of cognitive demand, student thinking, and mathematical reasoning. The findings from both of these studies showed that a task's level of cognitive demand was related to opportunities for student thinking.

\section{Reflection}

It has been long understood that teacher reflection is an important aspect of teacher development (Brown \& Borko, 2003; Rogers, 2002; Schön, 1983, 1987). As a key component of teacher change, reflection has been at the heart of inquiry and is cyclical resulting in action (Franke et al., 1998; Philipp, Flores, Sowder, \& Schappelle, 1994; Sowder, J. T., 2007). In many reform types of mathematics professional development, change in teachers' practice was often the goal; thus, many studies have included opportunities for reflection as part of the professional development structure (Fennema et al. 1997; Joyner, 1997; Nelson, 1997). Opportunities for collective discussion and support have been found to be critical in providing opportunities for reflection as a part of mathematics professional development (Sherin \& Han, 2004; Sherin \& Van Es, 2005). As Ball (1997) aptly stated,

Reflection is central to learning to teach. For the most part, this perspective focuses on structure and context, emphasizing that teachers need time, space, and encouragement to reflect in ways that facilitate their learning - by talking with 
others, by keeping a journal, by engaging in action research. (p. 90)

Teachers at any stage in their development are still learning; therefore, providing teachers these opportunities, as Ball described, has been considered a significant aspect of an effective mathematics professional development program.

In the literature, effective mathematics professional development afforded elementary teachers the time to engage in reflection, ultimately affecting their practice in positive ways. In the video clubs described in the noticing studies (Sherin \& Han, 2004; Sherin \& van Es, 2005; van Es \& Sherin, 2002), reflection was the central activity of the teachers. In these studies, video slowed down the events of the classrooms and afforded the participants multiple views of the interactions from different perspectives than in their role as teachers. This new lens on teaching allowed the teachers to hear and see the children's thinking in new ways and to unearth the salient features of the teaching situations. Their discussions became richer as time went on as they grappled with the heart of the children's learning through their questions and actions. For these teachers, the discussions resulted in shifts in their thinking, and, for many, their teaching; teachers began to notice students' mathematical thinking and attended to students' ideas in ways that otherwise would have been dismissed (Sherin \& van Es, 2009). Similarly, Whitenack, Knipping, Novinger, Coutts \& Reys (1998) reported that multiple opportunities for teachers to view students' mathematical thinking on video prompted them to reflect and arrive at deeper understandings about students' knowledge. Video as a catalyst for reflection in these studies appeared to impact teachers' beliefs and practice.

Other mathematics professional development that used reflective methods also noted an impact on teachers' instruction and attitudes. Gabriele and Joram (2007) found 
that teachers' engagement in think-aloud reflection about their instruction provided increased self-efficacy. Philipp et al. (1994) noted that extraordinary mathematics teachers took the time to reflect on their own learning, came prepared to sessions, and reported thinking about seminar sessions on their own time outside of seminars and work. This reflective characteristic was found in each of the four teachers they studied. As the researchers noted, the teachers were in the process of gradual and ongoing change in their teaching practice. Being reflective was the characteristic that seemed to promote change. In the process of understanding inquiry on practice and change, Franke et al. (1998) reported teachers' generative change, or changes in their epistemological framework, as prompted by mathematics professional development. They pointed out that a teacher engaged in practical inquiry "can be viewed as a teacher questioning and reflecting about his/her practice with a specific focus. The focus of a teacher's practical inquiry determine[d] what a teacher [saw] as critical, and what constitute[d] an opportunity for reflection" (p. 68). Inquiry was identified as a key process that was central to the professional development and was a significant part of teachers' generative change. Using the reflective process, Blanton and Kaput (2005) required teachers to keep written reflections on their teaching and to note instances of students' algebraic reasoning and ways they promoted algebraic reasoning. In this study, teachers were constantly challenged to reflect on their practice and the results linked teachers' practices to increased student achievement.

It was clear from the literature that reflection played a significant role in mathematics professional development. The act of reflection has been a critical component of growing as a teacher and has often been linked to changes in practice and 
student achievement. To effectively reflect, Rogers (2002) called for teachers to be present in the moment of teaching. For Rogers, presence meant to be alert, attentive, and awake to the students' thinking and the content of the instruction. Covering the material, listening for the right answer, or just keeping the students engaged was not enough to promote learning. "It is by practicing this process outside the moment - reflecting on action - that teachers are able to employ the various components in the moment and reflect as the action unfolds" (p. 237). Indeed, reflection as a central component to mathematics professional development has shown to deepen teachers' attention toward students' thinking and bring about shifts in practice.

\section{Conclusion}

In conclusion, teaching elementary mathematics has been shown by the research to be a highly complex task. Thus, teachers need opportunities through effective professional development to develop their mathematical knowledge for teaching, as well as the ability to notice students' mathematical thinking and develop and sustain the cognitive demand of their lessons. Teachers must have not only the knowledge of mathematics for teaching but also the pedagogy and understanding of children's thinking and reasoning to improve their instruction; this is not an easy task. However, research has shown that teachers have the capacity to learn and adapt their practice to meet children's learning needs if given the opportunity. Clearly, more needs to be known about the teaching and learning process and how teacher knowledge relates to student thinking and instruction. Examining the relationships between teacher noticing of student thinking, the cognitive demand of tasks, and mathematical knowledge for teaching are constructs ripe for continued exploration and research at the elementary level. 


\section{Chapter Three: Methodology \\ Research Design}

This study used a quantitative design to analyze data drawn from a long-term mathematics professional development project funded by a California Improving Teacher Quality grant. The purpose of this study was to examine the possible relationships between three variables: 1) teacher noticing of student mathematical thinking, 2) cognitive demand of enacted tasks, and 3) teacher mathematical knowledge for teaching tercile levels.

My initial prediction of how these three variables were thought to interact is illustrated in the following conceptual model:

Figure 3

Conceptual Model

Conceptual Model for Teacher Instructional Shifts in MPD

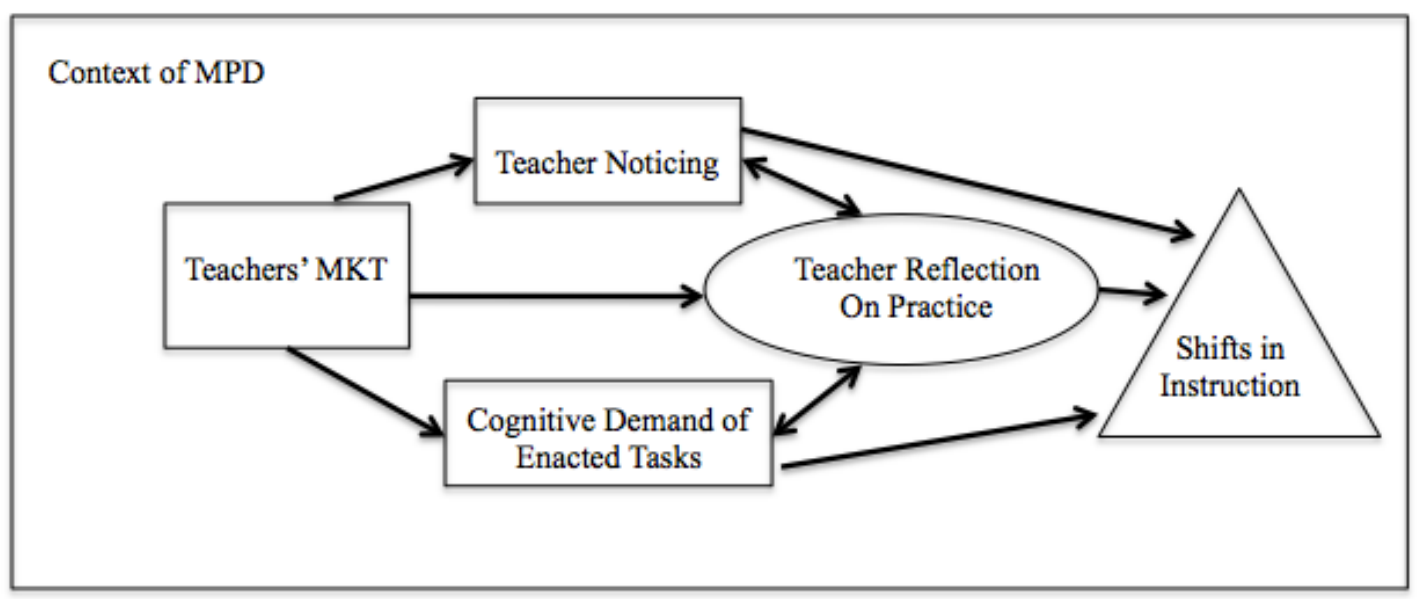

(Coddington, 2013)

Creswell (2009) suggested that models are beneficial for showing hypothesized relationships between variables and providing a foundation for understanding the 
research design of quantitative studies. A conceptual model, such as Figure 3, provides insight into the researcher's theoretical perspective of how the variables might interact. In this study, I hypothesized that the variables shown in Figure 3 were closely interrelated. It was my perspective that teachers' mathematical knowledge for teaching was a foundational variable that mediated teacher noticing and the cognitive demand of enacted tasks. Moreover, I believed that teacher noticing and the cognitive demand of enacted tasks ultimately influence shifts in instruction, though mediated by teachers' reflection on practice. Thus, by examining the relationships between these three variables, teacher noticing, cognitive demand of enacted tasks, and mathematical knowledge for teaching, I hope to assist the field of education in better understanding shifts in teachers' instruction while engaged in professional development.

\section{Context of the Study}

It is important to understand the professional development context from which the data for this study was drawn. The Making Algebra Accessible Project (MAAP) was the result of a partnership that brought together teacher education faculty from Claremont Graduate University, a mathematics professor from Pitzer College, and principals and teachers from four elementary schools. The mathematics professional development took place in an urban high-need southern California school district that serviced a large minority population. Funding for this project was provided by a California Improving Teacher Quality grant with the purpose of reducing the achievement gap. The goals of MAAP were to:

(1) Increase teachers' pedagogical content knowledge as it relates to early algebraic thinking; (2) Increase student performance on state-wide 
mathematics assessments; (3) Increase English Learners' performance on state-wide mathematics assessments; (4) Increase student success in taking and passing Algebra in later years; and (5) Develop professional learning communities. (CPEC, 2012)

MAAP's monthly seminars and summer institutes were specifically focused on developing teachers' pedagogical content knowledge in early algebraic thinking (see Figure 4). These ways of thinking, or reasoning, are highly interrelated and can be developed in very young children while learning arithmetic (Carpenter, Franke, \& Levi, 2003). During MAAP, the teachers were engaged in activities to develop and enhance students' mathematical thinking. This was a particular type of thinking called early algebraic reasoning. MAAP's intent was to assist teachers in recognizing early algebraic reasoning, as well as to discuss and explore ways to promote opportunities for children's early algebraic reasoning.

Figure 4

Forms of Early Algebraic Thinking

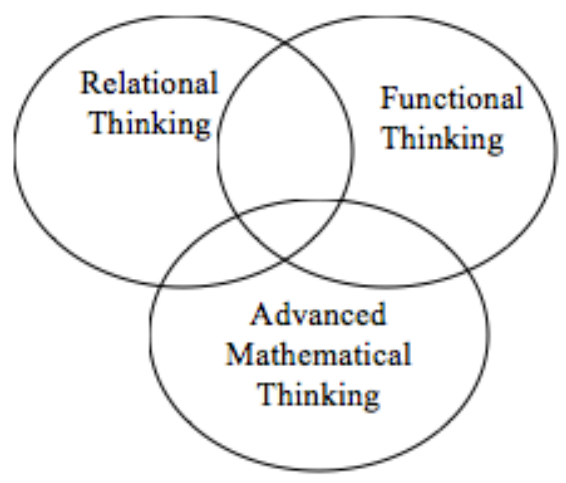

(Brown, 2012) 
Two cohorts of teachers were involved in the professional development that consisted of teachers from kindergarten through third grade (first cohort) and teachers from fourth through sixth grade (second cohort). The first cohort participated in the professional development for two years between 2008-2010, and the second cohort from 2009-2011. There was one year of overlap during which both groups met together. The professional development included monthly seminars, monthly lesson observations that were video-recorded, and two two-week summer institutes. In total, the teachers experienced 102 hours of professional development over the two years with an additional 32 hours of involvement in professional development related activities (Brown, 2012).

There were four participating schools in the project: two treatment schools that received professional development and two control schools that did not receive any professional development. Each of the schools represented a majority of English language learners (ELLs) and a high percentage of students qualifying for free or reduced lunch. All of the participating schools were in Program Improvement status at the start of MAAP (see Table 2).

Table 2

School Characteristics at Start of Year 1

\begin{tabular}{lllll} 
& Site A & Site E* & Site B & Site D* \\
\hline Student Population & 657 & 544 & 910 & 859 \\
\% Hispanic & 94 & 85 & 92.5 & 96 \\
\% African American & 3 & 9 & 4 & 1 \\
\% Asian & 2 & 1.5 & $<1$ & $<1$ \\
\% White & $<1$ & 3.5 & 2 & 2 \\
\% Free or Reduced Lunch & 93 & 85 & 95 & 94 \\
\% ELL & 59 & 48 & 51 & 56 \\
PI (Program Improvement) & Yes & Yes & Yes & Yes \\
\hline
\end{tabular}

Note. ${ }^{*}$ Control Sites

(Brown, 2012) 


\section{Sample}

There were 54 participating teachers in MAAP, and the whole population was used as the sample for this study, since the participant size was small. The sample represented teachers from kindergarten through sixth grade at two treatment schools. There were 34 participating kindergarten through third grade teachers and 20 fourth through sixth grade teachers. Also invited to participate were teachers on special assignment, special education teachers, and academic coaches; however, this group did not participate in video-recorded observations or video reflections.

Individual ethnographic data was not gathered on the participants in order to secure their anonymity; however, some general information about the participants' teaching experiences was gained through the MAAP Teacher Survey given during the second year of the grant. Treatment teachers who were surveyed $(N=38)$ had two to 32 years of teaching experience. Nine teachers reported teaching more than 25 years. Twenty-three teachers held master's degrees, and all but one teacher reported participation in some type of mathematics related professional development at the district or school level prior to MAAP.

The teachers' hours of participation were recorded at all professional development activities, and these hours were totaled and recorded over two years of participation. Teachers who participated more than $75 \%$ were considered high-level participants; those with more than $50 \%$ were considered moderate-level participants; and those below 50\% were considered low-level participants. Regardless of how many hours the teachers participated, all second-year data for each cohort was included in this study. 


\section{Protection of Human Subjects}

At the start of MAAP funding in 2008, the research design, surveys, and participation forms were approved by the Internal Review Board (IRB) of both Claremont Graduate University and Pitzer College. An amendment was made to the forms after the first year that was approved by the IRB at both universities. The data and analysis for this dissertation's study fits within the parameters of both the original IRB and the amended IRB approval.

When the grant was funded, the teachers from the treatment schools met with the MAAP Project Director at their school site to go over the details of the project. During the initial meeting, teachers were promised confidentiality and anonymity and were assured their identities would be protected and that pseudonyms would be used in any future reports of the data. The teachers were also given release forms for their participation. These signed forms were stored in a locked cabinet at Claremont Graduate University under the care of the Teacher Education Department.

The classroom videos used in this dissertation were those gathered during the MAAP classroom observations; thus, the videos with student and teacher participants are under the auspices of the grant. Those students pictured on the videos submitted parent/guardian permission forms that were signed and retained at the beginning of the project. For each year of participation, the students were asked to complete release forms. Those students who did not have a signed form were seated in the room outside of the camera's lens. The participant video permission forms for the students were kept in a locked cabinet under the care of Teacher Education at CGU. 
The funding for this project was based on whole school participation and teachers were expected to participate as a collective. The participants understood that "whole school" meant $80 \%$ participation from each school and they also realized the funding of the project was contingent on their participation. The teachers' participation was highly encouraged and supported by their administration and thus the teachers were more than "motivated volunteers." The teachers were paid by the grant for their involvement outside of their normal district-contracted day 25 dollars per hour for attendance at seminars and summer institutes. Payment was also given to the teachers for activities outside of school, such as viewing their lesson videos, writing reflections, and other grant related paperwork.

If for some reason the teachers chose not to participate in MAAP, they were given the liberty to leave the project. Over the four years of the grant, three teachers chose to end their participation for personal reasons while several others left the project due to long-term illness, re-assignment, non-renewal of teaching contract, or retirement. A few teachers did not want their videos viewed or coded by the research team $(n=2)$, and thus they were given the copies of their CDs. It is important to note that the grant took place during a severe economic crisis in California that reduced teacher positions and encouraged early retirement through incentive packages.

Since this study was situated within the MAAP grant, the data created and generated was still considered data analysis on behalf of the MAAP professional development and ultimately belongs to the State of California. All reports of the data will give credit to the State of California for the grant funding, to Claremont Graduate University, Pitzer College, as well as the Project Director and MAAP research team. 


\section{Research Questions \& Planned Analysis}

The research questions central to this study called for an examination of the relationship between three teacher variables: level of noticing, level of cognitive demand of enacted tasks, and mathematical knowledge for teaching tercile level. Table 3 shows a summary of the research design. 
Table 3

Summary of the Research Design

Research Question 1: How do teachers' written reflections and observations of their mathematics lessons explain teachers' levels of noticing in the second year of mathematics professional development focused on developing teachers' mathematical knowledge for teaching?

\begin{tabular}{|l|l|l|}
\hline $\begin{array}{l}\text { Data: } \\
\text { Teacher reflections }\end{array}$ & $\begin{array}{l}\text { Variables: } \\
\text { 1) Individual teacher noticing } \\
\text { levels }\end{array}$ & $\begin{array}{l}\text { Methods: } \\
\text { Descriptive statistics (mean } \\
\text { and mode) }\end{array}$ \\
\cline { 2 - 3 } & $\begin{array}{l}\text { 2) Group teacher noticing } \\
\text { levels }\end{array}$ & $\begin{array}{l}\text { Descriptive statistics (mean } \\
\text { and mode) } \\
\bullet \text { Paired Samples } t \text {-Test } \\
\text { (intermediate and ending } \\
\text { noticing level, analyzed by } \\
\text { cohort) }\end{array}$ \\
& \\
\hline
\end{tabular}

Research Question 2: How do teachers' self-selected video segments of mathematics lessons explain the level of cognitive demand of the teachers' enacted tasks during the second year of mathematics professional development focused on developing teachers' mathematical knowledge for teaching?

\begin{tabular}{|l|l|l|}
\hline $\begin{array}{l}\text { Data: } \\
\text { 5-minute segments from } \\
\text { video-recorded lessons }\end{array}$ & $\begin{array}{l}\text { Variables: } \\
\text { 1) Individual teacher cognitive } \\
\text { demand levels }\end{array}$ & $\begin{array}{l}\text { Methods: } \\
\text { - Descriptive statistics (mean } \\
\text { and mode) }\end{array}$ \\
\cline { 2 - 3 } & $\begin{array}{l}\text { 2) Group teacher cognitive } \\
\text { demand levels }\end{array}$ & $\begin{array}{l}\text { - Paired Samples } t \text {-Test } \\
\text { (intermediate /ending } \\
\text { cognitive demand level, } \\
\text { analyzed by cohort) }\end{array}$ \\
\hline
\end{tabular}

Research Question 3: How do teachers' levels of mathematical knowledge for teaching relate to teachers' levels of noticing and levels of cognitive demand in enacted tasks during the second year of mathematics professional development focused on developing teachers' mathematical knowledge for teaching?

Data:

Teacher reflections

Video-recorded lessons

Teacher MKT tercile levels

Variables:
1) Teacher noticing levels
2) Teacher cognitive demand
levels
3) Teacher MKT tercile levels

Methods:

- Pearson correlation (ending level, analyzed by grade level, school, and level of participation)

Note. "Beginning level" refers to the level at the start of Year 1 of the MPD. "Intermediate level" refers to the level at the start of Year 2 of MPD. "Ending level" refers to the level at the end of Year 2 of the MPD. 


\section{Data}

\section{5-Minute Video Segments and Reflections}

During MAAP, the teachers were observed approximately once a month during which a research team member video-recorded the teachers' mathematics lesson. The teachers were asked to reflect on their videos monthly and to respond to specific questions on two separate forms. The Post-Observation Reflection Form asked the teachers to write a reflection on the observed lesson, identify connections that they saw between the observed lesson and the MAAP seminars, and comment on the type of discourse that occurred during the lesson. A second form, the Video Reflection Form, asked the teachers to identify a 5-minute segment from their lesson by beginning and ending time, to situate the context of the lesson, and describe why they selected the segment. The teachers were asked to plan their lessons keeping the ideas from the seminars in mind, though they were not given specific curricula or content to cover. As data for this dissertation, both the Post Observation Reflection and Video Reflection Forms for each video were considered as one reflection.

\section{MKT Tercile Levels}

As participants in MAAP, the teachers' mathematical knowledge for teaching was assessed at the start of the project prior to treatment and at four other times throughout the course of the teachers' two-year participation using the Learning Mathematics for Teaching survey. This survey is a well-respected, nationally normed assessment tool (Hill, 2010; Hill \& Ball 2004; Hill et al., 2007; Hill, et al., 2004) that is used often in comparison pre- and post-tests in professional development to measure teachers' growth in mathematical knowledge (Bell et al., 2010; Charalambous, 2010; Santagata, 2009). 
The MAAP Final Report (Brown, 2012), explained how the Learning Mathematics for Teaching survey scores were interpreted:

Since the LMT instrument used IRT theory to develop their instrument, all scores are $\theta$ scores that are based on a standard scale with a mean of 0 and a standard deviation of 1. Due to this characteristic, the growth scores can be interpreted as effect sizes. Thus, a growth score of .3 equals an increase of $.3 \mathrm{SD}$, which corresponds to an effect size of Cohen's d of .3. (p. 31)

A key finding of the MAAP professional development was the statistically significant growth of teachers' mathematical knowledge for teaching (see Table 4). According to the MAAP Final Report (Brown, 2012),

There was a significant overall increase of $(0.43, p<.01)$ for the treatment group and no overall change for the control group $(\mathrm{p}>.05)$. We also observed a significant increase for teachers who stayed one year $(0.52, \mathrm{p}=.04)$ or two years $(0.49, \mathrm{p}<.001)$. There was no change for the group with less than one year of participation. Neither control group showed any significant overall change (p $>.05)$. (p. 31) 
Table 4

Total LMT Change Score Analysis, Treatment, and Control

\begin{tabular}{rlrrrr}
\hline & & $\begin{array}{c}\text { Mean } \\
\text { Difference }\end{array}$ & \multicolumn{1}{c}{$t$} & $d f$ & Sig. (2-tailed) \\
\hline \multirow{3}{*}{ Treatment } & $<$ Year & -0.058 & -0.552 & 5 & 0.605 \\
& 1 Year & 0.524 & 2.429 & 8 & 0.041 \\
& 2 Years & 0.488 & 6.749 & 38 & 0.000 \\
& Overall & 0.433 & 6.412 & 53 & 0.000 \\
\hline \multirow{3}{*}{ Control } & 1 Year & 0.080 & 0.436 & 11 & 0.672 \\
& 2 Years & 0.082 & 0.929 & 44 & 0.358 \\
& Overall & 0.082 & 1.034 & 56 & 0.306 \\
\hline
\end{tabular}

(Brown, 2012, p. 31)

The mathematical knowledge for teaching scores from the LMT during MAAP were analyzed by tercile ranking. To better understand this process, the MAAP Final Report was again helpful:

Both treatment and control site teachers' knowledge was measured annually with the Learning Mathematics for Teaching (LMT) survey. Even though the LMT is scored using a continuous measure, we also analyzed the teachers' scores in terms of their tercile ranking. This analysis was carried out because we believe that the linearity assumption would be violated if we used a continuous LMT variable. Also, previous research (Hill, Rowan, \& Ball, 2005) has shown that the relationship between teachers' mathematical knowledge for teaching (the content knowledge measured by the LMT) and student achievement is not consistent across the scoring continuum but rather significant effects existed between teachers scoring in the lowest $20-30 \%$ of teachers and those scoring in the top 
four deciles (Hill et al., 2005). This research indicates that attention should be paid to teachers' tercile rankings when considering growth.

In our research, the two cut points for the terciles were based on the norming sample and not the study sample. That is, $1^{\text {st }}$ tercile teachers are teachers whose LMT score falls below $33^{\text {rd }}$ percentile for the norming sample, $2^{\text {nd }}$ tercile are teachers between $33^{\text {rd }}$ and $66^{\text {th }}$ percentile, and $3^{\text {rd }}$ tercile are teachers above $66^{\text {th }}$ percentile. Since our cut points are based on the norming sample, distribution of teachers across the three terciles was not equal in this study. (Brown, 2011, p.

Thus, it is important to note that the $1^{\text {st }}$ tercile represented those teachers scoring below -1 $S D$ from the mean, the $2^{\text {nd }}$ tercile between -1 and $+1 S D$, and the $3^{\text {rd }}$ tercile above $+1 S D$ above the mean. At the start of MAAP, $46 \%(n=25)$ of teachers scored in the $1^{\text {st }}$ tercile. Permission to use the mathematical knowledge for teaching tercile levels in this dissertation was granted by the MAAP Project Director, Dr. Stacy Brown. The data provided by MAAP included the mathematical knowledge for teaching tercile rankings for each teacher $\left(1^{\text {st }}\right.$ tercile, $2^{\text {nd }}$ tercile, or $3^{\text {rd }}$ tercile) from the start of the project to the end; however, the teachers' individual LMT survey scores were not provided due to IRB protections.

\section{Instrumentation}

Two of the data sources for this study, teachers' written reflections on their own video-recordings and 5-minute self-selected video segments, were coded based on two separate frameworks: the Framework for Learning to Notice Student Mathematical 
Thinking (van Es, 2011) and The Task Analysis Guide (Stein and Smith, 1998). The following section describes these two instruments in more detail.

\section{The Framework for Learning to Notice Student Mathematical Thinking}

The Framework for Learning to Notice Student Mathematical Thinking (van Es, 2011) was used in this study to analyze teacher noticing of student thinking through written reflections on their own lessons. This framework was applied to the written reflections to analyze two aspects of teacher noticing: What Teachers Notice and How Teachers Notice. Within each of these two categories, four levels were coded: 1 Baseline, 2 -Mixed, 3 -Focused, and 4 -Extended. The progression in each category moved from a general observation of the class to a more detailed attention to student thinking. In the What Teachers Notice category, a Level 1 reflected comments on the whole class environment, learning, behaviors, and pedagogy. Level 2 comments reflected a focus on pedagogy and showed beginning reflection on particular students' thinking or behavior. A Level 3 response focused on particular students' mathematical thinking. In a Level 4 response, the teacher attended to the relationship between an individual student's mathematical thinking and also made connections between teaching strategies and student thinking. In the second category, How Teachers Notice, a Level 1 reflection formed general impressions, was evaluative in nature, and provided little or no evidence. A Level 2 reflection highlighted noteworthy events, included some evaluative or interpretive comments and began to include comments on specific events and interactions. For a Level 3 response, the teacher's reflection highlighted specific noteworthy events, included interpretive comments, provided evidence, and elaborated on the interactions. A 
Level 4 reflection highlighted noteworthy events, gave interpretive comments, provided evidence, and made connections between events and principles of teaching and learning.

The Framework for Learning to Notice Student Mathematical Thinking was a new framework proposed by van Es (2011) and was developed from an extensive video collection derived from van Es and Sherin's video club studies that occurred from 2000 2001. In the video clubs, teachers viewed video segments of their teaching and discussed what they noticed. In the creation of this framework, van Es carefully identified categories of teacher responses to the videos using a systematic process. A detailed process of idea unit analysis of the teachers' discourse was described by van Es that resulted in ten idea units. The meaning and scope of categories evolved from a detailed analysis of patterns and variations from ten video clubs resulting in two main categories or dimensions. For each category, van Es then developed a trajectory. These analyses resulted in the Framework for Learning to Notice Student Mathematical Thinking. This framework, though published, has not been applied to any other known published research; thus, one third of the reflections was coded by the MAAP research team to support this instrument's reliability.

\section{The Task Analysis Guide}

A second set of data for this study resulted from an analysis of the cognitive demand of the enacted tasks captured in the 5-minute segments of the teachers' videos. The Task Analysis Guide (Stein and Smith, 1998) was used as the instrument for coding the cognitive demand of the enacted tasks. Stein and her fellow researches used this guide broadly in their middle school research to measure the cognitive demand of tasks found both in curricular materials as well as enacted tasks (Stein et al., 2009). Through their 
work on the QUASAR Project, Stein and her colleagues developed the criteria for measuring the cognitive demand in mathematical tasks. They applied these criteria to multiple settings to evaluate teachers' enactment of mathematical tasks and the fidelity of the curricula's implementation by teachers to promote and sustain cognitive demand during instruction (Henningsen \& Stein, 1997; Stein et al., 1996; Stein \& Kaufman, 2010; Stein \& Smith, 1998). A formal introduction of the levels of cognitive demand occurred in Stein and Smith's 1998 publication and was used subsequently in professional development to train teachers to recognize the cognitive demand placed on students while engaging in a mathematical task. Research on cognitive demand has been of great interest to the field since its inception in the 1990s and the QUASAR Project was considered a foundational study that helped researchers further understand the role of mathematics tasks as used in middle school instruction.

The Task Analysis Guide outlines four categorical levels of cognitive demand. The first level, Memorization Tasks described tasks that were solely focused on memorized knowledge and reproduction of that knowledge. This knowledge was described as "facts, rules, formulae, or definitions that were committed to memory" (Stein \& Smith, 1998, p. 348). Tasks of this nature did not make connections to the underlying concepts or meaning, nor did they require procedures because they were too short or a procedure did not exist. The second level, Procedures without Connections Tasks, was algorithmic, used a specific procedure or one that was evident, required limited cognitive demand to complete successfully, did not connect to the concepts or meaning underlying the procedure, and required no explanations. The third level, Procedures with Connections Tasks, made connections between the deeper levels of 
understandings of concepts and ideas behind the tasks, suggested pathways to follow that were connected to the underlying conceptual ideas, were represented in multiple ways and made connections between representations, and required cognitive effort that could not be followed mindlessly. Finally, the fourth level, Doing Mathematics Tasks, required complex, nonalgorithmic thinking that was not predictable, well-rehearsed, or explicitly suggested by the task. The task required students to explore the concepts, processes, and relationships, examine the types of possible solutions, and exert significant cognitive effort that might produce some level of anxiety. These 5-minute segments were scored based on the Level $1-4$ as suggested by the sequence of the guide: Level 1 was Memorization Tasks up to Level 4 that was Doing Mathematics Tasks.

\section{Procedures}

\section{Reliability}

To ensure consistency in the scoring of teachers' reflections and video-segments, reliability was established by having members of the MAAP research team code one third of the entire data. Four members of the MAAP research team, Wayne Snyder, Kristen Baldridge, Becky Orona, and myself, twice convened to code both the teachers' reflections and video segments. These individuals were selected to code since they were a part of the original team that researched the MAAP professional development and were intimately involved with the project and gathering of data.

A systematic sampling technique was used to select the representative one-third sample of teachers to be scored by the team. Using a list of the 54 participating teachers in the population, I selected every third teacher. Subsequently, the 17 teachers' 
reflections and videos were coded by the team using the two coding frameworks previously described.

\section{Team, Paired, and Individual Coding}

Members of the MAAP team met on two Saturdays during the summer of 2013 to code both the written reflections and the video segments. On the first day, the team members met and began with a discussion about the noticing framework used to analyze the written reflections. We noted the differences between the four levels of cognitive demand and then applied the framework using a few sample reflections that I had previously selected from the 17 teachers' data. At first, we read each individual reflection and then discussed its perceived level as a group. Nuances of the framework language were discussed and we came to consensus on a final level for each task. We agreed to assign the highest level attributed to each reflection according to the identified level on the framework. From the reflections we scored together, an exemplar was identified for each level from $1-4$. Together, we coded 14 reflections from three different teachers as a group to reduce variations in scoring. Then we broke into pairs and coded the rest of the written reflections systematically by teacher. The team worked in pairs to code the remaining teachers' reflections. When discrepancies arose, we discussed them fully until consensus was reached. A record was kept by each pair of coders to record the scoring for each of the reflections. After the coding session, I transferred these records into an Excel file.

Similarly, the same MAAP research team members met on a second day to code the video segments. We began by discussing the Task Analysis Guide. In their book, Stein et al. (2009) provide a set of tasks that exemplify the type of thinking needed for 
each level of cognitive demand as described in the guide. The team solved the eight tasks individually without knowing the prescribed levels, and then we discussed as a group the level we believed each exemplified. This discussion helped to tease out the thinking level of each problem and the differences represented between the levels of cognitive demand as described by the framework guide. We then, as a group, applied the framework to seven video segments from four teachers selected from the one-third coding sample. We watched each individual video segment as a group and then discussed the segment and its level of cognitive demand. As questions arose in the coding, we stopped and discussed each until consensus was reached. A paper record of the results was kept of the coding that I later transferred into an Excel file. After coding each of the seven video segments, we broke into pairs to continue coding the rest of the 17 teachers' data. When discrepancies arose, we again talked through the problem as a group and came to consensus on the final score. The coding ended after the 17 teachers' video data were coded.

The team made specific decisions about the coding of the reflections that helped to shape our protocol. For example, if the Video Reflection Form was present but no 5minute segment was selected by the teacher, the written description of the segment's context as described on the form was used to identify the segment. In some cases, the teachers identified more than five minutes, in others they identified less; regardless of the amount identified, the segments were included in the data collection, as specified by the teacher. Also, if there was no Video Reflection Form completed for a lesson, the video data was not included in the data collection since there was no 5-minute identified segment. Eliminating video data based on the missing Video Reflection Forms reduced 
the amount of viable video data for this study; however, we found it unreasonable to code data upon which the teacher had not reflected.

After the MAAP team coded one third of the data, I continued to code the data independently, keeping in mind the decisions and justifications we had made as a group. Coding continued until all of the video and reflection data for the second year were exhausted. Overall, a total of 132 videos and 113 reflections were coded. All the records from these coding sessions were recorded and maintained systematically in an Excel file.

\section{Coding Data for SPSS}

To organize the data representing participation levels in MAAP, three codes were developed (see Table 5 below). This data came directly from the MAAP research records. The variable representing the teacher participation was named Participation Levels and the data was coded categorically as either level 1 -Low, 2 -Moderate, and 3 -High. Level 1 represented teachers who had Low/Low participation over two years of the MAAP professional development. This meant they had less than 50\% participation both year 1 and year 2, thus they were Low/Low. Level 1 also represented teachers within the category of $N A /$ Low and Low/NA as labeled in the MAAP records. $N A / L o w$ meant that they had not participated the first year and had less than 50\% the second year. Low/NA meant that they had participated less than $50 \%$ the first year and had no participation the second year.

Those teachers coded as Level 2 participants represented teachers who had Low/Mod, Mod/Low, and Mod/Mod levels of participation according to the MAAP data. Low/Mod and Mod/Low participation represented teachers who had less than $50 \%$ in one year of participation and between $50 \%$ and $75 \%$ in the other year. Mod/Mod participation 
meant that teachers had more than $50 \%$ during both years of participation. This category also included High/Low, and Low/High participants. High/Low or Low/High meant that they had high participation in one year and less than $50 \%$ during the second.

Finally, Level 3 participation represented teachers who had high levels of participation. In the MAAP data, these teachers were listed as High/High, which meant they had participated more than $75 \%$ during both years of the professional development. Additionally, High/Mod or Mod/High participation represented 50\% participation one year and over $75 \%$ participation during the second.

Table 5

SPSS Coding for Participation Variable

\begin{tabular}{ll} 
SPSS & MAAP \\
Participation Level & Corresponding Participation Category \\
\hline 1- Low Participation & Low/Low, NA/Low, Low/NA \\
$2-$ Moderate Participation & Low/Mod, Mod/Low, Mod/Mod \\
$3-$ High Participation & High/High, High/Mod, Mod/High
\end{tabular}

Codes were also developed for MKT tercile beginning and ending tercile levels. The beginning MKT tercile levels represented the beginning scores of the participants' first year. The MKT tercile beginning and ending levels were coded in SPSS as variables: Beginning MKT Tercile Level and Ending MKT Tercile Level. For these two variables, the categorical codes recorded in SPSS were: 1 - Tercile 1,2-Tercile 2, and 3 -Tercile 3 (see Table 6 below). 
Table 6

SPSS Coding for MKT Tercile Level Variables

Beginning MKT Tercile Level Ending MKT Tercile Level

1 - Tercile 1

1 - Tercile 1

2 - Tercile 2

2 - Tercile 2

3 - Tercile 3

3 - Tercile 3

The teachers' cohort grade levels were coded in SPSS for both the K-3 and 4-6 cohorts. The variable representing the cohort was labeled Cohort Grade Level and was coded categorically as $1-K-3$ Cohort and 2-4-6 Cohort.

To identify the school where the teacher taught, a variable of School was added to SPSS. This variable was coded as either $1-$ Zinnia Elementary $^{l}$ or $2-$ Willow

Elementary.

\section{Missing Data}

The variables included in the study contained missing data between $2 \%-42 \%$.

These data were coded in SPSS as 99. Forty teachers' data were coded in this study since 14 teachers either did not have viable second-year data or they had withdrawn from the project.

\section{Data Analysis}

\section{Question 1}

How do teachers' written reflections and observations of their mathematics lessons explain teachers' levels of noticing in the second year of mathematics

\footnotetext{
${ }^{1}$ All names are pseudonyms.
} 
professional development focused on developing teachers' mathematical knowledge for teaching?

The reflection data was carefully prepared and organized in an Excel sheet and an analysis of the individual teacher data was conducted. The means and modes were calculated for each individual teacher's reflections. These results measured the teacher noticing level and the most common noticing level per teacher. An overall grand mean for the individual teacher reflections was calculated by averaging the noticing level mean. This resulted in a variable that was named Mean Noticing Level, and the data for this variable was transferred into SPSS per teacher.

Several analyses were conducted using the noticing level variables to examine the teachers' noticing levels as a group. Descriptive statistics of the variables Intermediate Noticing Level, Ending Noticing Level, and Mean Noticing Level were conducted in SPSS and resulted in the mean, mode, and standard deviation for the group teacher data. Additionally, a Paired Samples $t$-Test was conducted comparing the means of the variables Intermediate Noticing Level and Ending Noticing Level. This data was also grouped and analyzed by the variable, Cohort Grade Level, to look at possible differences between the means of each cohort. Pearson's correlations were used to analyze the relationships between noticing variables as well as Participation Level and Cohort Grade Level. These data were also grouped by participation and cohort level during Pearson's correlations.

\section{Question 2}

How do teachers' self-selected video segments of mathematics lessons explain the level of cognitive demand of the teachers' enacted tasks during the second year of 
mathematics professional development focused on developing teachers' mathematical knowledge for teaching?

Initially, the mean and mode were calculated for the individual teachers' video segments. The results measured the mean cognitive demand levels over the course of the second year for each teacher and the most common level of cognitive demand. An overall grand mean for the 5-minute video recorded segments was calculated for each teacher's video data and resulted in a variable named Mean Cognitive Demand Level. This variable was recorded in SPSS.

To analyze the teachers' cognitive demand as a group, several different analyses were conducted. First, the mean, mode, and standard deviation were analyzed using the Intermediate Cognitive Demand, Ending Cognitive Demand, and Mean Cognitive Demand variables. Pearson's correlations were conducted on the cognitive demand variables as well as cohort and participation level. The correlations were also grouped by Cohort Grade Level and Participation Level. A Paired Samples $t$-Test was conducted using the Intermediate Cognitive Demand and Ending Cognitive Demand variables. The data in this analysis was also conducted on the same variables grouped by Participation Level and Cohort Grade Level.

Since two new variables were added during the analysis for Question 1 and Question 2, a complete list of variables in SPSS is presented in Table 7 below. 
Table 7

Variables in SPSS

\begin{tabular}{l} 
Variables \\
\hline Intermediate Cognitive Demand \\
Ending Cognitive Demand \\
Intermediate Noticing Level \\
Ending Noticing Level \\
Mean Cognitive Demand \\
Mean Noticing Level \\
Beginning MKT Tercile Level \\
Ending MKT Tercile Level \\
Cohort Grade Level \\
Participation Level \\
School
\end{tabular}

\section{Question 3}

How do teachers' levels of mathematical knowledge for teaching relate to teachers' levels of noticing and levels of cognitive demand in enacted tasks during the second year of mathematics professional development focused on developing teachers' mathematical knowledge for teaching?

To analyze the relationships between noticing, cognitive demand, and mathematical knowledge for teaching, Pearson's correlations were conducted. Correlations were conducted by whole group on the variables, Beginning MKT Tercile Level, Ending MKT Tercile Level, Intermediate Noticing level, Ending Noticing Level, Intermediate Cognitive Demand Level, and Ending Cognitive Demand Level, Participation, Cohort Grade Level, and School. These data were further grouped by: Cohort Grade Level, School, and Participation Level. This analysis was conducted to better understand the relationship and variance between these variables. Additionally, linear regressions 
were conducted on the following variables: Participation Level and Beginning MKT Tercile Level, to predict Ending MKT Tercile Level; Participation Level and Intermediate Noticing Level, to predict Ending Noticing Level; and, Intermediate Cognitive Demand Level and Participation Level, to predict Ending Cognitive Demand.

\section{Limitations}

There were several limitations to this study that should be noted. One limitation was the small sample size. Since this study was part of a larger study, the population was limited to the two treatment schools. Additionally, not all the teachers participated equally in the project during the second year and this limited the numbers of videos and reflections that were completed. Teachers who had moderate to low participation were missing video and reflection data and this impacted some of the results. Some teachers had video data, though they did not complete the reflection forms and this reduced the amount of valid data. In a few cases, the video data was missing and could not be found. Furthermore, the teacher participants were under a great deal of stress during the two years of the professional development due to the Program Improvement status of their schools and the economic climate of California; therefore, the teachers' responses may have been rushed and limited in depth and attention to detail. Finally, the majority of the statistical strength of this study was limited to correlation and thus cannot prove causality between variables. 


\section{Chapter Four: Results \\ Sample}

The data analyzed and reported in this study were drawn from 40 of 54 participant teachers in the MAAP professional development. There were fewer participants due to attrition and lack of second year data. The participants included 30 kindergarten through third grade teachers and 10 fourth through sixth grade teachers. Fifty-three percent of the teachers were from Zinnia Elementary and 48\% were from Willow Elementary. An analysis of the participation levels showed that $53 \%$ of the teachers were considered high level participants, 35\% were moderate level participants, and 13\% were low level participants.

\section{Analyses}

\section{Data}

Both the reflections and videos for the 40 teachers were coded. On average, teachers had four videos over the course of the second year. In total, there were 132 video segments and 113 teacher reflections coded in gathering these results.

\section{Variables}

To better understand the variables in this study, descriptive analyses were conducted in SPSS to provide a richer view of the variables. All of the main variables were analyzed for mean and standard deviation (see Table 8). 
Table 8

Whole Group Descriptive Statistics

\begin{tabular}{lccr} 
Variable & $N$ & $M$ & $S D$ \\
\hline Intermediate Cognitive Demand Level & 24 & 2.71 & .550 \\
Ending Cognitive Demand Level & 24 & 2.79 & .884 \\
Mean Cognitive Demand Level & 25 & 2.65 & .454 \\
Intermediate Noticing Level & 31 & 2.19 & .946 \\
Ending Noticing Level & 31 & 2.29 & 1.039 \\
Mean Noticing Level & 32 & 2.22 & .74 \\
Beginning MKT Tercile Level & 37 & 1.62 & .639 \\
Ending MKT Tercile Level & 37 & 1.92 & .795 \\
Cohort Grade Level & 40 & 1.25 & .439 \\
Participation Level & 40 & 2.40 & .709 \\
School & 40 & 1.48 & .506 \\
\hline
\end{tabular}

\section{Research Question 1}

How do teachers' written reflections and observations of their mathematics

lessons explain teachers' levels of noticing in the second year of mathematics

professional development focused on developing teachers' mathematical knowledge for

teaching?

Descriptive analysis. The individual teacher noticing data was analyzed for both mean and mode. The analysis indicated that the overall mean noticing level for the teachers in the second year was $2.22(S D=.74, N=32)$. The teachers' overall group noticing mode was 2.24 with a $S D$ of .970 . Twenty-eight percent of teachers had a noticing mode of 1 - Baseline, $28 \%$ of had a mode of $2-$ Mixed, $36 \%$ had a mode of $3-$ Focused, and $8 \%$ had a noticing mode of $4-$ Extended. These results indicated that the teachers were more likely to have noticing levels that were at 1 -Baseline and 2 -Mixed during their second year of the MAAP professional development, which meant that they 
were more attuned to their class at large, their own pedagogy, and were more likely to form general impressions of events.

When analyzing the teacher data as a group, descriptive statistics were conducted to compare the intermediate and ending noticing levels. The mean intermediate noticing level was $2.19(S D=.946, N=31)$ and the mean ending noticing level was $2.29(S D=$ $1.039, N=31)$ (see Table 8 above).

The whole group intermediate and ending noticing data was analyzed by frequencies as is shown in Table 9. The ending noticing data showed changes from the initial levels, particularly between level 2 -Mixed and level 3 -Focused. Shifts between the intermediate and ending noticing levels are shown in Table 10. By the end of the second year of the MAAP professional development, more teachers were in the top two levels of noticing. This meant that teachers were attending more to the relationships between students' mathematical thinking and their instruction and were including more interpretive comments about their students' thinking than at the beginning of the second year.

Table 9

Whole Group Intermediate Noticing Level

\begin{tabular}{lcclccc}
\cline { 2 - 3 } & \multicolumn{2}{c}{ Intermediate Noticing Level } & & \multicolumn{2}{c}{ Ending Noticing Level } \\
Variable & $N$ & $\%$ & & Variable & $N$ & $\%$ \\
\hline 1-Baseline & 8 & 26 & & 1-Baseline & 9 & 29 \\
2-Mixed & 12 & 39 & & 2-Mixed & 8 & 26 \\
3-Focused & 8 & 26 & & 3-Focused & 10 & 32 \\
4-Extended & 3 & 10 & & 4-Extended & 4 & 13
\end{tabular}


Table 10

Shifts Between Intermediate and Ending Noticing Levels

\begin{tabular}{lccc}
$\begin{array}{l}\text { Noticing } \\
\text { Level }\end{array}$ & $\begin{array}{c}\text { Intermediate Noticing } \\
\text { Level }(\%)\end{array}$ & $\begin{array}{c}\text { Ending Noticing Level } \\
(\%)\end{array}$ & $\begin{array}{c}\Delta \text { Noticing } \\
\text { Level }(\%)\end{array}$ \\
\hline 1-Baseline & $26(n=8)$ & $29(n=9)$ & $+3(n=+1)$ \\
2-Mixed & $39(n=12)$ & $26(n=8)$ & $-13(n=-4)$ \\
3-Focused & $26(n=8)$ & $32(n=10)$ & $+6(n=+2)$ \\
4-Extended & $10(n=3)$ & $13(n=4)$ & $+3(n=+1)$
\end{tabular}

Chi Square $\left(\chi^{2}\right)$ Test. The intermediate and ending noticing variables in Table 10 were further analyzed by a chi square test. The results showed $\chi^{2}$ (obtained) $=1.222$ and the $\chi^{2}$ (critical) $=7.815$ at the Alpha .05 level with a $d f=3$. Since $\chi^{2}$ was not significant, the null hypothesis was accepted which meant that there was no relationship between the variables.

Paired samples $t$-test. To further investigate the differences between the intermediate and ending noticing levels, a paired-samples $t$-test was conducted to compare the means of the two variables. On average, the Ending Noticing Level was greater $(M=2.29, S E=.187)$ than the Intermediate Noticing Level $(M=2.19, S E=.170)$. This difference was not significant, $t(30)=-.516, p>.05, r=.58$; however, it represented a moderate effect size.

The data was grouped by the variable Cohort Grade Level and another paired samples $t$-test was conducted to analyze potential differences in the means. No significance was found between the variables Intermediate Noticing Level and Ending Noticing Level for the K-3 Cohort. Neither was there any significance difference found between the 4-6 Cohort's means for the variables Intermediate Noticing Level and Ending 
Noticing Level $(M=1.83 S E=.477)$. The findings showed little significance when comparing the means of the intermediate and ending noticing levels for both cohorts; however, for the 4-6 Cohort, there was a moderate effect size found in the comparison of the means of the intermediate and ending noticing levels, $t(5)=-1.000, p>.05, r=.41$.

Bivariate correlation. To analyze the relationship between the variables Intermediate Noticing Level and Ending Noticing Level a Pearson's correlation was conducted on the whole group data. The correlation between the teachers' intermediate and ending noticing level was significant, $r=.45, p<.05, r^{2}=.20$. This correlation indicated there was a moderately positive relationship between teachers' intermediate noticing levels and teachers' ending noticing levels, and that $20 \%$ of the ending noticing level variance could be explained by the intermediate noticing level.

Another Pearson's correlation was conducted between the variables Intermediate Noticing Level and Ending Noticing Level for both the K-3 and the 4-6 Cohorts. The correlation for the K-3 Cohort did not indicate a significant relationship. It is important to note that although the analysis was conducted for the 4-6 Cohort, the sample size for this cohort dropped below optimal levels $(n<10)$. The correlation comparing the relationship between intermediate and ending noticing levels for the 4-6 Cohort, however, was significant, $r=.94, p<.01, r^{2}=.89$, indicating a strong positive relationship between intermediate and ending noticing levels for the 4-6 Cohort. The results can be understood to mean that $89 \%$ of the ending noticing level variance was explained by the intermediate noticing level. 


\section{Research Question 2}

How do teachers' self-selected video segments of mathematics lessons explain the level of cognitive demand of the teachers' enacted tasks during the second year of mathematics professional development focused on developing teachers' mathematical knowledge for teaching?

Descriptive statistics. To begin, individual teacher data were analyzed by calculating the overall grand mean for the teachers' mean cognitive demand levels, as well as the overall grand mode to learn more about the levels of cognitive demand in the video segments. The analysis of the mean cognitive demand level indicated a grand mean of $2.65(S D=4.54, N=25)$. The grand mean for the teachers' mode of cognitive demand level was $2.82(S D=.529, N=17)$. From these analyses, it appeared that teachers as a

group were more likely to plan lessons that had a cognitive demand level of either a level 2 - Procedures without Connections Tasks or a level 3 -Procedures with Connections Tasks.

Frequency analyses were conducted on the whole group data to look specifically at teachers' intermediate and ending levels of cognitive demand in their 5-minute video segments. As shown in Table 11, the intermediate cognitive demand frequencies indicated that $33 \%$ of teachers were at level 2 - Procedures without Connections Tasks, 63\% at level 3 - Procedures with Connections Tasks, and 4\% were at level 4 -Doing Mathematics Tasks. These results indicated that at the start of the second year of the professional development the majority of teachers were at the third level of cognitive demand. At this level, mathematics lessons were more connected to concepts and ideas, required more cognitive effort, and used multiple representations. 
As indicated in Table 11 below, the ending cognitive demand frequencies showed that $50 \%$ of teachers' were at level 2 -Procedures without Connections Tasks, $21 \%$ were at level 3 -Procedures with Connections Tasks, and 29\% were at level 4-Doing Mathematics Tasks. It is interesting to note that there was a shift in the number of teachers in level 3 at the end of the second year of the MAAP professional development; many of the teachers either moved up to a higher level of cognitive demand or they moved down to use procedures and tasks without connections during the year. Primarily, there were a larger number of teachers who moved to a higher cognitive demand in their lessons. This shift is demonstrated in Table 12 below. These results suggested that the majority of teachers were using the ideas and concepts introduced in the MAAP professional development and engaged their students more often in problem solving and working through cognitively demanding tasks.

Table 11

Intermediate and Ending Cognitive Demand Level

\begin{tabular}{|c|c|c|c|c|c|}
\hline \multicolumn{3}{|c|}{ Intermediate Cognitive Demand Level } & \multicolumn{3}{|c|}{ Ending Cognitive Demand Level } \\
\hline Variable & $N$ & $\%$ & Variable & $N$ & $\%$ \\
\hline 1-Memorization Tasks & 0 & 0 & 1-Memorization Tasks & 0 & 0 \\
\hline 2-Procedures without & & & 2-Procedures without & & \\
\hline Connections Tasks & 8 & 33 & Connections Tasks & 12 & 50 \\
\hline $\begin{array}{l}\text { 3-Procedures with } \\
\text { Connections Tasks }\end{array}$ & 15 & 63 & $\begin{array}{l}\text { 3-Procedures with } \\
\text { Connections Tasks }\end{array}$ & 5 & 21 \\
\hline $\begin{array}{l}\text { 4-Doing Mathematics } \\
\text { Tasks }\end{array}$ & 1 & 4 & $\begin{array}{l}\text { 4-Doing Mathematics } \\
\text { Tasks }\end{array}$ & 7 & 29 \\
\hline
\end{tabular}


Table 12

Shifts in Teachers' Intermediate and Ending Cognitive Demand Levels

Cognitive Demand

Level

Intermediate

Ending Cognitive

$\Delta$ Cognitive Cognitive Demand

Demand Level (\%)

Demand $(\%)$ Level $(\%)$

1- Memorization 0

0

0

Tasks

2- Procedures without

$33 \%(n=8)$

$50 \%(n=12)$

$+17 \%(n=+4)$

Connections Tasks

3- Procedures with Connections Tasks

$63 \%(n=15)$

$21 \%(n=5)$

$-42 \%(n=-10)$

4-Doing Mathematics

Tasks

$4 \%(n=1) \quad 29 \%(n=7) \quad+25 \%(n=+6)$

Chi Square $\left(\chi^{2}\right)$ Test. The intermediate and ending cognitive demand variables

in Table 11 were further analyzed by a chi square test. The results showed $\chi^{2}$ (obtained) $=$ 10.3 and the $\chi^{2}$ (critical) $=7.815$ at the Alpha .05 level with a $\mathrm{d} f=3$. According to the results, $\chi^{2}$ was significant, thus the null hypothesis was rejected which meant there was a relationship between the variables Intermediate Cognitive Demand Level and Ending Cognitive Demand Level.

Cramer's $\boldsymbol{V}$. To test the strength of the relationship between Intermediate Cognitive Demand Level and Ending Cognitive Demand Level, Cramer's $V$ was calculated. The results showed a moderate relationship between the variables $(V=.655)$.

\section{Characteristics of Ending Cognitive Demand Level 4 Participants. A closer}

examination was conducted of the data surrounding the seven participants who were at a cognitive demand level 4. The results of these characteristics are shown in the Table 13 below. Two similarities were clear: the majority $(86 \%, n=6)$ had a high level of 
participation in the professional development ( $75 \%$ or greater), and the majority $(86 \%, n$ =6) were in the K-3 Cohort. Interestingly, the teachers represented all levels of MKT, from terciles $1-3$, and not all of the teachers shifted MKT tercile levels. Four of the seven $(57 \%)$ teachers increased one tercile level of mathematical knowledge, though their ending tercile levels were anywhere from tercile 1 to tercile 3 . Since four teachers were beginning at the first tercile, it is likely that these teachers grew in their mathematical knowledge for teaching, even though they did not move into the next tercile. Though it appeared that participation and grade level seemed to be the most prevalent characteristics of teachers with an ending cognitive demand level 4 , careful consideration of these teachers' MKT tercile levels further characterized them as teachers "in motion"those teachers who were in the midst of their own learning and cognitive growth.

Table 13

Characteristics of Participants With an Ending Cognitive Demand Level 4

\begin{tabular}{lccccccc} 
Teacher & $\begin{array}{l}\text { Intermediate } \\
\text { Noticing } \\
\text { Level }\end{array}$ & $\begin{array}{l}\text { Ending } \\
\text { Noticing } \\
\text { Level }\end{array}$ & $\begin{array}{l}\text { Beginning } \\
\text { MKT } \\
\text { Tercile } \\
\text { Level }\end{array}$ & $\begin{array}{l}\text { Ending } \\
\text { MKT } \\
\text { Tercile } \\
\text { Level }\end{array}$ & $\begin{array}{l}\text { Grade } \\
\text { Level } \\
\text { Cohort }\end{array}$ & $\begin{array}{l}\text { Participation } \\
\text { Level }\end{array}$ & School \\
\hline A & 3 & 3 & 2 & 3 & K-3 & Moderate & Willow \\
B & 1 & 2 & 1 & 1 & K-3 & High & Zinnia \\
C & 3 & 4 & 1 & 2 & K-3 & High & Zinnia \\
D & 2 & 3 & 1 & 2 & K-3 & High & Zinnia \\
E & 3 & 3 & 3 & 3 & K-3 & High & Willow \\
F & 4 & 2 & 1 & 1 & K-3 & High & Willow \\
G & 1 & 1 & 2 & 3 & $4-6$ & High & Willow
\end{tabular}

Paired samples $t$-test. A paired-samples $t$-test was conducted on the whole group data to examine the differences between the means of the variables Intermediate Cognitive Demand Level and Ending Cognitive Demand Level. The $t$-test indicated no significant difference in the means between the two variables. 
The data was grouped by the K-3 and 4-6 Cohorts and another paired samples $t$ test was conducted to see if there was a difference in the means for the intermediate and ending cognitive demand levels. There was no significant mean difference found in the K-3 Cohort's variables Intermediate Cognitive Demand Level or Ending Cognitive Demand Level. Nor was there any significant mean difference found in the 4-6 Cohort's Intermediate Cognitive Demand Level $(M=2.50, S E=.289)$ or Ending Cognitive Demand Level $(M=2.75, S E=.479), t(3)=-.397, p>.05, r=.58$. Even though these results indicated no significant difference in the means of the intermediate and ending cognitive demand variables by cohort, there was a medium effect size noted in the 4-6 cohort results.

Bivariate correlation. Pearson's correlations were conducted to analyze the relationship between the variables, Intermediate Cognitive Demand and Ending Cognitive Demand for the whole group and also for the K-3 and 4-6 Cohorts. There was no significant relationship found between the two variables for the whole group, nor for either cohort.

Additional Pearson's correlations were conducted on the whole group data to further investigate the relationships between participation and other cognitive demand variables. Pearson's correlations were conducted between the variable Participation Level, and Intermediate Cognitive Demand Level; Participation Level and Ending Cognitive Demand Level; and Participation and Cohort Grade Level. The results are shown in Table 14 below. The findings indicated a moderately positive relationship between Participation Level and Intermediate Cognitive Demand Level, $r=.60, p<.01$, 
$r^{2}=.36$. As interpreted by the statistic $r^{2}$, participation level explained $36 \%$ of the variance of the teachers' intermediate cognitive demand level.

Table 14

Whole Group Correlations - Cognitive Demand, Participation, and Cohort Level

\begin{tabular}{|c|c|c|c|c|c|}
\hline Variable & & $\begin{array}{l}\text { Participation } \\
\text { Level }\end{array}$ & $\begin{array}{l}\text { Intermediate } \\
\text { Cognitive } \\
\text { Demand Level }\end{array}$ & $\begin{array}{l}\text { Ending } \\
\text { Cognitive } \\
\text { Demand } \\
\text { Level }\end{array}$ & $\begin{array}{l}\text { Cohort } \\
\text { Grade } \\
\text { Level }\end{array}$ \\
\hline \multirow{3}{*}{ Participation Level } & Pearson Correlation & 1 & $.602^{* *}$ & .307 & .231 \\
\hline & Sig. (2-tailed) & & .002 & .145 & .157 \\
\hline & $\mathrm{N}$ & 39 & 24 & 24 & 39 \\
\hline \multirow{3}{*}{$\begin{array}{l}\text { Intermediate } \\
\text { Cognitive Demand } \\
\text { Level }\end{array}$} & Pearson Correlation & $.602^{* *}$ & 1 & .317 & -.173 \\
\hline & Sig. (2-tailed) & .002 & & .131 & .419 \\
\hline & $\mathrm{N}$ & 24 & 24 & 24 & 24 \\
\hline \multirow{3}{*}{$\begin{array}{l}\text { Ending Cognitive } \\
\text { Demand Level }\end{array}$} & Pearson Correlation & .307 & .317 & 1 & -.022 \\
\hline & Sig. (2-tailed) & .145 & .131 & & .920 \\
\hline & $\mathrm{N}$ & 24 & 24 & 24 & 24 \\
\hline \multirow{3}{*}{$\begin{array}{l}\text { Cohort Grade } \\
\text { Level }\end{array}$} & Pearson Correlation & .231 & -.173 & -.022 & 1 \\
\hline & Sig. (2-tailed) & .157 & .419 & .920 & \\
\hline & $\mathrm{N}$ & 39 & 24 & 24 & 39 \\
\hline
\end{tabular}

Note. ${ }^{* *}$ Correlation is significant at the 0.01 level (2-tailed).

To examine whether the correlation between intermediate cognitive demand and participation varied by cohort, the data was grouped by the variable Cohort Grade Level and another Pearson's correlation was conducted between Intermediate Cognitive Demand Level, Ending Cognitive Demand Level, and Participation Level. A moderately positive relationship was found in the K-3 Cohort between Intermediate Cognitive Demand Level and Participation Level, $r=.63, p<.01, r^{2}=.39$ (see Table 15 below); however, there were no other significant relationships found between these variables and the 4-6 Cohort. These results indicated that $39 \%$ of the variance in the K-3 Cohort's 
intermediate cognitive demand was explained by their level of participation in the MAAP professional development.

Table 15

K-3 Cohort Correlations - Cognitive Demand Level and Participation

\begin{tabular}{llrrr} 
& & $\begin{array}{c}\text { Intermediate } \\
\text { Cognitive } \\
\text { Demand Level }\end{array}$ & $\begin{array}{c}\text { Ending } \\
\text { Cognitive } \\
\text { Demand Level }\end{array}$ & $\begin{array}{c}\text { Participation } \\
\text { Level }\end{array}$ \\
\hline Intermediate Cognitive & Pearson Correlation & 1 & .428 & $.626^{* *}$ \\
Demand Level & Sig. (2-tailed) & 20 & .060 & .003 \\
& $\mathrm{~N}$ & & 20 & 20 \\
Ending Cognitive Demand & Pearson Correlation & .428 & 1 & .256 \\
Level & Sig. (2-tailed) & .060 & 20 & .275 \\
& $\mathrm{~N}$ & 20 & & 20 \\
Participation Level & Pearson Correlation & $.626^{* *}$ & .256 & 1 \\
& Sig. (2-tailed) & .003 & .275 & \\
& $\mathrm{~N}$ & 20 & 20 & 29 \\
\hline
\end{tabular}

Note. ${ }^{* *}$ Correlation is significant at the 0.01 level (2-tailed).

\section{Research Question 3}

How do teachers' levels of mathematical knowledge for teaching relate to teachers' levels of noticing and levels of cognitive demand in enacted tasks during the second year of mathematics professional development focused on developing teachers' mathematical knowledge for teaching?

Bivariate correlation. A Pearson's correlation analysis was conducted using the whole group data to explore the relationships between the main ending variables Ending MKT Tercile Level, Ending Noticing Level, Ending Cognitive Demand Level, Cohort Level, Participation Level, and School. The findings are shown in Table 16 below. A significant moderately positive correlation was found between the variables Ending $M K T$ Tercile Level and Participation Level, $r=.43, p<.01, r^{2}=.19$. It can be interpreted that $19 \%$ of the variance of teachers' ending mathematical knowledge for teaching was 
explained by the level of participation in MAAP. The relationship between the variables Cohort Grade Level and Ending MKT Tercile Level was not significant; however, it may have been significant had the sample been larger. A Type II error may have occurred due to the small sample size. Overall, the findings showed increased professional development participation was related to increased teacher knowledge.

Table 16

Whole Group Correlations - Ending Cognitive Demand Level Variables With Cohort Grade Level, Participation Level, and School

\begin{tabular}{|c|c|c|c|c|c|c|c|}
\hline & & $\begin{array}{c}\text { Ending } \\
\text { Cognitive } \\
\text { Demand } \\
\text { Level }\end{array}$ & $\begin{array}{c}\text { Ending } \\
\text { Noticing } \\
\text { Level }\end{array}$ & $\begin{array}{l}\text { Ending } \\
\text { MKT } \\
\text { Tercile } \\
\text { Level }\end{array}$ & $\begin{array}{l}\text { Cohort } \\
\text { Grade } \\
\text { Level }\end{array}$ & $\begin{array}{l}\text { Participa- } \\
\text { tion Level }\end{array}$ & School \\
\hline \multirow{4}{*}{$\begin{array}{l}\text { Ending Cognitive } \\
\text { Demand Level }\end{array}$} & Pearson & & & & & & \\
\hline & Correlation & 1 & .246 & .008 & -.022 & .307 & -.125 \\
\hline & Sig. (2-tailed) & & .247 & .971 & .920 & .145 & .561 \\
\hline & $\mathrm{N}$ & 24 & 24 & 22 & 24 & 24 & 24 \\
\hline \multirow{3}{*}{$\begin{array}{l}\text { Ending Noticing } \\
\text { Level }\end{array}$} & $\begin{array}{l}\text { Pearson } \\
\text { Correlation }\end{array}$ & .246 & 1 & .132 & -.219 & .188 & .041 \\
\hline & Sig. (2-tailed) & .247 & & .496 & .236 & .310 & .828 \\
\hline & $\mathrm{N}$ & 24 & 31 & 29 & 31 & 31 & 31 \\
\hline \multirow{3}{*}{$\begin{array}{l}\text { Ending MKT } \\
\text { Tercile Level }\end{array}$} & $\begin{array}{l}\text { Pearson } \\
\text { Correlation }\end{array}$ & .008 & .132 & 1 & .300 & $.434^{* *}$ & .090 \\
\hline & Sig. (2-tailed) & .971 & .496 & & .072 & .007 & .595 \\
\hline & $\mathrm{N}$ & 22 & 29 & 37 & 37 & 37 & 37 \\
\hline \multirow{4}{*}{ Cohort Grade Level } & Pearson & & & & & & \\
\hline & Correlation & -.022 & -.219 & .300 & 1 & .231 & -.072 \\
\hline & Sig. (2-tailed) & .920 & .236 & .072 & & .157 & .661 \\
\hline & $\mathrm{N}$ & 24 & 31 & 37 & 39 & 39 & 39 \\
\hline \multirow{4}{*}{ Participation Level } & Pearson & & & & & & \\
\hline & Correlation & .307 & .188 & $.434^{* *}$ & .231 & 1 & -.141 \\
\hline & Sig. (2-tailed) & .145 & .310 & .007 & .157 & & .391 \\
\hline & $\mathrm{N}$ & 24 & 31 & 37 & 39 & 39 & 39 \\
\hline \multirow{4}{*}{ School } & Pearson & & & & & & \\
\hline & Correlation & -.125 & .041 & .090 & -.072 & -.141 & 1 \\
\hline & Sig. (2-tailed) & .561 & .828 & .595 & .661 & .391 & \\
\hline & $\mathrm{N}$ & 24 & 31 & 37 & 39 & 39 & 39 \\
\hline
\end{tabular}

Note. ${ }^{* *}$ Correlation is significant at the 0.01 level (2-tailed). 
Table 17

K-3 Cohort Correlations - Ending Cognitive Demand level Variables With Cohort Grade Level, Participation Level, and School

\begin{tabular}{|c|c|c|c|c|c|c|}
\hline & & $\begin{array}{l}\text { Ending } \\
\text { Cognitive } \\
\text { Demand } \\
\text { Level }\end{array}$ & $\begin{array}{l}\text { Ending } \\
\text { Noticing } \\
\text { Level }\end{array}$ & $\begin{array}{l}\text { Ending } \\
\text { MKT } \\
\text { Tercile } \\
\text { Level } \\
\end{array}$ & $\begin{array}{l}\text { Participation } \\
\text { Level }\end{array}$ & School \\
\hline $\begin{array}{l}\text { Ending Cognitive } \\
\text { Demand Level }\end{array}$ & $\begin{array}{l}\text { Pearson } \\
\text { Correlation } \\
\text { Sig. (2-tailed) } \\
\text { N }\end{array}$ & $\begin{array}{c}1 \\
20\end{array}$ & $\begin{array}{r}.311 \\
.182 \\
20\end{array}$ & $\begin{array}{r}. .022 \\
.928 \\
19\end{array}$ & $\begin{array}{r}.256 \\
.275 \\
20\end{array}$ & $\begin{array}{r}-.208 \\
.380 \\
20\end{array}$ \\
\hline $\begin{array}{l}\text { Ending Noticing } \\
\text { Level }\end{array}$ & $\begin{array}{l}\text { Pearson } \\
\text { Correlation } \\
\text { Sig. (2-tailed) } \\
\text { N }\end{array}$ & $\begin{array}{r}.311 \\
.182 \\
20\end{array}$ & $\begin{array}{r}1 \\
25\end{array}$ & $\begin{array}{r}.200 \\
.350 \\
24\end{array}$ & $\begin{array}{r}.202 \\
.332 \\
25\end{array}$ & $\begin{array}{r}.296 \\
.151 \\
25\end{array}$ \\
\hline $\begin{array}{l}\text { Ending MKT } \\
\text { Tercile Level }\end{array}$ & $\begin{array}{l}\text { Pearson } \\
\text { Correlation } \\
\text { Sig. (2-tailed) } \\
\text { N }\end{array}$ & $\begin{array}{r}-.022 \\
.928 \\
19\end{array}$ & $\begin{array}{r}.200 \\
.350 \\
24\end{array}$ & 28 & $\begin{array}{r}.401^{*} \\
.034 \\
28\end{array}$ & $\begin{array}{r}.073 \\
.713 \\
28\end{array}$ \\
\hline Participation Level & $\begin{array}{l}\text { Pearson } \\
\text { Correlation } \\
\text { Sig. (2-tailed) } \\
\text { N }\end{array}$ & $\begin{array}{r}.256 \\
.275 \\
20\end{array}$ & $\begin{array}{r}.202 \\
.332 \\
25\end{array}$ & $\begin{array}{r}.401^{*} \\
.034 \\
28\end{array}$ & $\begin{array}{c}1 \\
29\end{array}$ & $\begin{array}{r}-.087 \\
.654 \\
29\end{array}$ \\
\hline School & $\begin{array}{l}\text { Pearson } \\
\text { Correlation } \\
\text { Sig. (2-tailed) } \\
\text { N }\end{array}$ & $\begin{array}{r}-.208 \\
.380 \\
20\end{array}$ & $\begin{array}{r}.296 \\
.151 \\
25\end{array}$ & $\begin{array}{r}.073 \\
.713 \\
28\end{array}$ & $\begin{array}{r}-.087 \\
.654 \\
29\end{array}$ & 29 \\
\hline
\end{tabular}

Note. *Correlation is significant at the 0.05 level (2-tailed). 
Table 18

4-6 Cohort Correlations - Ending Cognitive Demand Level Variables With Cohort Grade Level, Participation Level, and School

\begin{tabular}{|c|c|c|c|c|c|c|}
\hline & & $\begin{array}{l}\text { Ending } \\
\text { Cognitive } \\
\text { Demand } \\
\text { Level }\end{array}$ & $\begin{array}{c}\text { Ending } \\
\text { Noticing } \\
\text { Level }\end{array}$ & $\begin{array}{l}\text { Ending } \\
\text { MKT } \\
\text { Tercile } \\
\text { Level }\end{array}$ & $\begin{array}{l}\text { Participation } \\
\text { Level }\end{array}$ & School \\
\hline $\begin{array}{l}\text { Ending Cognitive } \\
\text { Demand Level }\end{array}$ & $\begin{array}{l}\text { Pearson } \\
\text { Correlation } \\
\text { Sig. (2-tailed) } \\
\text { N }\end{array}$ & 1 & $\begin{array}{r}.000 \\
1.000 \\
4\end{array}$ & $\begin{array}{r}. \mathrm{b} \\
.000 \\
3\end{array}$ & $\begin{array}{r}.522 \\
.478 \\
4\end{array}$ & $\begin{array}{r}.302 \\
.698 \\
4\end{array}$ \\
\hline Ending Noticing Level & $\begin{array}{l}\text { Pearson } \\
\text { Correlation } \\
\text { Sig. (2-tailed) } \\
\text { N }\end{array}$ & $\begin{array}{r}.000 \\
1.000 \\
4\end{array}$ & 6 & $\begin{array}{r}.456 \\
.440 \\
5\end{array}$ & $\begin{array}{r}.349 \\
.497 \\
6\end{array}$ & $\begin{array}{r}-.773 \\
.071 \\
6\end{array}$ \\
\hline $\begin{array}{l}\text { Ending MKT Tercile } \\
\text { Level }\end{array}$ & $\begin{array}{l}\text { Pearson } \\
\text { Correlation } \\
\text { Sig. (2-tailed) } \\
\text { N }\end{array}$ & $\begin{array}{r}. \dot{b} \\
.000 \\
3\end{array}$ & $\begin{array}{r}.456 \\
.440 \\
5\end{array}$ & 1 & $\begin{array}{r}.177 \\
.649 \\
9\end{array}$ & $\begin{array}{r}.354 \\
.351 \\
9\end{array}$ \\
\hline Participation Level & $\begin{array}{l}\text { Pearson } \\
\text { Correlation } \\
\text { Sig. (2-tailed) } \\
\text { N }\end{array}$ & $\begin{array}{r}.522 \\
.478 \\
4\end{array}$ & $\begin{array}{r}.349 \\
.497 \\
6\end{array}$ & $\begin{array}{r}.177 \\
.649 \\
9\end{array}$ & $\begin{array}{c}1 \\
10\end{array}$ & $\begin{array}{r}-.255 \\
.477 \\
10\end{array}$ \\
\hline School & $\begin{array}{l}\text { Pearson } \\
\text { Correlation } \\
\text { Sig. (2-tailed) } \\
\text { N }\end{array}$ & $\begin{array}{r}.302 \\
.698 \\
4\end{array}$ & $\begin{array}{r}-.773 \\
.071 \\
6\end{array}$ & $\begin{array}{r}.354 \\
.351 \\
9\end{array}$ & $\begin{array}{r}-.255 \\
.477 \\
10\end{array}$ & 10 \\
\hline
\end{tabular}

Note. b. Cannot be computed because at least one of the variables is constant.

The size of the 4-6 Cohort was below optimal levels $(n<10)$ and should be interpreted with caution.

Another Pearson's correlation of the variables, Ending MKT Tercile Level, Ending

Noticing Level, Ending Cognitive Demand Level, Participation Level, and School, was

conducted with the data grouped by cohort. The results are shown in Table 17 and 18

above. No significant relationships were found in the 4-6 Cohort, though this could be due

to the small sample size. A Type II error may have occurred affecting the relationship

between School and Ending Noticing Level $(p>.05)$. A positively moderate significant 
correlation was evident however in the K-3 Cohort between the variables Participation Level and Ending MKT Tercile Level, $\mathrm{r}=.40, p<.05, r^{2}=.16$. This meant that $16 \%$ of $\mathrm{K}-3$ teachers' mathematical knowledge for teaching was explained by their participation in the MAAP professional development. These results indicated that increased participation level in the professional development was related to the increased K-3 teachers' mathematical knowledge development for the K-3 Cohort as well as the whole group (see Table 19). Table 19 Summary of Ending MKT Tercile Level Variables Correlated and Participation

\begin{tabular}{llccrr}
\multicolumn{1}{c}{ Grouping } & Variable & $r$ & $\begin{array}{c}\text { Sig. } \\
(2 \text {-tailed })\end{array}$ & $N$ & $r^{2}$ \\
\hline Whole Group & Ending MKT Tercile Level & .43 & .007 & 37 & .18 \\
K-3 & Ending MKT Tercile Level & .40 & .034 & 28 & .16 \\
\hline
\end{tabular}

To analyze any other potential relationships between cognitive demand, noticing, and MKT for the whole group, a correlation was conducted to examine relationships between the variables Intermediate Noticing Level, Intermediate Cognitive Demand Level, Beginning MKT Tercile Level, Ending Noticing level, Ending Cognitive Demand Level, Ending MKT Tercile Level, Participation Level, and Cohort Grade Level. The results are shown in Table 20 below.

The findings in Table 20 showed several significant relationships. Those not already reported earlier in this chapter included: Intermediate Noticing Level and Intermediate Cognitive Demand Level, $r=.50, p<.05, r^{2}=.25 ;$ Beginning MKT Tercile Level and Cohort Grade Level, $r=.44, p<.01, r^{2}=.19 ;$ Beginning MKT Level and Participation Level, $r=.37, p<.05, r^{2}=.14$; and Beginning MKT Tercile Level and 
Ending MKT Tercile Level, $r=.70, p<.01, r^{2}=.49$. Interestingly, this analysis showed that the level of intermediate noticing accounted for $25 \%$ of the variance of the beginning cognitive demand level. In addition, there were many correlations found in association with the Beginning MKT Tercile Level variable.

Table 20

Whole Group Correlations - Intermediate and Ending Noticing, Intermediate and Ending Cognitive Demand, Beginning and Ending MKT Tercile Level, Participation Level, and Cohort Grade Level

\begin{tabular}{|c|c|c|c|c|c|c|c|}
\hline & & $\begin{array}{l}\text { Intermediate } \\
\text { Noticing } \\
\text { Level }\end{array}$ & $\begin{array}{l}\text { Intermediate } \\
\text { Cognitive } \\
\text { Demand } \\
\text { Level }\end{array}$ & $\begin{array}{l}\text { Beginning } \\
\text { MKT } \\
\text { Tercile } \\
\text { Level }\end{array}$ & $\begin{array}{l}\text { Ending } \\
\text { MKT } \\
\text { Tercile } \\
\text { Level }\end{array}$ & $\begin{array}{l}\text { Cohort } \\
\text { Grade } \\
\text { Level }\end{array}$ & $\begin{array}{l}\text { Particip- } \\
\text { ation } \\
\text { Level }\end{array}$ \\
\hline $\begin{array}{l}\text { Intermediate } \\
\text { Noticing Level }\end{array}$ & $\begin{array}{l}\text { Pearson } \\
\text { Correlation } \\
\text { Sig. (2-tailed) } \\
\text { N }\end{array}$ & 31 & $\begin{array}{r}.497^{*} \\
.013 \\
24\end{array}$ & $\begin{array}{r}.248 \\
.195 \\
29\end{array}$ & $\begin{array}{r}.097 \\
.616 \\
29\end{array}$ & $\begin{array}{r}-.277 \\
.131 \\
31\end{array}$ & $\begin{array}{r}.122 \\
.515 \\
31\end{array}$ \\
\hline $\begin{array}{l}\text { Intermediate } \\
\text { Cognitive } \\
\text { Demand Level }\end{array}$ & $\begin{array}{l}\text { Pearson } \\
\text { Correlation } \\
\text { Sig. (2-tailed) } \\
\text { N }\end{array}$ & $\begin{array}{r}.497^{*} \\
.013 \\
24\end{array}$ & 24 & $\begin{array}{r}.051 \\
.820 \\
22\end{array}$ & $\begin{array}{r}.023 \\
.920 \\
22\end{array}$ & $\begin{array}{r}-.173 \\
.419 \\
24\end{array}$ & $\begin{array}{r}.602^{* *} \\
.002 \\
24\end{array}$ \\
\hline $\begin{array}{l}\text { Beginning } \\
\text { MKT Tercile } \\
\text { Level }\end{array}$ & $\begin{array}{l}\text { Pearson } \\
\text { Correlation } \\
\text { Sig. (2-tailed) } \\
\text { N }\end{array}$ & $\begin{array}{r}.248 \\
.195 \\
29\end{array}$ & $\begin{array}{r}.051 \\
.820 \\
22\end{array}$ & 37 & $\begin{array}{r}.703^{* *} \\
.000 \\
37\end{array}$ & $\begin{array}{r}.440^{* *} \\
.006 \\
37\end{array}$ & $\begin{array}{r}.372^{*} \\
.023 \\
37\end{array}$ \\
\hline $\begin{array}{l}\text { Ending MKT } \\
\text { Tercile Level }\end{array}$ & $\begin{array}{l}\text { Pearson } \\
\text { Correlation } \\
\text { Sig. (2-tailed) } \\
\text { N }\end{array}$ & $\begin{array}{r}.097 \\
.616 \\
29\end{array}$ & $\begin{array}{r}.023 \\
.920 \\
22\end{array}$ & $\begin{array}{r}.703^{* *} \\
.000 \\
37\end{array}$ & 37 & $\begin{array}{r}.300 \\
.072 \\
37\end{array}$ & $\begin{array}{r}.434^{* *} \\
.007 \\
37\end{array}$ \\
\hline $\begin{array}{l}\text { Cohort Grade } \\
\text { Level }\end{array}$ & $\begin{array}{l}\text { Pearson } \\
\text { Correlation } \\
\text { Sig. (2-tailed) } \\
\text { N }\end{array}$ & $\begin{array}{r}-.277 \\
.131 \\
31\end{array}$ & $\begin{array}{r}-.173 \\
.419 \\
24\end{array}$ & $\begin{array}{r}.440^{* *} \\
.006 \\
37\end{array}$ & $\begin{array}{r}.300 \\
.072 \\
37\end{array}$ & $\begin{array}{r}1 \\
39\end{array}$ & $\begin{array}{r}.231 \\
.157 \\
39\end{array}$ \\
\hline $\begin{array}{l}\text { Participation } \\
\text { Level }\end{array}$ & $\begin{array}{l}\text { Pearson } \\
\text { Correlation } \\
\text { Sig. (2-tailed) }\end{array}$ & $\begin{array}{r}.122 \\
.515 \\
31\end{array}$ & $\begin{array}{r}.602^{* *} \\
.002 \\
24\end{array}$ & $\begin{array}{r}.372^{*} \\
.023 \\
37\end{array}$ & $\begin{array}{r}.434^{* *} \\
.007 \\
37\end{array}$ & $\begin{array}{r}.231 \\
.157 \\
39\end{array}$ & 39 \\
\hline
\end{tabular}

Note. *Correlation is significant at the 0.05 level (2-tailed). **Correlation is significant at the 0.01 level (2-tailed). 
For the analysis shown in Table 20 above, it was apparent that the variable Beginning MKT Tercile Level was significantly correlated with several other variables. As indicated by the results, the shared variance between the whole group Beginning MKT Tercile Level and Cohort Grade Level variables was 19\%. The shared variance between the whole group's Beginning MKT Tercile Level and Participation Level variance was 14\%. The shared variance between the whole group Ending MKT Tercile Level and Beginning MKT Level variables was $49 \%$.

Additional Pearson's correlations were conducted to determine if grouping by cohort had any impact on the relationship between the intermediate cognitive demand and intermediate noticing variables. A summary of these results is shown in Table 21 below. When grouped by cohort, the results indicated a significant positively moderate correlation for the K-3 Cohort, $r=.46, p<.05, r^{2}=.21$ between intermediate cognitive demand and intermediate noticing. There was, however, no significance found for the 4-6 Cohort between intermediate cognitive demand and intermediate noticing. These findings indicated that for the K-3 Cohort, the intermediate cognitive demand and the intermediate noticing had a shared variance of $21 \%$. It seemed that the teachers' ability to notice student thinking increased with the level of cognitive demand in their lessons. 
Table 21

Summary of Intermediate Cognitive Demand and Intermediate Noticing Correlations Results

\begin{tabular}{clcccc} 
Grouping & \multicolumn{1}{c}{ Variable 1 } & Variable 2 & $r$ & $\begin{array}{c}\text { Sig. } \\
(2 \text {-tailed })\end{array}$ & $r^{2}$ \\
\hline Whole Group & $\begin{array}{l}\text { Intermediate } \\
\text { Noticing Level }\end{array}$ & $\begin{array}{c}\text { Intermediate } \\
\text { Cognitive Demand } \\
\text { Level }\end{array}$ & .50 & $.013^{*}$ & .25 \\
K-3 Cohort & Intermediate & $\begin{array}{c}\text { Intermediate } \\
\text { Noticing Level }\end{array}$ & .46 & $.042^{*}$ & .21 \\
4-6 Cohort & Intermediate & $\begin{array}{c}\text { Level } \\
\text { Intermediate } \\
\text { Noticing Level }\end{array}$ & $\begin{array}{c}\text { Cognitive Demand } \\
\text { Level }\end{array}$ & & .58 \\
\hline
\end{tabular}

Note. *Correlation is significant at the 0.05 level (2-tailed).

The size of the 4-6 Cohort was below optimal levels $(n<10)$ and should be interpreted with caution.

A Pearson's correlation was conducted with the data grouped by cohort to analyze the relationship between the variables Beginning MKT Tercile Level and Ending MKT Tercile Level and Intermediate Noticing Level and Ending Noticing Level. The results are shown in Tables 22 and 23 below. No significance was found in the K-3 Cohort; however, a significant relationship was found in the 4-6 Cohort between Beginning MKT Tercile Level and Intermediate Noticing Level and Ending MKT Tercile Level and Ending Noticing Level. It is important to note that although the analysis was conducted, the sample size for the 4-6 Cohort dropped below optimal levels $(n<10)$. Due to the sample size, these correlation results should be interpreted with caution. The results showed a significant strong positive relationship between Beginning MKT Tercile Level and Intermediate Noticing Level, $r=.94, p<.05, r^{2}=.88$. The results also indicated a significant strong positive relationship between Beginning MKT Tercile Level and Ending Noticing Level, $r$ $=.91, p<.05, r^{2}=.83$. From this analysis, it can be interpreted that the 4-6 Cohort's 
beginning MKT level explained $88 \%$ of the variance of their intermediate noticing level, and that the 4-6 Cohort's beginning MKT level explained $83 \%$ of the variance of their ending noticing level.

Table 22

K-3 Correlations - Beginning and Ending MKT Tercile Level and Intermediate and Ending Noticing Level

\begin{tabular}{|c|c|c|c|c|c|}
\hline & & $\begin{array}{l}\text { Intermediate } \\
\text { Noticing } \\
\text { Level }\end{array}$ & $\begin{array}{l}\text { Ending } \\
\text { Noticing } \\
\text { Level }\end{array}$ & $\begin{array}{c}\text { Beginning } \\
\text { MKT } \\
\text { Tercile } \\
\text { Level }\end{array}$ & $\begin{array}{l}\text { Ending } \\
\text { MKT } \\
\text { Tercile } \\
\text { Level }\end{array}$ \\
\hline \multirow{4}{*}{$\begin{array}{l}\text { Intermediate Noticing } \\
\text { Level }\end{array}$} & Pearson & 1 & .235 & .279 & .220 \\
\hline & Correlation & & & & \\
\hline & Sig. (2-tailed) & & .259 & .187 & .301 \\
\hline & $\mathrm{N}$ & 25 & 25 & 24 & 24 \\
\hline \multirow{4}{*}{ Ending Noticing Level } & Pearson & .235 & 1 & -.057 & .200 \\
\hline & Correlation & & & & \\
\hline & Sig. (2-tailed) & .259 & & .791 & .350 \\
\hline & $\mathrm{N}$ & 25 & 25 & 24 & 24 \\
\hline \multirow{4}{*}{$\begin{array}{l}\text { Beginning MKT } \\
\text { Tercile Level }\end{array}$} & Pearson & 279 & -.057 & 1 & $.723^{* *}$ \\
\hline & Correlation & & & & \\
\hline & Sig. (2-tailed) & 187 & .791 & & .000 \\
\hline & $\mathrm{N}$ & 24 & 24 & 28 & 28 \\
\hline \multirow{3}{*}{$\begin{array}{l}\text { Ending MKT Tercile } \\
\text { Level }\end{array}$} & $\begin{array}{l}\text { Pearson } \\
\text { Correlation }\end{array}$ & .220 & .200 & $.723^{* *}$ & 1 \\
\hline & Sig. (2-tailed) & .301 & .350 & .000 & \\
\hline & $\mathrm{N}$ & 24 & 24 & 28 & 28 \\
\hline
\end{tabular}

Note. ${ }^{* *}$ Correlation is significant at the 0.01 level (2-tailed). 
Table 23

4-6 Correlations - Beginning and Ending MKT Tercile Level and Intermediate and Ending Noticing

\begin{tabular}{|c|c|c|c|c|c|}
\hline & & $\begin{array}{c}\text { Intermediate } \\
\text { Noticing } \\
\text { Level }\end{array}$ & $\begin{array}{l}\text { Ending } \\
\text { Noticing } \\
\text { Level }\end{array}$ & $\begin{array}{c}\text { Beginning } \\
\text { MKT } \\
\text { Tercile } \\
\text { Level }\end{array}$ & $\begin{array}{l}\text { Ending } \\
\text { MKT } \\
\text { Tercile } \\
\text { Level }\end{array}$ \\
\hline \multirow{3}{*}{$\begin{array}{l}\text { Intermediate } \\
\text { Noticing Level }\end{array}$} & Pearson Correlation & 1 & $.942^{* *}$ & $.943^{*}$ & .343 \\
\hline & Sig. (2-tailed) & & .005 & .016 & .572 \\
\hline & $\mathrm{N}$ & 6 & 6 & 5 & 5 \\
\hline \multirow{3}{*}{$\begin{array}{l}\text { Ending Noticing } \\
\text { Level }\end{array}$} & Pearson Correlation & $.942^{* *}$ & 1 & $.913^{*}$ & .456 \\
\hline & Sig. (2-tailed) & .005 & & .030 & .440 \\
\hline & $\mathrm{N}$ & 6 & 6 & 5 & 5 \\
\hline \multirow{3}{*}{$\begin{array}{l}\text { Beginning MKT } \\
\text { Tercile Level }\end{array}$} & Pearson Correlation & $.943^{*}$ & $.913^{*}$ & 1 & .354 \\
\hline & Sig. (2-tailed) & .016 & .030 & & .351 \\
\hline & $\mathrm{N}$ & 5 & 5 & 9 & 9 \\
\hline Ending MKT & Pearson Correlation & .343 & .456 & .354 & 1 \\
\hline \multirow[t]{2}{*}{ Tercile Level } & Sig. (2-tailed) & .572 & .440 & .351 & \\
\hline & $\mathrm{N}$ & 5 & 5 & 9 & 9 \\
\hline
\end{tabular}

Note. ${ }^{* *}$ Correlation is significant at the 0.01 level (2-tailed).

*Correlation is significant at the 0.05 level (2-tailed).

The size of the 4-6 Cohort was below optimal levels $(n<10)$ and should be interpreted with caution.

The intermediate cognitive demand and intermediate noticing variables were grouped by participation level and a Pearson's correlation was conducted to examine the relationship. For the low participation level there was no analysis that SPSS could generate due to missing data. The moderate level participation results were non-significant as were the high level participation results. These findings indicated that there was no relationship between intermediate cognitive demand and intermediate noticing variables when grouped by participation level.

A Pearson's correlation was conducted between Beginning MKT Tercile Level, Ending MKT Tercile Level, and Participation Level with the data grouped by cohort to examine any possible relationships. Tables 24 and 25 show these results below. The results 
indicated no significance for the 4-6 Cohort; however for the K-3 Cohort, a positive strong correlation was found between the beginning and ending MKT level, $r=.72, p<.01, r^{2}$

$=.52$, and a moderately positive correlation was found between the ending MKT level and participation level, $r=.40, p<.05, r^{2}=.16$.

Table 24

K-3 Cohort Correlations - Beginning and Ending MKT Tercile Level and Participation

\begin{tabular}{llrrr} 
& & $\begin{array}{c}\text { Beginning MKT } \\
\text { Tercile Level }\end{array}$ & $\begin{array}{c}\text { Ending MKT } \\
\text { Tercile Level }\end{array}$ & $\begin{array}{c}\text { Participation } \\
\text { Level }\end{array}$ \\
\hline Beginning MKT Tercile & Pearson Correlation & 1 & .723 & .267 \\
Level & Sig. (2-tailed) & & .000 & .169 \\
& $\mathrm{~N}$ & 28 & 28 & 28 \\
Ending MKT Tercile & Pearson Correlation & $.723^{* *}$ & & $.401^{*}$ \\
Level & Sig. (2-tailed) & .000 & 1 & .034 \\
& $\mathrm{~N}$ & 28 & 28 & 28 \\
& & & & \\
Participation Level & Pearson Correlation & .267 & $.401^{*}$ & 1 \\
& Sig. (2-tailed) & .169 & .034 & 29 \\
& $\mathrm{~N}$ & 28 & 28 & 29 \\
\hline
\end{tabular}

Note. ${ }^{* *}$ Correlation is significant at the 0.01 level (2-tailed).

*Correlation is significant at the 0.05 level (2-tailed).

Table 25

4-6 Cohort Correlations - Beginning and Ending MKT Tercile Level and Participation

\begin{tabular}{llrrr} 
& & $\begin{array}{c}\text { Beginning MKT } \\
\text { Tercile Level }\end{array}$ & $\begin{array}{c}\text { Ending MKT } \\
\text { Tercile Level }\end{array}$ & $\begin{array}{c}\text { Participation } \\
\text { Level }\end{array}$ \\
\hline $\begin{array}{l}\text { Beginning MKT Tercile } \\
\text { Level }\end{array}$ & $\begin{array}{l}\text { Pearson Correlation } \\
\text { Sig. (2-tailed) }\end{array}$ & 1 & .354 & .125 \\
& $\mathrm{~N}$ & 9 & .351 & .749 \\
Ending MKT Tercile & Pearson Correlation & .354 & 9 & 9 \\
Level & Sig. (2-tailed) & .351 & 1 & .177 \\
& $\mathrm{~N}$ & 9 & 9 & .649 \\
& & & & 9 \\
Participation Level & Pearson Correlation & .125 & .177 & 1 \\
& Sig. (2-tailed) & .749 & .649 & \\
& $\mathrm{~N}$ & 9 & 9 & 10 \\
\hline
\end{tabular}

Note. The size of the 4-6 cohort was below optimal levels $(n<10)$ and should be interpreted with caution. 
Similarly, a Pearson's correlation was conducted between Beginning MKT Tercile Level, Ending MKT Tercile Level, and Cohort Grade Level, with the data grouped by participation level. These results are shown in Tables 26 and 27 below. There was only one significant relationship found in these results; when grouped by Participation Level, a strong positive relationship was identified between the variables Beginning MKT Tercile Level and Ending MKT Tercile Level, $r=.70, p<.01, r^{2}=.49$. According to SPSS, the low level participant correlation could not be computed since there was a large amount of missing data. Therefore, the tables represent only the moderate and high participation level results.

Table 26

Moderate Level Participation Correlations - MKT Tercile Levels and Cohort Grade Level

\begin{tabular}{llrrr} 
& & $\begin{array}{c}\text { Beginning MKT } \\
\text { Tercile Level }\end{array}$ & $\begin{array}{c}\text { Ending MKT } \\
\text { Tercile Level }\end{array}$ & $\begin{array}{c}\text { Cohort Grade } \\
\text { Level }\end{array}$ \\
\hline Beginning MKT & Pearson Correlation & 1 & .507 & .320 \\
Tercile Level & Sig. (2-tailed) & & .064 & .264 \\
& $\mathrm{~N}$ & 14 & 14 & 14 \\
Ending MKT Tercile & Pearson Correlation & .507 & & .162 \\
Level & Sig. (2-tailed) & .064 & & .579 \\
& $\mathrm{~N}$ & 14 & 14 & 14 \\
& & & & \\
Cohort Grade Level & Pearson Correlation & .320 & .162 & 1 \\
& Sig. (2-tailed) & .264 & .579 & 14 \\
& $\mathrm{~N}$ & 14 & 14 & \\
\hline
\end{tabular}


Table 27

High Level Participation Correlation - MKT Tercile Levels and Cohort Grade Level

\begin{tabular}{llrrr} 
& & $\begin{array}{c}\text { Beginning } \\
\text { MKT Tercile } \\
\text { Level }\end{array}$ & $\begin{array}{c}\text { Ending MKT } \\
\text { Tercile Level }\end{array}$ & $\begin{array}{c}\text { Cohort Grade } \\
\text { Level }\end{array}$ \\
\hline $\begin{array}{l}\text { Beginning MKT Tercile } \\
\text { Level }\end{array}$ & Pearson Correlation & 1 & $.702^{* *}$ & .373 \\
& Sig. (2-tailed) & & .000 & .096 \\
& $\mathrm{~N}$ & 21 & 21 & 21 \\
Ending MKT Tercile Level & Pearson Correlation & $.702^{* *}$ & & .182 \\
& Sig. (2-tailed) & .000 & & .429 \\
& $\mathrm{~N}$ & 21 & 21 & 21 \\
Cohort Grade Level & Pearson Correlation & .373 & .182 & 1 \\
& Sig. (2-tailed) & .096 & .429 & 21 \\
\hline
\end{tabular}

**. Correlation is significant at the 0.01 level (2-tailed).

Since many variables were significantly correlated with Beginning MKT Tercile

Level, a summary table is presented in Table 28 below.

Table 28

Summary of Variables Correlated With Beginning MKT Tercile Level

\begin{tabular}{llccc} 
Grouping & Correlated Variable & $r$ & $r^{2}$ & $\begin{array}{c}\text { Sig. } \\
\text { (2-tailed) }\end{array}$ \\
\hline Whole Group & Ending MKT Tercile Level & .70 & .49 & $<.001$ \\
Whole Group & Cohort Grade Level & .44 & .19 & .006 \\
Whole Group & Participation Level & .37 & .14 & .023 \\
K-3 Cohort & Ending MKT Tercile Level & .72 & .52 & $<.001$ \\
High Participation & Ending MKT Tercile Level & .70 & .49 & $<.001$ \\
Level & Intermediate Noticing Level & .94 & .88 & .016 \\
*4-6 Cohort & Ending Noticing Level & .91 & .83 & .030 \\
\hline
\end{tabular}

Note: *The size of the 4-6 Cohort was below optimal levels $(n<10)$ and should be interpreted with caution. 
Linear regression. A regression was conducted to analyze the change in Ending MKT Tercile Level by predicting its ending level. The variables used in the regression were Participation Level and Beginning MKT Tercile Level since they were found the most often in correlation with other variables and research has shown that long-term participation in PD can increase MKT (Bell et al., 2010; Yoon et al., 2007). A forced entry method was used and missing data were treated with mean substitution. The regression results are presented in Table 29 below.

The regression results showed that $R^{2}$ was .52 indicating that the independent variables, Beginning MKT Tercile Level and Participation Level, predicted 52\% of the change in the Ending MKT Tercile Level; this was a strong prediction. Only the teachers' beginning MKT was a significant strong predictor of the change in teachers' ending MKT level.

Table 29

Regression Results Predicting Ending MKT Tercile Level

\begin{tabular}{lccc}
\multicolumn{1}{c}{ Variable } & Beta & $t$ & sig $t$ \\
\hline 1. Beginning MKT & .649 & 5.321 & $<.001$ \\
Tercile Level & & & \\
Participation Level & .167 & 1.372 & .179 \\
$N=39$ & & & \\
$R=.721$ & & & \\
$R^{2}=.520$ & & & \\
$F=19.481$ & & & \\
$\operatorname{Sig} F=<.001$ & & &
\end{tabular}

A second regression was conducted to predict the Ending Noticing Level with the independent variables Participation Level and Intermediate Noticing Level. A forced entry method was used and missing data were treated with mean substitution. The results are 
shown in Table 30 below. These results indicated that Intermediate Noticing Level and Participation Level predicted 22\% $\left(R^{2}=.22\right)$ of the dependent variable, Ending Noticing Level; this was a moderate prediction. Intermediate noticing was found to be a significant predictor of ending noticing $(p<.01)$.

Table 30

Regression Results Predicting Ending Noticing Level

\begin{tabular}{lccc}
\multicolumn{1}{c}{ Variable } & Beta & $t$ & sig $t$ \\
\hline 1. Intermediate & .435 & 2.933 & .006 \\
Noticing Level & & & \\
Participation Level & .127 & .858 & .396 \\
$\mathrm{~N}=39$ & & & \\
$\mathrm{R}=.467$ & & & \\
$\mathrm{R}^{2}=.218$ & & & \\
$\mathrm{~F}=5.024$ & & & \\
Sig F $=.012$ & & &
\end{tabular}

A third regression was conducted to analyze whether the dependent variable, Ending Cognitive Demand Level, could be predicted by the independent variables, Intermediate Cognitive Demand Level and Participation Level. A forced entry method was used in this regression and missing data were treated with mean substitution. The regression results are presented in Table 31 below.

The results of the regression showed that neither independent variable, Intermediate Cognitive Level nor Participation Level, was able to significantly predict the level of cognitive demand. 
Table 31

Regression Results Predicting Ending Cognitive Demand Level

\begin{tabular}{lccc}
\multicolumn{1}{c}{ Variable } & Beta & $t$ & sig $t$ \\
\hline $\begin{array}{l}\text { 1. Intermediate } \\
\text { Cognitive Level }\end{array}$ & .407 & 1.402 & .170 \\
Participation Level & & & \\
& .128 & .702 & .487 \\
$\mathrm{~N}=39$ & & & \\
$\mathrm{R}=.335$ & & & \\
$\mathrm{R}^{2}=.113$ & & & \\
$\mathrm{~F}=2.283$ & & & \\
Sig F $=.117$ & &
\end{tabular}




\section{Chapter Five: Background, Discussion, Recommendations, and Conclusion Background}

The teaching and learning context is highly complex, and researchers have tried for years to uncover and study the variables associated with the process, particularly in mathematics. Variables such as mathematical knowledge for teaching, teacher noticing, and cognitive demand were known constructs found to mediate the classroom context (Hill et al., 2004; Stein et al., 2009; Sherin et al., 2011). Research has shown that teachers' mathematical knowledge for teaching was a key construct that had an effect on student achievement (Hill et al., 2004) and also influenced instruction (Hill et al., 2008; Charalambous, 2010). Researchers were able to measure MKT though little is currently known about its impact on teachers' ability to interpret student thinking or implement instruction.

Teacher noticing in mathematics was a recently identified construct researched by Sherin and colleagues through video clubs (Sherin \& Han, 2004; van Es \& Sherin, 2002). Sherin and colleagues found that when teachers viewed videotapes of classroom lessons they attended to different aspects of teaching, including pedagogy and student learning. Over time, the teachers' lens shifted and became more focused on student thinking and the mathematics in lessons, rather than on pedagogy. The video discussions also became richer in discourse related to student thinking that caused teachers to be challenged and shift their opinions and practice (Sherin \& Han, 2004; van Es \& Sherin, 2002; van Es \& Sherin 2006). Stein and her colleagues $(1998 ; 2009)$ developed and researched the construct of cognitive demand by examining characteristics of mathematics instruction and the rigor of tasks given to middle school students. They created professional development to assist 
teachers in recognizing cognitive demand in curriculum and to enact cognitively demanding tasks in teachers' own classrooms at the middle school level. Research on cognitive demand showed that teachers' knowledge of cognitive demand made a difference to the rigor of their mathematics lessons. With sustained professional development, the teachers in these studies grew in their ability to plan and select cognitively demanding tasks; however, the researchers noted that teachers had difficulty sustaining the cognitive demand to the end of the lesson (Stein et al., 1998).

In this dissertation, I examined all three of these constructs, mathematical knowledge for teaching, teacher noticing, and the cognitive demand in enacted tasks, in the context of one professional development aimed at elementary teachers teaching in two high-need low-performing schools. The purpose of the study was to investigate teachers' levels of noticing, the levels of cognitive demand in enacted tasks, and the relationship between these two constructs and teachers' level of mathematical knowledge for teaching. One-third of the data was coded with other members of the MAAP research team. We analyzed quantitative data from the MAAP professional development that occurred during 2008-2011 that included teachers' written reflections, 5-minute self-selected video segments from mathematics lessons, and mathematical knowledge for teaching tercile levels. These data were drawn from the second year of the MAAP professional development project.

The results of this study will be of interest to the field of education for several reasons. To begin, there is a limited understanding in the field of how teacher noticing, cognitive demand of enacted tasks, and teachers' mathematical knowledge influence 
teaching and learning. Only a few studies have shown the relationship between teachers' mathematical knowledge for teaching and level of instruction (Charalambous, 2010; Hill et al., 2008). Moreover, there is limited research on teachers' noticing of their own mathematics lessons during professional development (Sherin \& Han, 2004; Sherin \& van Es , 2005; Sherin \& van Es, 2009), and no research that analyzes teachers' mathematical knowledge for teaching in relationship to both teacher noticing and cognitive demand. Therefore, this study fills a gap in the literature and will provide the field with valuable data about the relationships between mathematical knowledge for teaching, teacher noticing, cognitive demand in enacted tasks within professional development.

The three main research questions guiding this study were:

1) How do teachers' written reflections and observations of their mathematics lessons explain teachers' levels of noticing in the second year of mathematics professional development focused on developing teachers' mathematical knowledge for teaching?

2) How do teachers' self-selected video segments of mathematics lessons explain the level of cognitive demand of the teachers' enacted tasks during the second year of mathematics professional development focused on developing teachers' mathematical knowledge for teaching?

3) How do teachers' levels of mathematical knowledge for teaching relate to teachers' levels of noticing and levels of cognitive demand in enacted tasks during the second year of mathematics professional development focused on developing teachers' mathematical knowledge for teaching? 


\section{Methodology}

All the participants in the MAAP professional development were included in the sample for this study, though only data from 40 of the 54 teachers were analyzed. Some data was missing due to attrition, and in some cases it could not be located. Regardless of how much was available, the data was analyzed and coded by teacher. The second year data included teachers' written reflections, 5-minute segments from videos, and teachers' mathematical knowledge for teaching tercile levels. In total, there were 132 videos and 113 reflections coded in the process of analyzing these results.

Several frameworks were used as instruments to code the teachers' written reflections for noticing levels and the 5-minute video segments selected by teachers for cognitive demand levels. These frameworks included the Task Analysis Guide (Stein et al., 2009) and the Framework for Learning to Notice Student Mathematical Thinking (van Es, 2011). One third of the coding was completed by the research team of both the written reflections and the video 5-minute segments for the second year data. I coded the rest of the data independently. Once the data was derived from the codes, I entered it into SPSS along with the MKT tercile, participation, school, and cohort level data provided by the MAAP professional development.

\section{Statistical Analyses}

In the statistical analyses, I employed descriptive statistics, correlation, paired samples $t$-tests, and linear regression. Initially, I evaluated all the variables for descriptive statistics. Then I conducted Pearson's correlations and paired samples $t$-tests to analyze the differences in the means of the initial and ending data for the MKT tercile levels, cognitive 
demand levels, and teacher noticing levels. Additional variables included in the correlations analyses were the variables, Participation Level, Cohort Grade Level, and School. These analyses indicated whether there were significant or non-significant differences in the means of initial and ending variables and also their effect sizes. I conducted Pearson's correlation to analyze relationships between variables. The data were analyzed both as a whole group and by either cohort or participation level. The last analyses I conducted were linear regressions to predict ending MKT levels, ending noticing levels, and ending cognitive demand levels.

\section{Major Findings}

1. There were notable shifts in the frequencies of teachers' noticing from the beginning to the end of the second year.

2. There were significant increases in the whole group and 4-6 Cohort's noticing levels from the beginning to the ending of the second year.

3. There were significant shifts in the levels of the teachers' cognitive demand in their lessons from the beginning to the ending of the second year.

4. The 4-6 Cohort had a significant relationship between the intermediate noticing level and the beginning and ending MKT tercile level.

5. The teachers' beginning mathematical knowledge for teaching level was significantly related to their ending MKT tercile level, participation level, and cohort.

6. The teachers' intermediate noticing level was significantly related to the intermediate level of cognitive demand in enacted tasks, in both the whole group 
and the K-3 Cohort.

7. The K-3 Cohort had significant correlations between mathematical knowledge for teaching, the cognitive demand of tasks, teacher noticing, and participation.

\section{Discussion}

There were many prominent findings and relationships as a result of the analyses in this study. These findings will be discussed in more detail by research question.

\section{Research Question 1}

Shifts in noticing. There were notable findings and interesting shifts in the frequencies over the course of the second year of data and between intermediate and ending noticing level. Upon close examination of the frequencies of the whole group noticing levels, I found shifts that occurred from the beginning to the end of the second year of professional development. By the end of the second year, there was a $9 \%$ increase of teachers in the top two levels of noticing (Focused and Extended). This meant that more teachers moved from making general comments about student learning and thinking to comments that highlighted specific events by honing in on specific students' thinking, and providing interpretations of students' actions with evidence. This seemed reasonable considering the professional development was focused on mathematics content for teaching and student thinking. Regularly, teachers came together in the professional development to discuss student work artifacts, selected video, and to discuss mathematical problems. Many of the problems that were brought to the foreground in seminars anticipated students' misconceptions and prompted teachers to dig deeply into the students' conceptual understandings. 
The shifts in noticing levels suggested that, during the second year of mathematics professional development, teachers applied their knowledge and made changes in their practice. This was consistent with the research on teacher change in professional development. For example, Jacobs et al. (2010) found that teachers' noticing levels increased after two years of professional development. Carpenter et al. (1999), Campbell \& Robles (1997), and Fennema et al. (1996) also reported changes in their participant teachers' instruction after several years of long-term professional development focused on students' thinking. Findings on change in practice often have relied on teacher self-report and were not considered reliable (Hill, 2010); however, the shifts noted in this study's findings were drawn from teachers' written reflections over the course of a year of professional development and for this reason are much more reliable.

In addition to the shift in frequencies, I found a significant relationship in the 4-6 Cohort between the intermediate and ending noticing levels $(p<.01)$ with an effect size growth of $89 \%$. Perhaps the staggered model and the intensive summer institutes made a difference between the two cohorts. The professional development started the first year with the K-3 Cohort and then added the 4-6 Cohort at the start of the second summer. Therefore, the first summer institute was held at the start of the 4-6 Cohort, whereas the K3 Cohort had their first summer institute at the end of their first year. Frontloading the professional development with a summer institute focused on student thinking and mathematical content for instruction may have increased the teachers' noticing in the second cohort. Conceivably, the fourth through sixth grade teachers had a heightened awareness of student thinking starting their first year of the program. As well, they most 
likely had stronger levels of mathematical knowledge for teaching (Hill, 2010) that guided their noticing. Although the 4-6 Cohort as a whole was more opinionated about the professional development, the 4-6 grade teachers did agree, according to MAAP anecdotal data, that listening to students was important and that they had provided more opportunities for students to share their thinking with others. As found during MAAP, when students were provided more opportunities to share their thinking, more opportunities were created for teachers to reflect on that thinking.

\section{Research Question 2}

Shifts in cognitive demand. The results indicated significant shifts in the cognitive demand of lessons. At the end of the second year, there was a $25 \%$ increase in the amount of lessons that reached a level 4 -Doing Mathematics Tasks. Conversely, there was a 17\% decrease of teachers in level 3 - Procedures with Connections Tasks who had dropped their lessons' cognitive demand from a level 3 to a level 2 -Procedures without Connections Tasks. This shift could be evidence of a type of settling effect at the end of the second year of professional development. It was possible that teachers made decisions by the end of their participation in the second year to adopt or not adopt the ideas and beliefs of the new practice. In the results of this study, more teachers moved to a higher level of cognitive demand than a lower cognitive demand level that showed more teachers chose to extend their students' reasoning and mathematical thinking.

Another possible reason for the negative shift in level could be inherent in teachers' attitudes and actions in preparation for spring testing. At the beginning of the year, teachers were more likely to focus on enhancing their instruction. As they moved toward 
periods of standardized testing, perhaps they resorted to more independent work that was more skill-based rather than conceptual and problem oriented, or perhaps they limited instruction to basic types of review materials. Regardless, more teachers moved to higher levels of cognitive demand over the course of the professional development than when they first began.

\section{Research Question 3}

There were many noteworthy relationships found between the main variables, MKT, cognitive demand, and noticing in this study. The significant relationships identified in the analyses will be further discussed by themes derived from the data.

Participation. In many of the significant findings, the variable Participation Level was a common link. A summary from the correlation results is shown in Table 32 below. Participation level refers to the degree to which teachers participated in the professional development during the two years. Participation level was found to have a significant positive relationship with both mathematical knowledge for teaching and cognitive demand variables when tested by whole group and when grouped by the K-3 Cohort ( $p$ $<.05)$. It appeared that the level of seminar and summer institute participation contributed to the level of mathematics learning that occurred in the MAAP classrooms. It is reasonable to conjecture from these findings that those teachers who participated at higher levels reaped numerous benefits from the professional development when it came to their own mathematical knowledge for teaching and designing tasks of richer cognitive demand for students. 
Table 32

Summary of Variables Correlated With Participation Level

\begin{tabular}{llccc} 
Grouping & Variable & $r$ & $\begin{array}{c}\text { Significance } \\
\text { (2-tailed) }\end{array}$ & $R^{2}$ \\
\hline Whole Group & $\begin{array}{l}\text { Intermediate Cognitive } \\
\text { Demand Level }\end{array}$ & .60 & .002 & .36 \\
Whole Group & Ending MKT Tercile Level & .43 & .007 & .19 \\
K-3 Cohort & $\begin{array}{l}\text { Intermediate Cognitive } \\
\text { Demand Level }\end{array}$ & .63 & .003 & .39 \\
K-3 Cohort & Ending MKT Tercile Level & .40 & .034 & .16 \\
\hline
\end{tabular}

Cognitive demand was correlated with the teachers' level of participation in the MAAP professional development. For example, a significant relationship was identified between participation and the whole group intermediate cognitive demand level. This indicated that high-level participants had higher cognitive demand than lower-level participants at the beginning of the second year of the program. Conversely, low-level participants had a lower cognitive demand level. Ultimately, this meant that those who participated to a greater degree showed higher levels of cognitive demand in their lessons. Also, participation level explained $36 \%$ of the variance in the intermediate cognitive demand. This meant that almost one third of the cognitive demand level could be explained by the amount of the teachers' participation in the beginning of the second year of the MAAP professional development. Clearly, this showed that the teachers benefited from their participation in the MAAP professional development and that it supported greater rigor and cognitive demand in their lessons.

Intermediate cognitive demand was also found to correlate with participation level for the K-3 Cohort. At this point in the professional development, teachers had experienced 
at least one year of seminars and at least one summer institute. If they had high levels of participation, the cognitive demand in their lessons also increased significantly $(p<.01)$. One might ask from these results, what transpired during MAAP seminars and summer institutes that could have led high-level participant teachers to strengthen their mathematical knowledge for teaching and the cognitive demand levels in lessons? Perhaps the answer to this question lies within the structure of the participation of the MAAP professional development and also its emphasis on both children's mathematical thinking and mathematical content.

Structure of MAAP's participation. It is difficult to require teachers to commit to high levels of attendance and participation in professional development over a long period of time. The MAAP professional development, however, was required to maintain $80 \%$ whole school participation over the life of the grant to maintain its funding status. The teachers knew when they agreed to participate that the funding was dependent on their commitment to participate. The majority of teachers complied with the participation requirements, especially when they began to value their learning during MAAP sessions.

Children's mathematical thinking. The focus of each of the MAAP seminars and summer institutes was on children's thinking and mathematics. At the seminars, teachers were regularly engaged in solving challenging problems after which the teachers applied their learning to the concepts at their own grade level. Seminars always included modeling and practice of mathematical representation, the use of concrete methods, and communicating mathematical thinking. In many sessions, teachers' own lesson videos were shared to analyze and discuss student thinking. Student artifacts were also brought in 
regularly and teachers made sense out of the students' solutions and written explanations. In the summer institutes, California Standards Test release items were used to generate grade-level discussion regarding the type of thinking required by students and teachers were asked to examine the mathematical communication needs of English language learners. The seminars and summer institutes were rich opportunities for teachers to learn more about the ways children think about mathematics and provided examples of ways to deepen students' reasoning and understanding.

Other studies have found professional development focused on children's mathematical thinking to be effective in promoting student learning and improved instruction. The Cognitively Guided Instruction program demonstrated the value of focusing on students' thinking and its positive impact on student achievement (Carpenter et al., 1999). Likewise, Blanton and Kaput's (2005) professional development study also focused also on student thinking. The results of Blanton and Kaput's study found an increase in teachers' ability to recognize students' strategies. Though these programs had similarities to the MAAP professional development, the one way that they were different was MAAP's use of teachers' own classroom videos. Not only did some of the videos become shared learning opportunities for discussion about student thinking during seminars but they were also viewed and reflected on regularly by the individual teachers. Many teachers commented in their reflections on group and individual student discourse as they engaged in mathematics. It was unknown exactly how much this influenced teachers' overall cognitive demand, though it was one more way that teachers had access to their students' thinking in a slower reflective setting. 
Content-focused professional development. The MAAP seminars and summer institutes were always content-focused. During MAAP, teachers gained mathematical knowledge and this made a difference in the teachers' choice of student task and the degree of cognitive demand during instruction. Stein et al. (2009) also found that professional development focused on student thinking and the cognitive demand of tasks caused teachers to become more aware of the richness of mathematics in their tasks. Also, they were more adept at evaluating their curriculum and selecting cognitively demanding tasks. Perhaps the teachers in the MAAP professional development also began to think differently about the types of tasks they were using to engage students and felt more confident in their selection and implementation of tasks related to problem solving.

The tasks at higher levels of cognitive demand required students to make more connections between the mathematics and the underlying mathematical concepts. A distinct characteristic of the higher-level task on the Task Analysis Guide was to use manipulatives, representations, or symbols to help express meaning. Also, students were required to provide explanations of their thinking. These tasks also required students to exert cognitive effort rather than be led through a procedure-type process where the teacher modeled or deconstructed the problem for the students. To teach in this way, MAAP participant teachers had to abandon preconceived notions about students' abilities. Even though they may have believed students were capable of solving the problems without assistance, many teachers did feel their students, as English learners, needed the support of scaffolding through solution steps. By gaining higher levels of cognitive demand throughout the PD, high-level participant teachers must have understood through the 
MAAP seminars and summer institutes that their students were capable of solving problems independent of the teacher and that they needed to make deeper connections to the underlying concepts. Taking away these bigger ideas about tasks and student learning may have given the teachers a new sense of confidence in knowing how to teach students in ways that were more cognitively demanding.

Mathematical knowledge for teaching. A significant result in the linear regression showed that teachers' beginning MKT tercile level predicted $50 \%$ of teachers' ending MKT tercile level. This strong prediction demonstrated the power of teachers' need for mathematical content and their capacity for growth. MAAP was focused on growing teachers' mathematical content and gave teachers' regular opportunities to wrestle with and dig into concepts and ideas that challenged their own held knowledge. It appeared that challenging teachers' mathematical knowledge for teaching along with a heightened ability to listen to student thinking made a difference.

According to the beginning MAAP mathematical knowledge for teaching tercile levels, there was a broad range of teacher knowledge represented in the K-6 group and there was a clear need for teachers to develop their mathematical knowledge for teaching. This was aligned with Hill's (2010) findings that teachers in schools of high poverty were more likely to have lower mathematical knowledge for teaching. MAAP teachers were in need of professional development focused on mathematical knowledge for teaching; thus, high levels of participation provided an opportunity to grow in mathematical content knowledge for teaching. Hill et al. (2005) also reported that teachers have the capacity to grow their mathematical knowledge for teaching when given the opportunity through 
professional development focused on content and student thinking. The findings of this study supported Hill's findings and also triangulated with the data on mathematical knowledge for teaching growth found in the MAAP final report (Brown, 2012). This report showed that the MAAP teachers' mathematical knowledge for teaching grew significantly over one $(p<.01)$ or two $(p<.001)$ years of involvement in the professional development. It can be surmised from the results of this study that increased levels of participation along with increased growth in mathematical knowledge provided the right foundation for teachers to become more knowledgeable and confident in their mathematics instruction.

Mathematical knowledge for teaching and 4-6 cohort noticing. The significant relationship between teachers' beginning MKT tercile levels and intermediate and ending 4-6 Cohort's noticing levels, though cautionary $(n<10)$, is an indicator of the likelihood of a relationship between these variables. In the case of the 4-6 Cohort, it is probable that these teachers had stronger levels of MKT (Hill, 2010) and were able to notice the mathematics in their students' thinking to a higher degree. As mentioned earlier, the summer institute also may have influenced teachers' ability to observe their students' thinking since the K-3 Cohort did not experience a summer institute until after their first year. As a result, the staggered model favored the 4-6 Cohort and may have jump-started their noticing. The finding of a relationship between MKT and noticing is an important finding even though cautionary, since this relationship has not been evident in prior research. Future research with a larger sample may help to provide reliable evidence to support this significance.

Mathematical knowledge for teaching, participation, and cohort. The results 
indicated that mathematical knowledge for teaching was related to both participation level and cohort. Teachers who had increased levels of participation also had increased levels of mathematical knowledge for teaching. Conversely, this meant lower level participants had lower mathematical knowledge for teaching levels. Since significant growth in mathematical knowledge for teaching was known to have occurred during the professional development, it is reasonable to infer that those who had high participation levels benefited from the ideas and content of the professional development and thus had increased levels of mathematical knowledge for teaching at the end of the professional development.

When grouped by cohort, the K-3 teachers showed a significant relationship between mathematical knowledge for teaching and level of participation. For this group, high levels of participation mattered. With higher levels of participation, they had increased levels of mathematical knowledge for teaching. As mentioned earlier, this correlated with Hill's (2010) findings on the mathematical knowledge for teaching levels of primary grade teachers and their general need for learning opportunities in mathematical content.

Cognitive demand and noticing. The correlation between cognitive demand and noticing indicated that cognitive demand explained $25 \%$ of the variance in teachers' noticing in the whole group and $21 \%$ of the variance in the K-3 Cohort's noticing (see Table 33 below). It seemed that teachers were able to identify the cognitive demand in the lessons they were observing, as well, they were likely seeing an increase in the cognitive demand in the lessons. Though it is unknown, it seems possible that the growth in teachers' mathematical knowledge for teaching levels could have impacted what teachers' were 
attending to when they listened to their lessons and student thinking. Perhaps this awareness, in conjunction with the professional development sessions focused on mathematical content, created a rich climate for teachers to become more aware of the cognitive demand in their own lessons. This would make sense for the group as a whole since this phenomenon was not seen just within the K-3 teachers' results but with the whole group data as well.

Table 33

Summary of Cognitive Demand and Noticing Correlations

\begin{tabular}{llllcr} 
Grouping & Variable 1 & Variable 2 & $r$ & $\begin{array}{c}\text { Sig. } \\
(2 \text {-tailed })\end{array}$ & $R^{2}$ \\
\hline Whole Group & $\begin{array}{l}\text { Intermediate Cognitive } \\
\text { Demand Level }\end{array}$ & $\begin{array}{l}\text { Intermediate Noticing } \\
\text { Level }\end{array}$ & .50 & .013 & .25 \\
K-3 Cohort & $\begin{array}{l}\text { Intermediate Cognitive } \\
\text { Demand Level }\end{array}$ & $\begin{array}{l}\text { Intermediate Noticing } \\
\text { Level }\end{array}$ & .46 & .042 & .21 \\
\hline
\end{tabular}

A model to explain this phenomenon is suggested in Figure 5 below. Mathematical knowledge for teaching prompted teachers' noticing of the cognitive demand in their lessons (or lack of cognitive demand). This, in turn, drew on teachers' developing mathematical knowledge for teaching. As this cycle continued, it required teachers to constantly dig more deeply into their knowledge, look for instances of the conceptual knowledge in their students' thinking, which then prompted the teachers to plan more rich cognitively demanding instruction, therefore putting into action what they learned about mathematics for teaching in the professional development. 
Figure 5

The MKT, Noticing, and Cognitive Demand Cycle

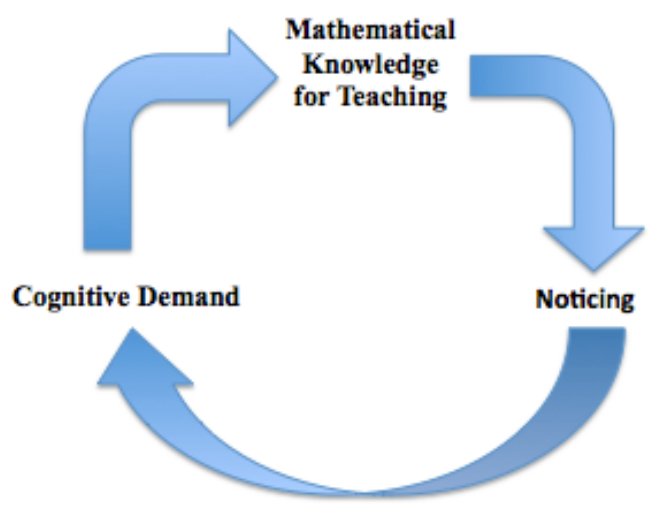

K-3 Cohort. According to the results, the K-3 Cohort had many significant correlations with the three variables: cognitive demand, mathematical knowledge for teaching, and noticing. The results also indicated that participation explained a moderate amount of the cognitive demand in lessons and their ending mathematical knowledge for teaching. Table 34 shows a summary of the significant findings below. These results pointed to the K-3 Cohort as a unique group, in comparison to the 4-6 Cohort. 
Table 34

Summary of K-3 Cohort Significant Correlations

\begin{tabular}{llllll}
\multicolumn{1}{c}{ Variable 1 } & \multicolumn{1}{c}{ Variable 2 } & $N$ & $r$ & $\begin{array}{c}\text { Sig. } \\
\text { (2-tailed) }\end{array}$ & $R^{2}$ \\
\hline Participation Level & $\begin{array}{l}\text { Intermediate } \\
\text { Cognitive Demand } \\
\text { Level }\end{array}$ & 20 & .63 & .003 & .39 \\
Participation Level & $\begin{array}{l}\text { Ending MKT } \\
\text { Tercile Level }\end{array}$ & 28 & .40 & .034 & .16 \\
$\begin{array}{l}\text { Beginning MKT } \\
\text { Tercile Level }\end{array}$ & $\begin{array}{l}\text { Ending MKT } \\
\text { Tercile Level }\end{array}$ & 28 & .72 & $<.001$ & .53 \\
$\begin{array}{l}\text { Intermediate Noticing } \\
\text { Level }\end{array}$ & $\begin{array}{l}\text { Intermediate } \\
\text { Cognitive Demand } \\
\text { Level }\end{array}$ & 20 & .46 & .042 & .21 \\
\hline
\end{tabular}

From Hill's (2010) national sample of mathematical knowledge for teaching levels and characteristics of elementary teachers, correlations showed that teachers in the primary grades often possessed lower levels of mathematical knowledge for teaching than their upper-grade counterparts. If these characteristics were applied to the K-3 Cohort in the current study, it is conceivable that MAAP's K-3 teachers had the most to gain from a professional development focused on mathematical knowledge for teaching. This can be seen in the results for the K-3 Cohort's correlation between beginning and ending mathematical knowledge for teaching $(p<.001)$. The teachers' beginning MKT tercile level explained $53 \%$ of the variance of their ending MKT tercile level. This strong variance indicated the importance of MAAP professional development for the K-3 teachers' development of mathematical knowledge for teaching.

There was also a positive significant relationship between the K-3 Cohort's noticing and cognitive demand levels; the teachers' intermediate noticing level explained 
$21 \%$ of their intermediate cognitive demand level $(p<.05)$. As mentioned earlier, intermediate refers to the start of the second year. At this point, the teachers had shown statistically significant growth in their mathematical knowledge for teaching, according to the MAAP final report (Brown, 2012). This growth likely enabled the teachers to notice mathematical content in the lessons they watched and upon which they reflected. Furthermore, the K-3 teachers were noticing at higher levels at the same time the levels of cognitive demand of their lessons increased. Since mathematical knowledge for teaching was known to have a positive impact on instructional quality (Hill et al., 2007), perhaps the K-3 Cohort's lessons became richer in cognitive demand and thus resulted in more mathematical learning complexity that the teachers unpacked and discussed in the written reflections.

A model to describe the relationships between the K-3 Cohort's mathematical knowledge for teaching, noticing, and participation was created to demonstrate the interactions between these variables (see Figure 6). It appeared that participation was a critical part of the K-3 teachers' experience in MAAP. Without their participation, much of the teachers' growth in the cognitive demand of their lessons would not have taken place, according to the variance described by the correlations. This growth is represented on the model by the arrows pointing up from participation level. Also, shifts were noticed in the teachers' noticing and in the cognitive demand of their lessons that meant the teachers had increased the cognitive difficulty and engagement in their lessons and were noticing more of their students' thinking. The increased mathematical engagement and increased noticing is noted on the inside of the model's triangle and is also represented by the arrows pointing 
up from participation. It is known that teachers' level of mathematical knowledge for teaching was increasing at the time that their cognitive demand and noticing were increasing. What is important to note about this model, is that it is particular to the K-3 teachers in MAAP. Also, this model takes place within a professional development that took place over the course of two years.

Figure 6

Model of K-3 Teachers in MKT-Focused Professional Development

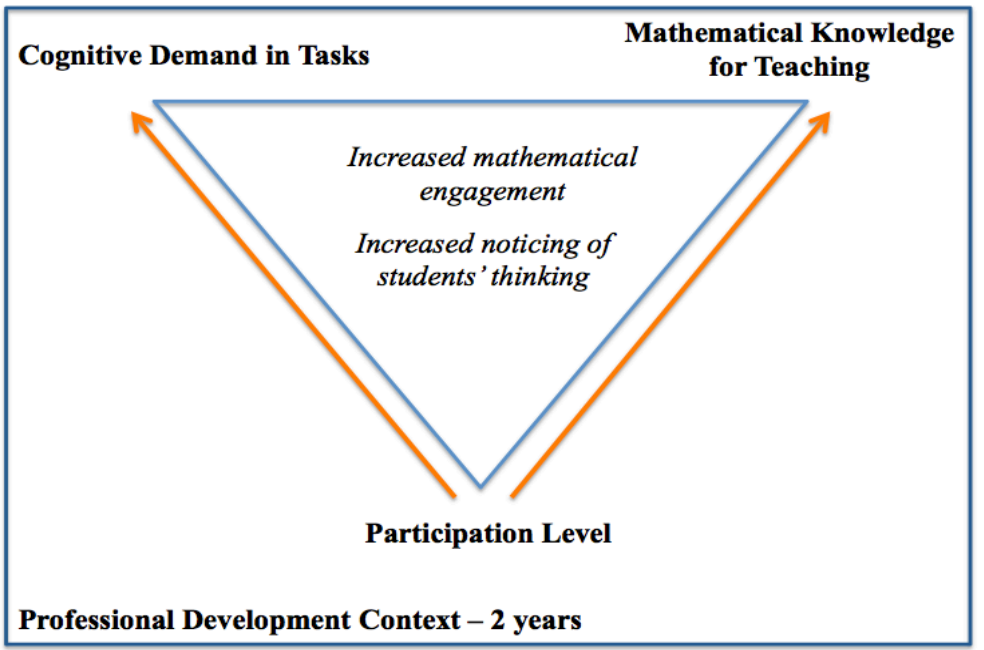

\section{Suggested Elementary Grade Task Analysis Guide}

Using the Tasks Analysis Guide (Stein \& Smith, 1998) to code the cognitive demand of teachers' video segments was extremely useful; however, at times it was evident that the guide was designed for middle school and not elementary classrooms. As the coding team recognized elements that seemed to be missing, the additions were noted. These recommended additions are shown below in Table 35 and represent some of the scenarios found repeatedly in the elementary classrooms during the coding of data in this study that were missing from the original Task Analysis Guide. 
Table 35

Suggested Additions - Elementary Classroom Task Analysis Guide

Task Level

Suggested Addition

Level 1 - Memorization Tasks

Level 2 - Procedures without

Connections Tasks

Level 3 - Procedures with Connections Tasks

Level 4 - Doing Mathematics Tasks
- $\quad$ No suggestions

- Reproduce class generated answers that include group or individual responses.

- Generate ideas and explanations that are unrelated to the underlying conceptual meaning.

- May have multiple pictures or manipulatives though students are not actively engaged in conceptual development.

- Build conceptual understanding either through whole class engagement or individually.

- Encourage students to produce and explain multiple possible solutions.

\section{Limitations}

There were many limitations associated with this study. First, the sample size was small. Since this study was part of a larger study, the population was limited to the two treatment schools. Second, not all the teachers participated equally in the project during the second year and this limited the number of videos and reflections that were completed. Teachers who had moderate to low participation were missing video and reflection data. Some teachers had video data, though they did not complete the reflection forms and this reduced the amount of valid data. In a few cases, the video data was missing. Third, the teacher participants were under a great deal of stress during the two years of the professional development due to the Program Improvement status of their schools and the 
economic climate of California; therefore, the teachers' responses may have been rushed and limited in depth and attention to detail. Finally, the majority of the statistical strength of this study was limited to correlation and thus cannot prove causality between variables.

\section{Recommendations}

1. The noticing results from this study support Darling-Hammond et al.'s (2009) conclusion that change in teacher practice occurs with on-going sustained professional development programs with at least 12 months of support; however, this study's findings also suggested that the second year of professional development is just as critical. Twelve months, as currently recommended in the research, may not be enough time to promote teacher change embedded in practice. The results from this study recommend to policy-makers and those overseeing grant requirements that at least 24 months of professional development be required to support teachers' growth in developing mathematical knowledge for teaching, noticing of student thinking, and increased cognitive demand of lessons.

2. Professional development focused on mathematical knowledge for teaching and student thinking is critical for all teachers to develop rigor in the cognitive demand of lessons and to develop mathematical knowledge for teaching. It is important for policy-makers, grant providers, and school districts to realize that greater professional development opportunities are needed at the elementary level that go beyond curriculum implementation. Most teachers do not receive long-term content-focused mathematics professional development; this is critical during a time of reform when we expect teachers to make significant changes in their 
instruction to improve student thinking and achievement.

3. It is rare for professional development studies to publish their participation rates in their program description; though, based on this study's findings it would seem prudent for future researchers to include participation data in published professional development descriptions. By doing this, the field can further understand how level of participation interacts among other key variables in professional development settings. Policy-makers and those providing grant funding should also take note that high participation was correlated with the highest degrees of MKT, cognitive demand, and noticing results. Grant recipients should be asked to comply with high, yet reasonable, levels of participation for maximum impact on results.

4. This study speaks to the need for teacher education programs to provide elementary teacher candidates with a stronger foundation in mathematical knowledge for teaching. It is the recommendation of this study to have a minimum of two mathematics classes at the pre-service level that directly relate to content for developing elementary pre-service teachers' mathematical knowledge for teaching. Not only will this build teachers' mathematical knowledge for teaching but it will also strengthen their confidence in math instruction.

5. Further research on the relationship between cognitive demand, noticing, and mathematical knowledge for teaching is warranted. More needs to be known about the influence of mathematical knowledge for teaching on instruction and the relationship between mathematical knowledge for teaching to what teachers notice 
when provided cognitively demanding lessons; or conversely, how cognitively demanding lessons promote noticing. Moreover, more should be known about what teachers can learn from viewing and reflecting on their own lessons and the impact of mathematical knowledge for teaching on this process, especially at the K-3 level. Future investigations may want to concentrate on such variables as collaboration, individual teacher characteristics, video use, and mathematical content. Particular attention should be given to how these potential variables might interact with participation, mathematical knowledge for teaching, and cognitive demand in tasks to better understand the dynamics between teaching and learning.

6. This study showed that K-3 teachers benefit particularly from professional development. Policy-makers and professional development providers who seek to impact instruction by targeting teachers' mathematical knowledge for teaching should be aware of the relationships between K-3 teachers and the variables found in this study. Continued investigation into the particular needs of K-3 teachers is warranted as well as the need to provide all elementary teachers with effective professional development to build capacity for mathematical knowledge for teaching.

7. Future research for evaluating enacted elementary mathematical tasks for cognitive demand using the suggested adaptations for the Task Analysis Guide is recommended. It would be beneficial to test the adapted guide to see if the additions assist in addressing the uniqueness of the elementary classroom. More studies that focus on analyzing the cognitive demand of elementary teachers' 
mathematics instruction are also needed.

\section{Conclusion}

In the conception of this study, it was my hypothesis that mathematical knowledge for teaching, teacher cognitive demand of tasks, and teacher noticing of student thinking would be related (see Figure 7 below). As the results indicated, mathematical knowledge for teaching was significantly correlated with level of participation, and cohort grade level. Likewise, significant relationships were found between cognitive demand level and noticing level for the whole group and the K-3 Cohort. Also discovered were significant correlations between teacher noticing and the cognitive demand of tasks; however, a direct correlation between MKT and cognitive demand of enacted tasks was not found. Additionally, a cautionary significant relationship was found between mathematical knowledge for teaching and teacher noticing. Of the three constructs, mathematical knowledge for teaching carried the most statistical power to predict and also to explain the variation in many of the correlations. Interestingly, participation level was a previously unknown variable that played an important role, as shown in the revised conceptual model (see Figure 8 below). 
Figure 7

Original Conceptual Model

Conceptual Model for Teacher Instructional Shifts in MPD

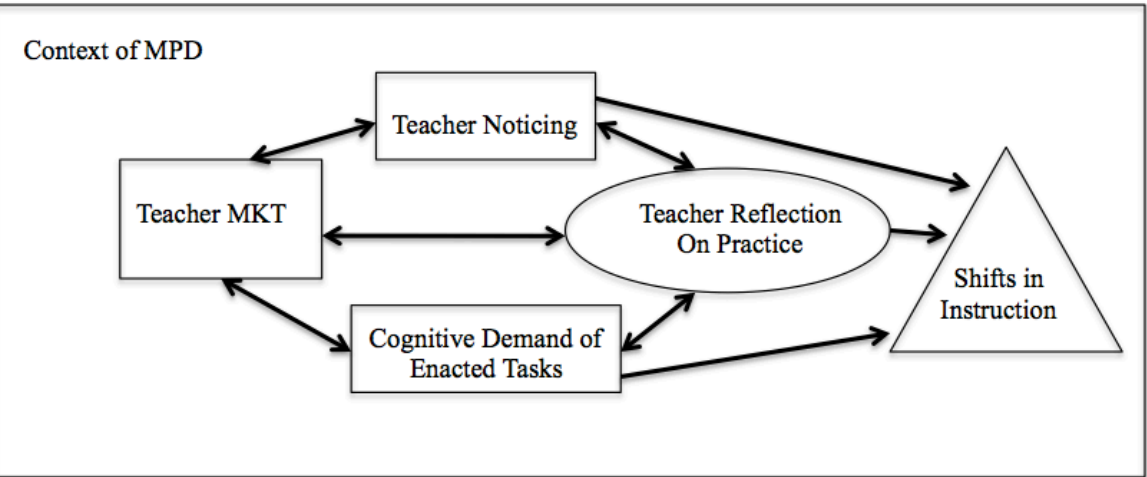

(Coddington, 2013)

Figure 8

Revised Conceptual Model

Revised Conceptual Model for Teacher Instructional Shifts in MPD

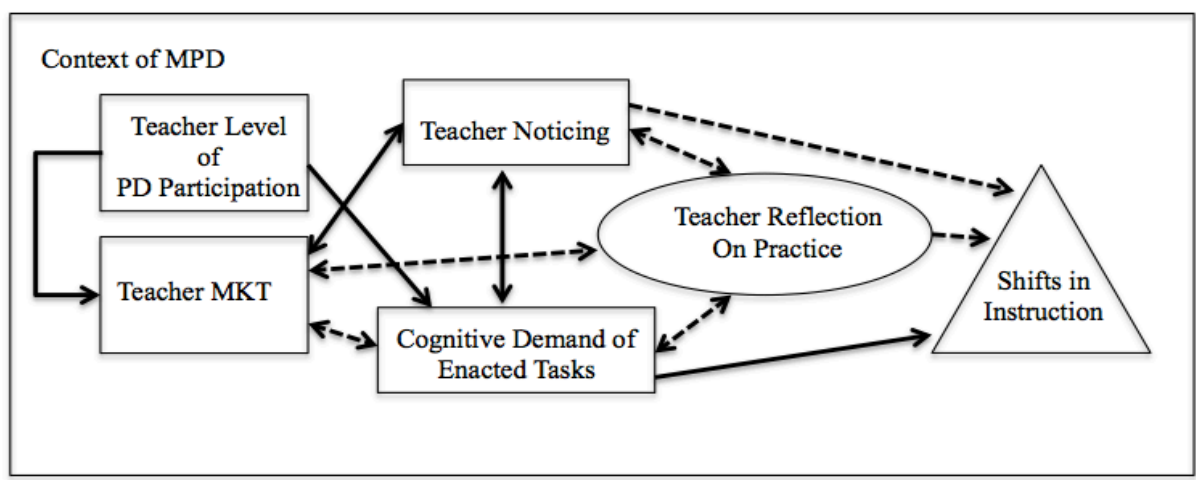

Confirmed Relationships

Hypothesized Relationships

(Coddington, 2014)

As hypothesized, there were shifts in the cognitive demand of enacted tasks over the course of the second year that indicated instructional change. Since the MAAP results showed that teachers' mathematical knowledge for teaching was also growing during the second year, it appeared that teachers' MKT influenced the shifts in instruction. This was 
highly possible considering previous research in this area that has linked MKT to levels of instruction (Charalambous, 2010). Within this study, there are unknown variables that must explain MKT, teacher noticing, and the cognitive demand of enacted tasks. These variables may become known with further research. The revised conceptual model presented in Figure 8 represents those variables that were identified in this study and those still hypothesized. To best support elementary teachers and to more fully understand the teaching and learning process, continued research is needed that focuses on developing teachers' mathematical knowledge for teaching, noticing of student thinking, and cognitive demand of lessons. 


\section{References}

Ball, D. L. (1990). The mathematical understandings that prospective teachers bring to teacher education. The Elementary School Journal, 90(4), 449-466.

Ball, D. L. (1997). Developing mathematics reform: What don't we know about teacher learning - but would make good working hypotheses. In S. N. Friel, \& G. W. Bright (Eds.), Reflections on our work: NSF teacher enhancement in K-6 mathematics, (pp. 78-111). New York, NY: University Press of America.

Ball, D., \& Cohen, D. (1999). Toward a Practice-Based Theory of Professional Education. Teaching as the learning profession. San Francisco: Jossey-Bass.

Ball, D. L., Hill, H. C., \& Bass, H. (2005). Knowing mathematics for teaching: Who knows mathematics well enough to teach third grade, and how can we decide? American Educator, 29(3), 14-46.

Ball, D. L., Thames, M. H., \& Phelps, G. (2008). Content knowledge for teaching: What makes it special? Journal of Teacher Education, 59(5), 389-407. Retrieved from http://jte.sagepub.com/content/59/5/389. doi: 10.1177/0022487108324554

Baroody, A. (1987). Children's mathematical thinking: A developmental framework for preschool, primary, and special education teachers. New York: Teachers College Press.

Battista, M. T. (1999). The mathematical miseducation of America' youth: Ignoring research and scientific study in education. Phi Delta Kappan, 80(6), 242-433.

Bell, C. A., Wilson, S. M., Higgins, T., \& McCoach, D. B. (2010). Measuring the effects of professional development on teacher knowledge: The case of developing 
mathematical ideas. Journal for Research in Mathematics Education, 41(5), 479513.

Blanton, M. L. \& Kaput, J. J. (2005). Characterizing a classroom practice that promotes algebraic reasoning. Journal for Research in Mathematics Education, 36(5), 412446.

Borko, H. (2004). Professional development and teacher learning: Mapping the terrain. Educational Researcher, 33(8), 3-15.

Brown, C. A. \& Borko, H. (2003). Becoming a mathematics teacher. In D. A. Grouws (Ed.), Handbook of research on mathematics teaching and learning: A project of the National Council of Teachers of Mathematics, (pp. 209-239). Reston, VA: National Council of Teachers of Mathematics.

Brown, S. A. (2012). MAAP Final Report (Report No. ITQ-08-0502). Report provided to the California Post-secondary Education Commission.

Brunvand, S. \& Fishman, B. (2006). Investigating the impact of the availability of scaffolds on preservice teacher noticing and learning from video. Journal of Educational Technology Systems, 35(2), 151-174.

California Postsecondary Education Commission (CPEC) (2010). Project description Making Algebra Accessible Project (MAAP). Retrieved from http://www.cpec.ca.gov/FederalPrograms /Projects_2008.asp

Campbell, P. F. (1996). Empowering children and teachers in the elementary mathematics classrooms of urban schools. Urban Education, 30, 449-475. 
Campbell, P. F. \& Robles, J. (1997). Project IMPACT: Increasing the mathematical power of all children and teachers. In S. N. Friel \& G. W. Bright (Eds.), Reflecting on our work: NSF teacher enhancement in K-6 mathematics (pp. 113-132). Lanham, MD: University Press of America.

Carpenter, T. P., Fennema, E., \& Franke, M. L. (1996). Cognitively guided instruction: A knowledge base for instruction. The Elementary School Journal, 97(1), 3-20.

Carpenter, T. P., Fennema, E., Franke, M. L., Levi, L., \& Empson, S. B. (1999). Children's mathematics: Cognitively guided instruction. Heinemann, 361 Hanover Street, Portsmouth, NH 03801-3912.

Carpenter, T. P., Franke, M. L., \& Levi, L. (2003). Thinking mathematically. Portsmouth, NH: Heinemann.

Cavanagh, S. (2009). NAEP scores put spotlight on standards. Education Week, 29(8), 1, 12.

Charalambous, C. Y. (2010). Mathematical knowledge for teaching and task unfolding: An exploratory study. The Elementary School Journal, 110(3), 247-278. Retrieved from http://www.jstor.org/stable/10.1086/648978

Cohen, D., \& Hill, H. (2000). Instructional policy and classroom performance: The mathematics reform in California. The Teachers College Record, 102(2), 294-343.

Creswell, J. W. (2009). Research design: Qualitative, quantitative, and mixed methods approaches. Sage. 
Darling-Hammond, L., \& Ball, D. L. (1998). Teaching for high standards: What policymakers need to know and be able to do. National Commission on Teaching \& America's Future.

Darling-Hammond, L., Wei, R. C., Andree, A., Richardson, N., and Orphanos, S. (2009). Professional learning in the learning profession: A status report on teacher development in the United States and abroad. Stanford University, CA: National Staff Development Council.

Desimone, L. M., Porter, A. C., Garet, M. S., Yoon, \& K. S., Birman, B. F. (2002). Effects of professional development on teachers' instruction: Results from a three-year longitudinal study. Educational Evaluation and Policy Analysis, 24(2), 81-112.

Doyle, W. (1983). Academic work. Review of educational research, 53(2), 159-199.

Doyle, W. (1988). Work in mathematics classes: The context of students' thinking during instruction. Educational Psychologist, 23(2), 167-180.

Drew, D. E. (2011). STEM the tide: Reforming science, technology, engineering, and math education in America. Baltimore, MD: The John Hopkins University Press.

Erickson, F. (2007). Ways of seeing video: Toward a phenomenology of viewing minimally edited footage. In R. Goldman, R. Pea, B. Barron, \& S. J. Derry (Eds.), Video research in the learning sciences, (pp. 145-155). Mahwah, NJ: Lawrence Erlbaum Associates.

Fennema, E., Carpenter, T. P. \& Franke, M. L. (1997). Cognitively Guided Instruction (CGI). In S. N. Friel \& G. W. Bright (Eds.), Reflections on our work: NSF teacher 
enhancement in K-6 mathematics (pp. 193-196). New York, NY: University Press of America.

Fennema \& Franke (2005). Teachers' knowledge and its impact. In D. A. Grouws (Ed.), Handbook of research on mathematics teaching and learning: A project of the National Council of Teachers of Mathematics, (pp. 147-164). Reston, VA: National Council of Teachers of Mathematics.

Fennema, E., Carpenter, T. P., Franke, M. L., Levi, L., Jacobs, V. R., \& Empson, S. B. (1996). Longitudinal study of learning to use children's thinking in mathematics instruction. Journal of Research in Mathematics Education, 27(4), 403-434.

Franke, M. L., Carpenter, T., \& Fennema, E., Ansell, E., Behrend, J. (1998).

Understanding teachers' self-sustaining, generative change in the context of professional development. Teacher and Teacher Education, 14(1), 67-80.

Franke, M. L., Webb, N. M., A. G., Chan, Ing, M., Freund, D., \& Battey, D. (2009). Teacher questioning to elicit students' mathematical thinking in elementary school classrooms. Journal of Teacher Education, 60(4), 380-392. doi: $10.1177 / 0022487109339906$.

Friel, S. N. \& Bright, G. W. (1997). Chapter I: Overview of the conference. In S. N. Friel, \& G. W. Bright (Eds.), Reflections on our work: NSF teacher enhancement in K-6 mathematics, (pp. 1-24). New York, NY: University Press of America.

Friel, S. N. \& Bright G. W. (1997). Common components and guiding principles for teacher enhancement programs. In S. N. Friel, \& G. W. Bright (Eds.), Reflections 
on our work: NSF teacher enhancement in K-6 mathematics, (pp. 7-24). New York, NY: University Press of America.

Gabriele, A. J., \& Joram, E. (2007). Teachers' reflections on their reform-based teaching in mathematics: Implications for the development of teacher self-efficacy. Action In Teacher Education, 29(3), 60-74.

Fuson, K. (1988). Children's counting and concepts of number. New York: Springer Verlag.

Garet, M. S., Porter, A. C., Desimone, L., Birman, B. F., \& Yoon, K. S. (2001). What makes professional development effective? Results from a national sample of teachers. American Educational Research Journal, 38(4), 915-945.

Good, T., Grouws, D., \& Ebmeier, H. (1983). Active mathematics teaching. New York: Longman.

Goodwin, C. (1994). Professional vision. American Anthropologist, 96(3), 606-633.

Hiebert, J. (1986). Conceptual and procedural knowledge: The case of mathematics. Hillsdale, NJ: Erlbaum.

Hiebert, J. \& Carpenter, T. P. (2003). Learning and teaching with understanding. In D. A. Grouws (Ed.), Handbook of research on mathematics teaching and learning: A project of the National Council of Teachers of Mathematics, (pp. 65-97). Reston, VA: National Council of Teachers of Mathematics.

Hiebert, J., \& Wearne, D. (1993). Instructional tasks, classroom discourse, and students' learning in second-grade arithmetic. American Educational Research Journal, 30(2), 393-425. 
Hill, H. C. (2010). The nature and predictors of elementary teachers' knowledge for teaching. Journal for Research in Mathematics Education, 41(5), 513-545.

Hill, H. C., \& Ball, D. L. (2004). Learning mathematics for teaching: Results from California's mathematics professional development institutes. Journal for Research in Mathematics Education, 35(5), 330-351. Retrieved from http://www.jstor.org/stable/30034819

Hill, H. C., Ball, D., Blunk, M., Goffney, I., \& Rowan, B. (2007). Focus article: Validating the ecological assumption: The relationship of measure scores to classroom teaching and student learning. Measurement, 5(2/3), 107-118. doi:10.1080/15366360701487138

Hill, H. C., Ball, D. L., \& Schilling, S. G. (2008). Unpacking pedagogical content knowledge: Conceptualizing and measuring teachers' topic-specific knowledge of students. Journal for Research in Mathematics Education, 372-400.

Hill, H. C., Beisiegel, M., \& Jacob, R. (2013). Professional Development Research Consensus, Crossroads, and Challenges. Educational Researcher, 42(9), 476-487.

Hill, H. C., Blunk, M. L., Charalambous, C. Y., Lewis, J. M., Phelps, G. C., Sleep, L., Ball, D. L. (2008). Mathematical knowledge for teaching and the mathematical quality of instruction: An exploratory study. Cognition and Instruction, 26, 430-511.

Hill, H. C., Rowan, B., \& Ball D. L. (2005). Effects of teachers' mathematical knowledge for teaching on student achievement. American Educational Research Journal, 42(2), 371-406. Retrieved from http://www.jstor.org/stable/3699380 doi: $10.3102 / 00028312042002371$ 
Hill, H. C., Schilling, S. G., \& Ball, D. L. (2004). Developing measures of teachers' mathematics knowledge for teaching. The Elementary School Journal, 105(1), 1130.

Jacobs, V. R., Franke, M. L., Carpenter, T. P., Levi, L., \& Battey, D. (2007). Professional development focused on children's algebraic reasoning in elementary school. Journal for Research in Mathematics Education, 38(3), 258-288.

Jacobs, V. R., Lamb, L. C., \& Philipp, R. A. (2010). Professional noticing of children's mathematical thinking. Journal for Research in Mathematics Education, 41(2), 169-202.

Jones, E., Hampton, E. M., Brown, E. M., \& Leinenbach, M. T. (2009). Impacting teacher mathematical knowledge and attitudes with grade-appropriate methods. Professional Development in Education, 35(2), 279-283.

Joyner, J. (1997). TEAM: Teaching excellence and mathematics. In S. N. Friel, \& G. W. Bright (Eds.), Reflections on our work: NSF teacher enhancement in K-6 mathematics, (pp. 223-228). New York, NY: University Press of America.

Kersting, N. B., Givvin, K. B., Sotelo, F. L., \& Stigler, J. W. (2010). Teachers' analyses of classroom video predict student learning of mathematics: Further explorations of a novel measure of teacher knowledge. Journal of Teacher Education, 61(1-2), 172181. doi: $10.1177 / 0022387109347875$

Kilpatrick, J. (1992). A history of research in mathematics education. In In D. A. Grouws (Ed.), Handbook of research on mathematics teaching and learning: A project of 
the National Council of Teachers of Mathematics, (pp. 1-38). Reston, VA: National Council of Teachers of Mathematics.

Koehler, M. S. \& Grouws, D. A. (1992). Mathematics teaching practices and their effects. In D. A. Grouws (Ed.). Handbook of research on mathematics teaching and learning: A project of the National Council of Teachers of Mathematics, (pp. 115126). Reston, VA: National Council of Teachers of Mathematics.

Loucks-Horsley, S. (1997). Teacher change, staff development and systemic change: Reflections from the eye of a paradigm shift. In S. N. Friel, \& G. W. Bright (Eds.), Reflections on our work: NSF teacher enhancement in K-6 mathematics, (pp. 133149). New York, NY: University Press of America.

Loucks-Horsley, S. \& Matsumoto, C. (1999). Research on professional development for teachers of mathematics and science: The state of the scene. School Science and Mathematics, 99(5), 258-271.

Loucks-Horsley, S., Stiles, K., \& Hewson, P. (1996). Principles of effective professional development for mathematics and science education: A synthesis of standards. ERIC Clearinghouse.

Ma, L. (1999). Knowing and teaching elementary mathematics: teachers' understanding of fundamental mathematics in China and the United States. Mahwah, NJ: Lawrence Erlbaum Associates.

Marr, D. (1982). Vision: A computational investigation into the human representation and processing of visual information. San Francisco: Freeman. 
Martin, W. G., \& Kasmer, L. (2010). Reasoning and sense making. Teaching Children Mathematics, 16(5), 284-291.

Mason, J. (2002). Researching your own practice: The discipline of noticing. Routledge.

Marx, R. W., \& Walsh, J. (1988). Learning from academic tasks. The Elementary School Journal, 207-219.

Mewborn, D. S. (2003). Teaching, teachers' knowledge, and their professional development. In J. Kilpatrick, W. G. Martin, and D. Schifter (Eds.), A research companion to principles and standards for school mathematics, (pp. 45-52). Reston, VA: The National Council of Teachers of Mathematics.

National Council for Teachers of Mathematics (2000), Principles and standards for school mathematics. Retrieved from http:/www.nctm.org/standards/

Nelson, B. S. (1997). Mathematics for tomorrow: Systemically-embedded teacher enhancement. In Reflections on our work: NSF teacher enhancement in K-6 mathematics, (pp. 229-235). New York, NY: University Press of America.

Philipp, R. A., Flores, A., Sowder, J. T., \& Schappelle, B. P. (1994). Conceptions and practices of extraordinary mathematics teachers. The Journal of Mathematical Behavior, 13(2), 155-180.

Rampey, B. D., Dion, G. S., \& Donahue, P. L. (2009). The nation's report card: Trends in academic progress in reading and mathematics 2008 (Research Report No. 2009479). Retrieved from National Center for Education Statistics: http://nces.ed.gov /nationsreportcard/pubs/main2008/2009479.asp 
Ravitch, D. (2000). Left back: A century of battles over school reform. New York: Simon \& Schuster.

Rogers, C. (2002). Voices inside schools seeing student learning: Teacher change and the role of reflection. Harvard Educational Review, 72(2), 230-254.

Ross, P. \& Gibson, S. A. (2010). Exploring a conceptual framework for expert noticing during literacy instruction. Literacy Research and Instruction, 49, 175-193.

Russ, R. S. \& Luna, M. J. (2013). Inferring teacher epistemological framing from local patterns in teacher noticing. Journal of Research in Science Teaching, 50(3), 284314.

Santagata, R. (2009). Designing video-based professional development for mathematics teachers in low-performing schools. Journal of Teacher Education, 60(1), 38-51.

Scherrer, J. \& Stein, M. K. (2012). Effects of a coding intervention on what teachers learn to notice during whole-group discussion. Journal of Mathematics Teacher Education, 1-20. doi: 10.1007/s10857-012-9207-2

Schön, D. (1983). The reflective practitioner: How professionals think in action. New York, NY: Basic Books.

Schön, D. (1987). Educating the reflective practitioner: Toward a new design of teaching and learning in the professions. San Francisco, CA: Jossey-Bass.

Sherin, M. G., \& Han, S. Y. (2004). Teacher learning in the context of a video club. Teaching and Teacher Education, 20, 163-183. doi:10.1016/j.tate.2003.08.001

Sherin, M. G., Jacobs, V. R., \& Philipp, R. A. (2011). Situating the study of teacher noticing. In M.G. Sherin, V. R. Jacobs, \& R. A. Philipp (Eds.), Mathematics 
teacher noticing: Seeing through teachers' eyes, (pp. 3-13). New York, NY: Routledge.

Sherin, M. G., Jacobs, V. R., \& Philipp, R. A. (Eds.). (2011). Mathematics teacher noticing: Seeing through teachers' eyes. New York, New York: Routledge.

Sherin, M., \& van Es, E. (2005). Using video to support teachers' ability to notice classroom interactions. Journal of Technology and Teacher Education, 13(3), 475491.

Sherin, M. G., \& van Es, E. A. (2009). Effects of video club participation on teachers' professional vision. Journal of Teacher Education, 60(1), 20-37. doi:10.1177/0022487108328155

Shulman, L. S. (1986). Those who understand: Knowledge growth in teaching. Educational Researcher, 15(2), 4-14.

Shulman, L. S. (1987). Knowledge and teaching: Foundations of the new reform. Harvard Educational Review, 57(1), 1-22.

Silver, E. (1987). Cognitive theory and research. In A. Schoenfeld (Ed.), Cognitive science and mathematics education. Hillsdale, JH: Erlbaum.

Silver, E. A., \& Stein, M. K. (1996). The Quasar project the" revolution of the possible" in athematics instructional reform in urban middle schools. Urban Education, 30(4), 476-521.

Skemp, R. (1987). The psychology of learning mathematics. Hillsdale, NJ: Erlbaum. 
Smith, M. S., Bill, V., \& Hughes, E. K. (2008). Thinking through a lesson: Successfully implementing high-level tasks. Mathematics Teaching in the Middle School, 14(3), $132-138$.

Sowder, J. T. (2007). The mathematical education and development of teachers. In F. K. Lester (Ed.), Second handbook of research on mathematics teaching and learning: A project of the National Council of Teachers of Mathematics (pp. 157-223). Charlotte, NC: Information Age Publishing.

Star, J. R., Lynch, K., \& Perova, N. (2011). Using video to improve mathematics' teachers' abilities to attend to classroom features: A replication study. In M. G. Sherin, Jacobs, V. R. \& Philipp, R. A. (Eds.), Mathematics teachers' noticing: Seeing through teachers' eyes, (pp. 117-133). New York, NY: Routledge.

Star, J. R. \& Strickland, S. K. (2008). Learning to observe: Using video to improve preservice mathematics teachers' ability to notice. Journal of Mathematics Teacher Education, 11, 107-125.

Stein, M. K., Grover, B. W., \& Henningsen, M. (1996). Building student capacity for mathematical thinking and reasoning: An analysis of mathematical tasks used in reform classrooms. American Educational Research Journal, 33(2), 455-488.

Stein, M. K. \& Kaufman, J. H. (2010). Selecting and supporting the use of mathematics curricula at scale. American Educational Research Journal, 47, 663-693.

Stein, M. K., \& Lane, S. (1996). Instructional tasks and the development of student capacity to think and reason: An analysis of the relationship between teaching and 
learning in a reform mathematics project. Educational Research and Evaluation, 2(1), 50-80.

Stein, M. K., \& Smith, M. S. (1998). Mathematical tasks as a framework for reflection: From research to practice. Mathematics Teaching in the Middle School, 3(4), 26875.

Stein, M. K., Smith, M. S., Henningsen, M. A., \& Silver, E. A. (2009). Implementing standards-based mathematics instruction: A casebook for professional development $\left(2^{\text {nd }} e d.\right)$. New York, NY: Teachers College Press.

Stevens, R., \& Hall, R. (1998). Disciplined perception: Learning to see in technoscience. Talking Mathematics in School: Studies of Teaching and Learning, 107-149.

Stigler, J. W. \& Hiebert, H. (1999). The teaching gap: Best ideas from the world's teachers for improving education in the classroom. New York, NY: Free Press.

Swars, S. L., Daane, C. J., \& Giesen, J. (2006). Mathematics anxiety and mathematics teacher efficacy: What is the relationship in elementary preservice teachers? School Science and Mathematics, 106(7), 306-315.

Tomanek, D., Talanquer, V., \& Novodvorsky, I. (2008). What do science teachers consider when selecting formative assessment tasks? Journal of Research in Science Teaching, 45(10), 1113-1130.

Thompson, C. L., \& Zeuli, J. S. (1999). The frame and the tapestry: Standards-based reform and professional development. Teaching as the learning profession: Handbook of policy and practice, 341-375. 
United States Department of Education Institute of Educational Sciences (2011). The nation's report card: Mathematics 2011. National Center for Education Statistics (NCES). Retrieved from http://nces.ed.gov/nationsreportcard/pubs/main2011/2012458.asp

van Es, E. A. (2011). A framework for learning to notice student thinking. In M.G. Sherin, V. R. Jacobs, \& R. A. Philipp (Eds.), Mathematics teacher noticing: Seeing through teachers' eyes, (pp. 134-151). New York, NY: Routledge.

van Es, E. A., \& Sherin, M. G. (2002). Learning to notice: Scaffolding new teachers' interpretations of classroom interactions. Journal of Technology and Teacher Education, 10(4), 571-596.

van Es, E. A. \& Sherin, M. G. (2006). How different video club designs support teachers in "learning to notice." Journal of Computing in Teacher Education, 22(4), 125-35.

Walker, E. N. (2007). Rethinking professional development for elementary mathematics teachers. Teacher Education Quarterly, 43(3), 113-134.

Whitenack, J. M., Knipping, N., Novinger, S., Coutts, L., \& Reys, B. (1998). Using technology to foster teachers' reflections about children's arithmetical thinking. Teaching Children Mathematics, 4(8), 484-87.

Wiley, D. E., \& Yoon, B. (1995). Teacher reports on opportunity to learn: Analyses of the 1993 California Learning Assessment System (CLAS). Educational Evaluation and Policy Analysis, 17(3), 355-370.

Wilson, S. (2009). Teacher quality: Education policy white paper. National Academy of Education. Retrieved from http://www.eric.ed.gov/ERICWebPortal/search/ 
detailmini.jsp?_nfpb=true\&_\&ERICExtSearch_SearchValue_0=ED531145\&ERIC ExtSearch_SearchType_0=no\&accno=ED531145

Wilson, S. M., \& Berne, J. (1999). Teacher learning and the acquisition of professional knowledge: An examination of research on contemporary professional development. Review of Research in Education, 24, 173-209.

Woodward, J. (2004). Mathematics education in the United States past to present. Journal of Learning Disabilities, 37(1), 16-31.

Yoon, K. S., Duncan, T. L., Lee, S. W., Scarloss, B., \& Shapley, K. L. (2007). Reviewing the evidence on how teacher professional development affects student achievement (Issues \& Answers Report, REL 2007-No. 033). Washington, DC: U.S. Department of Education, Institute of Education Sciences, National Center for Education Evaluation and Regional Assistance. Regional Education Laboratory Southwest. Retrieved from http://www.eric.ed.gov/ERICWebPortal/search/detailmini.jsp?_nfpb=true\&_\&ERI CExtSearch_SearchValue_0=ED531145\&ERICExtSearch_SearchType_0=no\&acc no $=\mathrm{E}$ 


\section{Appendix A: MAAP Video Reflection Form}

Making Algebra Accessible Project

Video Reflection Form

Teacher Name:

School Name:

Observation \# Date of Observation:

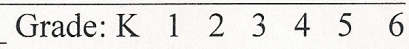

1. Please select a 5-minute segment of your lesson, which includes student discourse. Begin time: End time:

2. Please situate the segment within the context of your lesson.

3. Please describe why you selected the segment.

Thank you!

Reminder: The information you provide in the Pre-Observation Questionnaires is confidential. Any information provided will only be seen by members of the MAAP Professional Development and Research Team and will not be shared with school district personnel. (Revised: 5/19/13) 


\section{Appendix B: The Task Analysis Guide}

\section{TASK ANALYSIS GUIDE}

\section{Memorization Tasks}

- Involve either reproducing previously learned facts, rules, formulae, or definitions OR committing facts, rules, formulae, or definitions to memory.

- Cannot be solved using procedures because a procedure does not exist or because the time frame in which the task is being completed is too short to use a procedure.

- Are not ambiguous - such tasks involve exact reproduction of previously seen material and what is to be reproduced is clearly and directly stated.

- Have no connection to the concepts or meaning that underlie the facts, rules, formulae, or definitions being learned or reproduced.

\section{Procedures without Connections Tasks}

- Are algorithmic. Use of the procedure is either specifically called for or its use is evident based on prior instruction, experience, or placement of the task.

- Require limited cognitive demand for successful completion. There is little ambiguity about what needs to be done and how to do it.

- Are focused on producing correct answers rather than developing mathematical understanding.
Procedures with Connections Tasks

- Focus students' attention on the use of procedures for the purpose of developing deeper levels of understanding of mathematical concepts and ideas.

- Suggest pathways to follow (explicitly or implicitly) that are broad general procedures that have close connections to underlying conceptual ideas as opposed to narrow algorithms that are opaque with respect to underlying concepts.

- Usually are represented in multiple ways (e.g., visual diagrams, manipulatives, symbols, problem situations). Making connections among multiple representations helps to develop meaning.

- Require some degree of cognitive effort. Although general procedures may be followed, they cannot be followed mindlessly. Students need to engage with the conceptual ideas that underlie the procedures in order to successfully complete the task and develop understanding.

\section{Doing Mathematics Tasks}

- Require complex and nonalgorithmic thinking (i.e., there is not a predictable, well-rehearsed approach or pathway explicitly suggested by the task, task instructions, or a worked-out example).

- Require students to access relevant knowledge and experiences and make appropriate use of them in working through the task.

- Require students to analyze the task and actively examine task constraints that may limit possible solution strategies and solutions.

- Require considerable cognitive effort and may involve some level of anxiety for the student due to the unpredictable nature of the solution process required.

(Stein \& Smith, 1998)

Note. Used with permission 


\section{Appendix C: The Framework for Learning To Notice Student Mathematical Thinking}

\begin{tabular}{|c|c|c|c|c|}
\hline & $\begin{array}{l}\text { Level } 1 \\
\text { Baseline }\end{array}$ & $\begin{array}{l}\text { Level } 2 \\
\text { Mixed }\end{array}$ & $\begin{array}{l}\text { Level } 3 \\
\text { Focused }\end{array}$ & $\begin{array}{l}\text { Level } 4 \\
\text { Extended }\end{array}$ \\
\hline $\begin{array}{l}\text { What } \\
\text { Teachers } \\
\text { Notice }\end{array}$ & $\begin{array}{l}\text { Attend to whole class } \\
\text { environment, behavior, and } \\
\text { learning and to teacher } \\
\text { pedagogy }\end{array}$ & $\begin{array}{l}\text { Primarily attend to } \\
\text { teacher pedagogy } \\
\text { Begin to attend to } \\
\text { particular students' } \\
\text { mathematical } \\
\text { thinking and } \\
\text { behaviors }\end{array}$ & $\begin{array}{l}\text { Attend to particular } \\
\text { students' } \\
\text { mathematical } \\
\text { thinking }\end{array}$ & $\begin{array}{l}\text { Attend to the } \\
\text { relationship } \\
\text { between particular } \\
\text { students' } \\
\text { mathematical } \\
\text { thinking and } \\
\text { between teaching } \\
\text { strategies and } \\
\text { student } \\
\text { mathematical } \\
\text { thinking }\end{array}$ \\
\hline $\begin{array}{l}\text { How } \\
\text { Teachers } \\
\text { Notice }\end{array}$ & $\begin{array}{l}\text { Form general impressions } \\
\text { of what occurred } \\
\text { Provide descriptive and } \\
\text { evaluative comments } \\
\text { Provide little or no } \\
\text { evidence to support } \\
\text { analysis }\end{array}$ & $\begin{array}{l}\text { Form general } \\
\text { impressions and } \\
\text { highlight } \\
\text { noteworthy events } \\
\text { Provide primarily } \\
\text { evaluative with } \\
\text { some interpretive } \\
\text { comments } \\
\text { Begin to refer to } \\
\text { specific events and } \\
\text { interactions as } \\
\text { evidence }\end{array}$ & $\begin{array}{l}\text { Highlight } \\
\text { noteworthy events } \\
\text { Provide interpretive } \\
\text { comments } \\
\text { Refer to specific } \\
\text { events and } \\
\text { interactions as } \\
\text { evidence } \\
\text { Elaborate on events } \\
\text { and interactions }\end{array}$ & $\begin{array}{l}\text { Highlight } \\
\text { noteworthy events } \\
\text { Provide interpretive } \\
\text { comments } \\
\text { Refer to specific } \\
\text { events and } \\
\text { interactions as } \\
\text { evidence } \\
\text { Elaborate on events } \\
\text { and interactions } \\
\text { Make connections } \\
\text { between events and } \\
\text { principles of } \\
\text { teaching and } \\
\text { learning } \\
\text { On the basis of } \\
\text { interpretations, } \\
\text { propose alternative } \\
\text { pedagogical } \\
\text { solutions }\end{array}$ \\
\hline
\end{tabular}

Note. Used with permission. License ID \#3317200184939 


\section{Appendix D: MAAP Post-Observation Form}

\section{Making Algebra Accessible Project}

Post-Observation Form

Teacher Name:

School Name:

Observation \# Date of Observation:

Grade: $\mathrm{K} \quad 1 \quad \begin{array}{llllll}2 & 3 & 4 & 5 & 6\end{array}$

1. Use the space provided below to reflect on the observed lesson.

2. What connections do you see between the observed lesson and the MAAP seminar activities?

3. Which types of discourse occurred during the observed lesson? Please explain.

Reminder: The information you provide in the Pre-Observation Questionnaires is confidential. Any information provided will only be seen by members of the MAAP Professional Development and Research Team and will not be shared with school district personnel. (Revised: 5/19/13) 